\title{
Laser forming for sub-micron adjustment With application to optical fiber assembly
}




\section{LASER FORMING FOR SUB-MICRON ADJUSTMENT}

With APPLICATION TO OPTICAL FIBER ASSEMBLY

K.G.P. (Ger) Folkersma 


\section{Composition of the Graduation Committee:}

Chairman and secretary:

prof.dr. G.P.M.R. Dewulf

University of Twente

Promotor:

prof.dr.ir. J.L. Herder

University of Twente

Co-promotors:

dr.ir. D.M. Brouwer

University of Twente

dr.ir. G.R.B.E. Römer

University of Twente

\section{Members:}

prof.dr. G. Dearden

prof.dr.ir. T.H. van der Meer

University of Liverpool

prof.dr.ir. L. Abelmann

University of Twente

dr.ir. M. Tichem

University of Twente

dr. W. Hoving

Delft University of Technology

Anteryon B.V.

This work was performed at the Laboratory of Mechanical Automation and Mechatronics, Chair of Applied Laser Technology, Department of Mechanics, Solids, Surfaces \& Systems $\left(\mathrm{MS}^{3}\right)$, Faculty of Engineering Technology, University of Twente, P.O. Box 217, 7500 AE Enschede, the Netherlands.

This research was funded by the Dutch association Innovatiegericht OnderzoeksProgramma (IOP) Photonic Devices (IPD100014), part of the Ministry of Economic Affairs.

On the cover: 'Flow Light' by an unknown artist.

Laser forming for sub-micron adjustment

Ger Folkersma

Email: ger@folkersma.org

PhD Thesis, University of Twente, Enschede, the Netherlands

ISBN: 978-90-365-4018-6

DOI: $10.3990 / 1.9789036540186$

Copyright (C) December 2015 by K.G.P. Folkersma, the Netherlands

Printed by: Gildeprint - Enschede 


\section{LASER FORMING FOR SUB-MICRON ADJUSTMENT}

With APPLICATION TO OPTICAL FIBER ASSEMBLY

\section{DisSERTATION}

to obtain

the degree of doctor at the University of Twente, on the authority of the rector magnificus, prof.dr. H. Brinksma, on account of the decision of the graduation committee, to be publicly defended

on Tuesday the $15^{\text {th }}$ of December, 2015 at 16:45

by

\section{KlaAs GerRit Pieter Folkersma}

born on the $16^{\text {th }}$ of June, 1985

in Schildwolde, the Netherlands 
This thesis has been approved by the promotor.

prof.dr.ir. J.L. Herder

and the Co-promotors

dr.ir. D.M. Brouwer

dr.ir. G.R.B.E. Römer 


\section{Contributions}

The scientific output of this research was published in various journals and was presented at an international conference:

\section{Journals}

- Folkersma, K. G. P. Römer, G. R. B. E. Brouwer, D. M. Huis in 't Veld, A. J. "In-plane laser forming for high precision alignment". In: Optical engineering 53.12 (2014), pp. 126105-126105. DOI: $10.1117 / 1$. OE.53.12.126105.

- Folkersma, K. G. P. Brouwer, D. M. Römer, G. R. B. E. "Micro tube laser forming for precision component alignment". In: - (2015). Submitted for publication.

- Folkersma, K. G. P. Brouwer, D. M. Römer, G. R. B. E. "Robust precision alignment algorithm for micro tube laser forming". In: - (2015). Submitted for publication.

- Folkersma, K. G. P. Römer, G. R. B. E. Brouwer, D. M. Herder, J. L. "High precision optical fiber alignment using tube laser bending". In: The International Journal of Advanced Manufacturing Technology (2015). Accepted for publication. DOI: $10.1007 / \mathrm{s} 00170-015-8143-6$.

\section{Conference}

- Folkersma, K. G. P. Römer, G. R. B. E. Brouwer, D. M. Huis in 't Veld, A. J. "High precision laser forming for microactuation". In: Proc. SPIE, Laser Applications in Microelectronic and Optoelectronic Manufacturing (LAMOM) XIX. Vol. 8967. 2014, 89671B-89671B-12.

DOI: $10.1117 / 12.2037675$. 
In theory there is no difference between theory and practice. In practice there is.

Yogi Berra 


\section{Summary}

Recent advances in optical waveguide technology on photonic integrated circuit chips allow for mass production of devices that support short wavelengths in the near-UV spectrum. These devices are less tolerant to a lateral misalignment of the attached fibers, compared to that of devices operating at longer wavelengths, such as optical fiber communication systems. Devices operating at such short wavelengths require an alignment accuracy of about $0.1 \mu \mathrm{m}$, which cannot be achieved using passive alignment. A common solution is a one-time active alignment by measuring the coupling efficiency through the device, before bonding the fibers with adhesives. However, due to the shrinkage of the adhesives during and after the curing, the alignment accuracy is in the order of 1 micron.

Therefore, a laser forming actuator integrated in the device is proposed in this thesis, which can (re)align the fiber after the bonding process. Laser forming is a method to induce permanent plastic deformations in metallic components by controlled local laser heating.

To gain more insight the laser forming process, a planar three bridge actuator was studied first, using 2D and 3D FEM models and experiments. However, it was found that the calculated deformation after repeated laser forming steps can deviate up to $100 \%$ from the experiments, which was attributed to limitations in the strain hardening models. Additionally, a reduced model was developed that matches well with the 2D FEM model, but requires only a fraction of the computational load compared to the FEM model.

Displacement and temperature measurements showed significant scattering for repeated experiments. This scattering was attributed to differences in surface morphology of the actuator, affecting the laser absorption coefficient, as well as small deviations in geometry due to the manufacturing of the actuator samples. This process scattering limits the accuracy of the actuator when no feedback loop is used. Therefore, an algorithm has been developed that learns from the measured displacement of the fist 15 iterations, and adapts the laser power for the subsequent forming steps. Using this algorithm, it has been shown that $78 \%$ of the alignment trials end within $0.1 \mu \mathrm{m}$ of the target. The remaining $22 \%$ overshoots the target, and can not 
be corrected for, because the laser forming mechanism only allows for a contraction of the actuator bridges.

With the gained insight, a fiber alignment actuator was developed that consists of a stainless steel tube. The fiber is placed concentric in the tube and fixed to one end, while the other end of the tube is fixed to the chip. The tube can be bent locally by laser forming, resulting in a translation of the fiber tip. An experimental setup has been developed that allows for accurate placement of the laser spot on the tube, as well as optically measuring the fiber tip position with a repeatability better than $0.1 \mu \mathrm{m}$. Using this setup, it has been found that there exists significant scattering of the magnitude and direction of the bending. The bending magnitude showed an increase in scattering with increasing laser power, while the bending direction showed a decrease in scattering with increasing laser power.

Due to this tradeoff, an optimal laser power and optimal laser spot position can be found, that minimizes the number of steps to reach the target position. This is achieved by minimizing the expected value of the error after the current step, by using the statistical data obtained from displacement measurements of all previous bending steps. Simulations and experiments using this algorithm show that the fiber tip reaches the target position with an accuracy of $0.1 \mu \mathrm{m}$ with $95 \%$ certainty within 14.5 steps. The constant learning of this algorithm makes it robust for changes in process parameters, for example for changes in absorption coefficient. Moreover, the algorithm only needs a few calibration steps to learn a new material or tube geometry.

The displacement measurements used in the learning algorithm are not possible when the tube actuator is fixed to an optical chip, as the fiber is fully enclosed by the tube and chip. Therefore, a scanning algorithm has been developed, that searches for the target position of the fiber tip, by maximizing the measured coupling efficiency. The scanning motion is obtained by exploiting the thermal expansion motion of the tube. Using a low laser power, the yield stress of the tube is not exceeded, avoiding permanent plastic deformation of the tube. The accuracy of the scanned target position increases with decreasing distance to the target. Experiments showed that $90 \%$ of the scans have an error smaller than the actual distance to the target, which is a prerequisite for converging to the target position. Using this scanning algorithm, combined with the optimal parameters derived from the displacement measurements, the fiber tip can be aligned to the chip without any external displacement sensors. Experiments showed that the number of forming steps required to reach the target position within $0.2 \mu \mathrm{m}$ is between 5 and 16 .

A laser forming actuator and feedback algorithm for fiber alignment in two directions has been developed. Further research should go into the bonding of such an actuator to the optical chip and the addition of axial motion of the fiber in the laser forming actuator. Furthermore, the developed actuator and algorithms can be applied to any sub-micron adjustment case where laser forming is an option. 


\section{Samenvatting}

Recente ontwikkelingen in golfgeleiders op optische chips maken het mogelijk om deze op grote schaal te fabriceren voor toepassingen met golflengten nabij het UV spectrum. In vergelijking met toepassingen voor langere golflengten, zoals glasvezel communicatie, zijn deze chips echter minder tolerant voor uitlijnfouten bij het assembleren van de glasvezels aan deze chips. De vereiste laterale nauwkeurigheid van de vezel voor korte golflengten is ongeveer $0.1 \mu \mathrm{m}$, wat niet haalbaar is met passieve uitlijning. Een veelgebruikte oplossing is een eenmalige een actieve uitlijning, door het laservermogen door de fiber-chip verbinding te meten en te optimaliseren, waarna het geheel met een lijmverbinding wordt gefixeerd. Deze lijmverbinding kan echter door krimp bij het uitharden voor nieuwe uitlijnfouten zorgen, waardoor de uiteindelijke nauwkeurigheid in de orde van 1 micrometer komt.

Daarom wordt er in dit proefschrift een in het product geïntegreerde actuator voorgesteld, die na de assemblage in staat is eenmalig de glasvezel uit te lijnen. De beweging wordt verkregen door permanent plastische vervormingen in een metalen structuur aan te brengen met gecontroleerde lokale opwarming door absorbtie van laserenergie. Dit proces wordt ook wel laser-adjusteren genoemd.

Om meer inzicht te krijgen in het proces van laser-adjusteren, is als eerste een zogenaamde drie-bruggen actuator onderzocht middels eindige-elementen modellen en experimenten. Echter verschilden deze modellen en experimenten tot $100 \%$ van elkaar, wat een gevolg bleek te zijn van limitaties in het gebruikte verstevigingsmodel. Verder is een gereduceerd model ontwikkeld, dat goed overeenkomt met het 2D eindigeelementen model, terwijl het een fractie van de computertijd vergt.

Een significante spreiding in temperatuur en verplaatsing is gemeten tijdens experimenten. Dit was grotendeels te wijten aan verschillen in de oppervlaktestructuur van de actuatoren, wat invloed heeft op de absorptie van laserenergie in het materiaal. Ook kleine fabricagefouten in de actuatoren dragen bij aan deze spreiding. Deze spreiding in het proces limiteert de nauwkeurigheid van de actuator als er geen terugkoppeling van de positie wordt toegepast. Daarom is er een algoritme ontwikkeld dat leert van de gemeten verplaatsing van de eerste 15 laser-adjusteer stappen, en daarna het laservermogen aanpast voor de volgende stappen, aan de hand van de gemeten fout. Met 
dit algoritme en de modellen is aangetoond dat $78 \%$ van de uitlijn pogingen binnen $0.1 \mu \mathrm{m}$ van het doel eindigt. De uiteindelijke positie van de overige $22 \%$ is voorbij de doelpositie, wat niet meer gecorrigeerd kan worden omdat het laser-adjusteer principe alleen een contractie van de actuator toelaat.

Met deze opgedane kennis is een actuator ontwikkeld voor het uitlijnen van glasvezels. Deze actuator bestaat uit een buis met concentrisch daarin de glasvezel. De buis wordt aan één kant vastgezet aan de chip, en de andere kant aan de glasvezel. De buis kan lokaal gebogen worden door laser-adjusteren, met als gevolg een translatie van het uiteinde van de glasvezel. Voor deze actuator is een experimentele opstelling ontwikkeld die in staat is om de laserbundel nauwkeurig overal op het oppervlakte van de buis te positioneren, en tegelijkertijd optisch de positie van de glasvezel meet met een herhaalnauwkeurigheid van minder dan $0.1 \mu \mathrm{m}$. Metingen lieten een spreiding zien in de hoek en richting van de buiging. De spreiding in buighoek nam toe met toenemend laservermogen, terwijl de spreiding in buigrichting juist afnam met toenemend laservermogen.

Door deze tegenstrijdigheid kan een optimaal laservermogen en een optimale laserbundelpositie gevonden worden, waarmee het aantal stappen om de doelpositie te bereiken wordt geminimaliseerd. Deze optimale instellingen worden berekend door de verwachtingswaarde van de positiefout na de komende stap te minimaliseren, waarbij de statistische data van alle voorgaande stappen wordt gebruikt. Simulaties en experimenten met dit algoritme laten zien dat in 14.5 stappen de doelpositie wordt bereikt met een zekerheid van $95 \%$ en een maximale afwijking van $0.1 \mu \mathrm{m}$. Dit algoritme is robuust voor veranderingen in het proces, zoals veranderingen in de laser absorptie coëfficiënt. Ook zijn er slechts enkele calibratiestappen nodig om een nieuw materiaal of geometrie van de buis te kunnen gebruiken.

De positie van de fiber kan niet gemeten worden wanneer de actuator aan een optische chip is gefixeerd, omdat de glasvezel dan volledig omsloten is door de buis en de chip. Om desondanks toch de doelpositie te vinden is er een zoekalgoritme ontwikkeld, dat de gemeten inkoppeling van het licht maximaliseert. De hiervoor benodigde beweging wordt verkregen door de thermische expansie bij laag laservermogen, waarbij de vloeigrens van het materiaal niet wordt overschreden.

Experimenten hebben aangetoond dat $90 \%$ van de gevonden doelposities een kleinere fout heeft dan de daadwerkelijke afstand tot de doelpositie, wat een voorwaarde is om de fiber naar de doelpositie te laten convergeren. Dit zoekalgoritme, gecombineerd met de eerder bepaalde optimale procesinstellingen, is in staat de glasvezel uit te lijnen zonder positiesensoren. Dit is aangetoond met experimenten, waarbij 5 tot 16 stappen nodig waren om de doelpositie binnen $0.2 \mu \mathrm{m}$ te benaderen.

In dit proefschrift is een actuator ontworpen om een glasvezel in twee richtingen uit te lijnen ten opzichte van een optische chip, waarbij gebruik gemaakt wordt van laseradjusteren. Verder onderzoek is nodig naar de fixatie van de actuator aan de optische chip en naar de axiale uitlijning van de vezel, eventueel ook door laser-adjustering. Hoewel dit onderzoek specifiek gericht was op het uitlijnen van een glasvezel, zijn deze actuatoren en het algoritme toepasbaar op elk microassemblageprobleem waar laser-adjusteren een optie is. 


\section{Contents}

Contributions $\ldots \ldots \ldots \ldots \ldots \ldots \ldots \ldots \ldots \ldots \ldots \ldots \ldots \ldots \ldots \ldots \ldots \ldots \ldots$

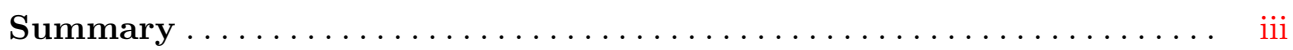





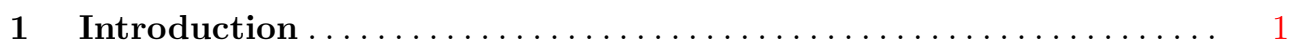

1.1 Background: Fiber micro-assembly $\ldots \ldots \ldots \ldots \ldots \ldots \ldots \ldots \ldots \ldots \ldots$



1.3 High precision micro assembly using laser forming . . . . . . . . . 7

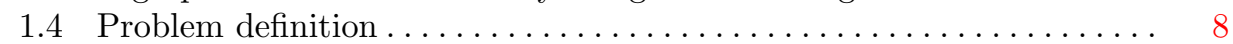

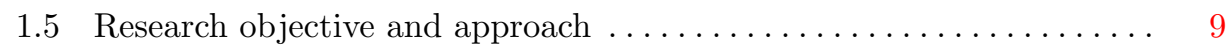



2 In-plane laser forming for high precision alignment $\ldots \ldots \ldots \ldots \ldots 11$







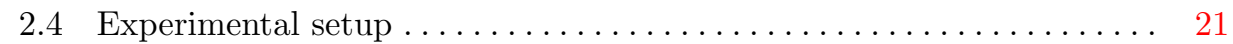

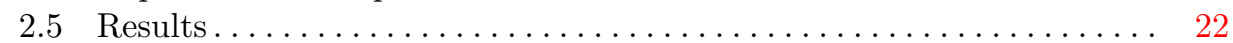

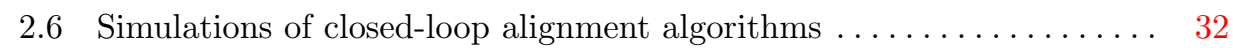

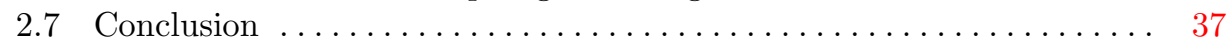

3 Micro tube laser forming for component alignment . . . . . . . . 39

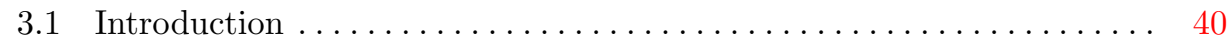

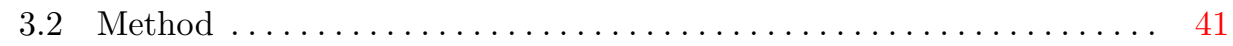

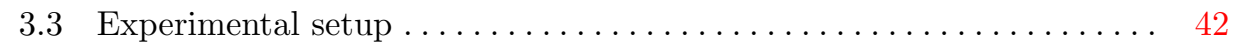



3.5 Towards prediction of optimal process parameters $\ldots \ldots \ldots \ldots \ldots \ldots 2$ 


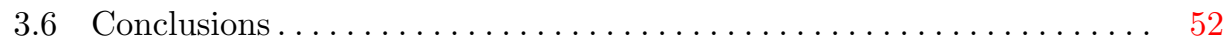

4 Robust precision alignment algorithm for micro tube laser forming 53

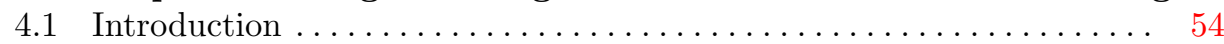



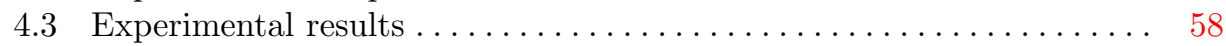

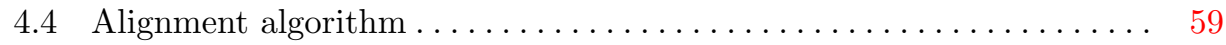

4.5 Results................................... 64

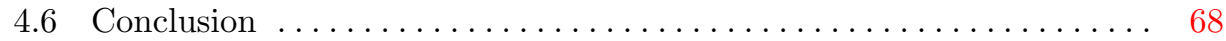

$5 \quad$ High precision optical fiber alignment using laser tube forming . 71

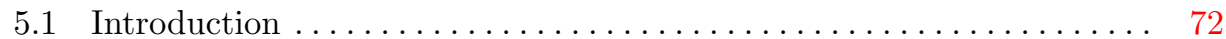



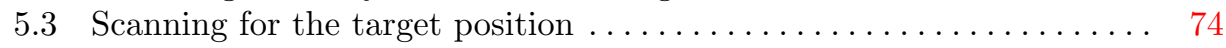

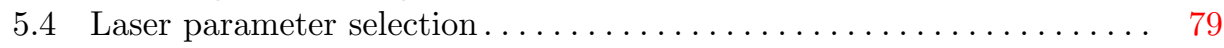

5.5 Stop condition of alignment iteration $\ldots \ldots \ldots \ldots \ldots \ldots \ldots \ldots \ldots$

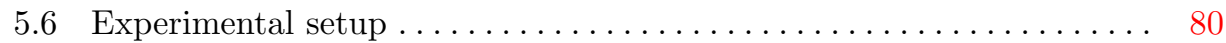





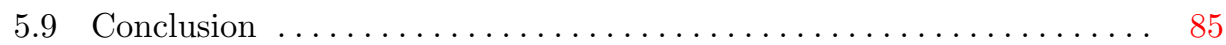

6 Conclusions and recommendations $\ldots \ldots \ldots \ldots \ldots \ldots \ldots \ldots$








\section{Nomenclature}

\section{Mathematical notation}

$\begin{array}{ll}x & \text { Scalar } \\ \boldsymbol{x} & \text { Vector or matrix } \\ \hat{\bullet} & \text { Estimate of } \bullet \\ \mathbf{E}[\bullet] & \text { Expected value of } \bullet \\ \boldsymbol{\bullet} & \text { Fit through measurements of } \bullet \\ \operatorname{sign}(x) & \text { Sign of } x:-1 \text { if } x \text { is negative, } 1 \text { if } x \text { is positive } \\ \bullet \bullet & \text { Moore-Penrose pseudoinverse of } \bullet\end{array}$

$\begin{array}{ll}\text { Abbreviations } \\ \text { \#D } & \text { \# Dimensional } \\ \text { BM } & \text { Buckling Mechanism } \\ \text { CTE } & \text { (linear) Coefficient of Thermal Expansion } \\ \text { DOF } & \text { Degree of Freedom } \\ \text { FEM } & \text { Finite Element Method } \\ \text { ILBC } & \text { Integrated Laser Beam Combiner, developed by XiO Photonics } \\ \text { MFD } & \text { Mode Field Diameter } \\ \text { OFC } & \text { Optical Fiber Communication } \\ \text { PIC } & \text { Photonic Integrated Circuit } \\ \text { PSD } & \text { Position Sensitive Diode } \\ \text { TBA } & \text { Three Bridge Actuator } \\ \text { TGM } & \text { Temperature Gradient Mechanism } \\ \text { UM } & \text { Upsetting Mechanism } \\ \text { RCLM } & \text { Removal of Compressive Layers Mechanism } \\ \text { LSF } & \text { Laser Shock Forming } \\ \text { UV } & \text { Ultraviolet }\end{array}$




\section{Roman symbols}

$\begin{array}{ll}A & \text { Laser absorption coefficient } \\ E & \text { Young's modulus } \\ F & \text { Force } \\ I & \text { Laser intensity distribution } \\ I_{\mathrm{a}} & \text { Second moment of area } \\ P & \text { Laser power } \\ \dot{Q} & \text { Heat flux } \\ T & \text { Temperature } \\ V & \text { Volume } \\ \boldsymbol{X} & \text { 2D Coordinate } \\ \boldsymbol{X}_{\mathrm{f}} & \text { Fiber tip location } \\ \boldsymbol{X}_{\mathrm{r}} & \text { Fiber tip location after bending } \\ \boldsymbol{X}_{\mathrm{d}} & \text { Fiber tip target location } \\ \boldsymbol{Y}_{\boldsymbol{N}} & \text { Matrix of } N \text { measurements } \\ c_{\mathrm{p}} & \text { Specific heat capacity } \\ d & \text { 1/e laser spot diameter } \\ d & \text { Axial distance of laser spot from fiber tip } \\ e & \text { Error (distance from target) } \\ i & \text { Iteration index } \\ g & \text { Gravitational constant } \\ k & \text { Three-bridge actuator bridge number } \\ l & \text { Three-bridge actuator bridge length } \\ l & \text { Free fiber length in tube } \\ r & \text { Fiber radius } \\ s & \text { Three-bridge actuator thickness } \\ t & \text { Time } \\ \Delta t & \text { Timestep length } \\ w & \text { 3-bridge actuator bridge width } \\ w_{\mathrm{c}} & \text { Mode-field diameter of a chip waveguide } \\ w_{\mathrm{f}} & \text { Three-bridge actuator translation of bridge } k \\ y_{k} & \text { Distributed load } \\ q & \end{array}$

\section{Greek symbols}

$\alpha$
$\alpha_{\mathrm{th}}$
$\beta$
$\beta_{k}$
$\delta_{\mathrm{d}}$
$\delta_{\mathrm{r}}$
$\delta_{\mathrm{g}}$
$\varepsilon^{\mathrm{th}}$

Tube bending angle

(linear) Coefficient of Thermal Expansion

Tube expansion angle

Relative factor of elastic strain in three-bridge actuator bridges

Distance to target location

Displacement magnitude after one laser forming step

Fiber tip displacement (sag) due to gravity

Thermal strain 


$\begin{array}{ll}\varepsilon^{\mathrm{el}} & \text { Elastic strain } \\ \varepsilon^{\mathrm{pl}} & \text { Plastic strain } \\ \varepsilon^{\text {tot }} & \text { Total strain } \\ \Phi_{N} & \text { Regression matrix } \\ \phi_{\exp } & \text { Direction of bending due to thermal expansion } \\ \phi_{\mathrm{r}} & \text { Tube bending direction after cooling } \\ \eta & \text { Optical coupling efficiency } \\ \kappa & \text { Thermal conductivity } \\ \theta & \text { Three-bridge actuator rotation } \\ \rho & \text { Material density } \\ \sigma & \text { (Von-Mises) stress } \\ \sigma_{\mathrm{y}} & \text { Yield stress } \\ \omega & \text { Tube bending direction error } \\ \Psi & \text { Estimate matrix }\end{array}$





\section{Chapter 1 Introduction}

\subsection{Background: Fiber micro-assembly}

A Photonic Integrated Circuit (PIC), also known as Planar Lightwave Circuit, is a device on which several optical (and often also electronic) components are integrated [1]. PICs are usually fabricated using wafer-scale technology on silicon or silica substrates (often called chips). These devices are widespread in infrared optical fiber communication (OFC) systems, and manufacturing and packaging of these devices is well established [2]. However for single-mode fiber coupled optical chips, the fiber alignment and bonding to the PIC and packaging is still the most expensive phase in the manufacturing of these devices [3]. The assembly tolerances in the sub-micrometer regime require specialized machinery and often manual labour.



Fig. 1.1: A packaged Integrated Laser Beam Combiner (ILBC) developed by XiO Photonics, with three input fibers on the left, and one output on the right.

Recent developments in waveguide technology allow for the manufacturing of devices supporting multiple wavelengths, including short wavelengths in the near-UV range [4]. Such a device is the Integrated Laser Beam Combiner (ILBC) developed by XiO Photonics in the Netherlands, see Fig. 1.1 and Fig 1.3a. This fiber-coupled device 
can combine a wide range of input wavelengths into a single output fiber with high efficiency. For example, four inputs from lasers in the UV to visible range $(405 \mathrm{~nm}$, $488 \mathrm{~nm}, 561 \mathrm{~nm}$ and $640 \mathrm{~nm}$ ) can be combined into one output fiber.

The single-mode waveguides and fibers that support such short wavelengths have a small mode field diameter (MFD). A small MFD means that the spot size at the connection interface between the fiber and waveguide is small, and therefore requires tighter lateral alignment tolerances [5]. However, fibers that are intolerant for lateral misalignment, are tolerant for angular misalignment (and vice versa) [5]. Therefore, the angular alignment is of secondary importance for short wavelength connections.

For comparison, Fig. 1.2 shows the theoretical coupling efficiency $\eta$ as a function of the lateral misalignment between two identical fibers. The efficiency is calculated using a Gaussian approximation for the fiber mode and neglecting any other optical losses. The dashed line indicates a typical single-mode fiber for OFC at a wavelength of $1310 \mathrm{~nm}$, and allows a misalignment up to $0.5 \mu \mathrm{m}$ to obtain a coupling efficiency of $99 \%$ or better. The solid line indicates a fiber used for the near-UV input of the ILBC at a wavelength of $405 \mathrm{~nm}$, and must be aligned within $0.1 \mu \mathrm{m}$ to obtain a coupling efficiency of $99 \%$.



Fig. 1.2: Theoretical coupling efficiency versus the lateral misalignment of two identical single-mode fibers. The dashed indicates a typical fiber used in optical fiber communications (Corning SMF-28), with a MFD of $9.2 \mu \mathrm{m}$ at a wavelength of $1310 \mathrm{~nm}$ [1]. The solid line indicates a fiber used for the near-UV input of the ILBC (Nufern S405-XP), with a MFD of $2.6 \mu \mathrm{m}$ at a wavelength of $405 \mathrm{~nm}$.

For longer wavelengths, passive assembly methods such as $\mathrm{V}$-groove arrays are widely used. With this method, one or more fibers are positioned and fixed in etched V-grooves in a glass or silicon substrate (see Fig. 1.3b). The end face of this fiber array is polished, and fixed to the chip with adhesives. However, this method can not be employed for the UV port of the ILBC, due to the geometrical tolerances (most notably the core-cladding concentricity) of commercial available fibers exceeding the align- 
ment requirements mentioned above [2]. This also implies that fiber array assemblies can not be aligned simultaneously for the short wavelengths, since the core-to-core pitch can not be guaranteed to be within the required tolerances.

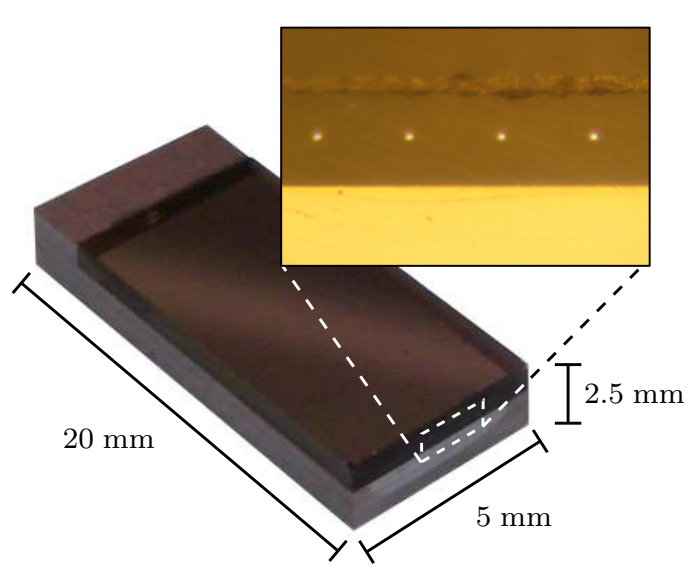

(a) ILBC chip and its dimensions.

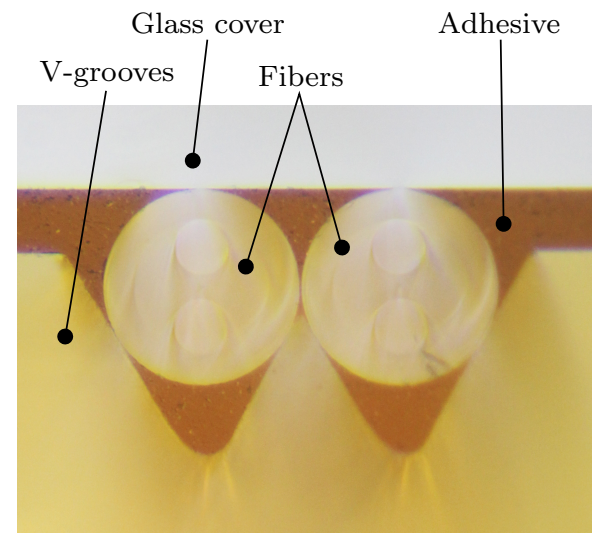

(b) Microscope image of an assembled fiber array.

Fig. 1.3: (a): The ILBC chip, covered with several silicon and glass layers to create a surface for stable assembly of the fiber array. The inset shows the end face where the waveguide exits can be clearly observed. (b): Two fibers in V-grooves in glass, used as a passive mounting method. Currently, the depicted face is polished, aligned to the chip, and bonded to the chip by UV-curing adhesives. The core of each fiber is not visible in this figure. Images courtesy of XiO Photonics, Enschede, the Netherlands

Therefore, currently a one-time active alignment per fiber is used for such devices, where the optical coupling efficiency is maximized by sending light through the device and measuring the transmitted power. A hill-climbing algorithm can be used to optimize the transmission while positioning the fiber by a high-precision motorized stage for example $[6,7]$. When the optimal position is found, the fiber is fixed to the chip, usually by UV-curing adhesive [2]. However, the adhesives are prone to shrinkage during and/or after the curing process, which causes misalignment after the final bonding step [8]. Other joining methods, such as welding, soldering and clamping lead to similar kind of misalignment problems due to inherent stress.

Moreover, the ILBC chip supports input powers over $300 \mathrm{~mW}$ (compared to about $0.5 \mathrm{~mW}$ in OFC [9]). Light loss due to misalignment is absorbed by the surrounding material at the interconnect and is dissipated as heat, which can damage the device and fiber. Due to the combination of this relatively high laser power with the small MFD, the allowed lateral misalignment for the near-UV (405 nm) input port of the ILBC is an order smaller compared to that of OFC systems. 


\subsection{Laser forming}

To re-align the fiber after the assembly steps, the use of laser adjusting is proposed in this thesis. By designing a laser forming actuator that is integrated in the optical device, the fiber tip position can be positioned relative to the chip after the first assembly and alignment steps. Additionally, the use of such an actuator allows for a 'coarse' initial assembly alignment, which can be achieved by simple passive alignment features on the chip and actuator.

Laser forming is a technique for deforming metallic components by controlled irradiation with a laser beam [10]. The localized laser-induced heating introduces thermal stresses which exceed the yield stress of the material, resulting in a permanent plastic deformation. It is a spring-back free [10] and contact-less process and can be used for high strength materials that are difficult to deform with conventional hard tooling [11]. This technique is usually employed in multiple steps, either to increase the deformation magnitude, or to converge to a desired deformation with small steps. Laser forming has been used for many macro [12-15] and micro [16-21] applications, ranging from from the forming of ship hulls [12] or correcting the shape of car body parts [15] to the aligning of components during fabrication of tape-recorders [18] or correcting the reed contact gap width in micro relays [21].

Laser forming mechanisms can be divided in thermal and non-thermal mechanisms. Three main thermal forming mechanisms have been identified [22, 23], namely the Temperature Gradient Mechanism, the Upsetting Mechanism and the Buckling Mechanism. Each mechanism is associated with specific combinations of component geometries, material properties and laser parameters, and are discussed in the following.

The Temperature Gradient Mechanism (TGM) is the most common thermal laser forming mechanism found in literature, see Fig 1.4. It is mostly applied for 2D or $3 \mathrm{D}$ bending of sheet metal, by scanning the laser beam across the surface of the sheet. This mechanism is dominant if there is a steep thermal gradient over the thickness of the component. This gradient is achieved when the laser beam diameter is in the order of the sheet thickness [22] and the interaction time is short. The TGM can be broken down in three steps:

1. The absorbed laser energy heats the top layer of the sheet. The thermal expansion induces compressive stresses, resulting in a bending away from the laser beam (Fig 1.4a).

2. The yield stress reduces with the increasing temperature. The compressive stress exceeds the yield stress, resulting in compressive plastic deformation in the top layer of the sheet (Fig 1.4b).

3. After laser irradiation and upon cooling down, the top layer contracts. Due to the effective shortening of the top layer, the sheet bends towards the laser beam (Fig $1.4 \mathrm{c})$. 


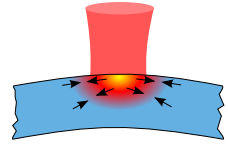

a

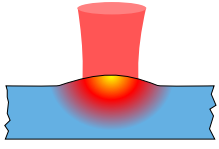

$\mathrm{b}$

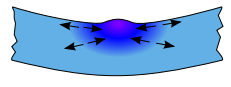

C

Fig. 1.4: Temperature Gradient Mechanism (TGM).

In contradiction to the TGM, the Upsetting Mechanism (UM) is the dominant mechanism when an uniform temperature profile is present over the thickness of the component, see Fig 1.5. This generally is the case when the laser beam diameter at the surface is large compared to the component thickness and the interaction time is long. This mechanism is the main mechanism in laser tube bending [14]. The UM can be broken down in three steps:

1. The absorbed laser energy results in an almost uniform temperature profile over the thickness of the component (Fig 1.5a). The thermal expansion is impeded by the (cold) surrounding material and induces compressive stresses in the heated volume.

2. The yield stress reduces with increasing temperature. The compressive stress exceeds the yield stress, resulting in compressive plastic deformation of the heated volume (Fig 1.5b).

3. After laser irradiation and upon cooling down, the heated volume shrinks and the heated volume effectively contracts. (Fig 1.5c).

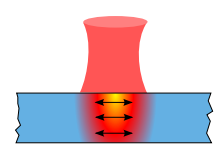

a

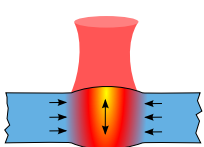

$\mathrm{b}$

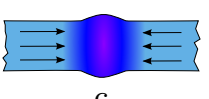

$\mathrm{C}$

Fig. 1.5: Upsetting Mechanism (UM).

The Buckling Mechanism (BM) is similar to the UM, see Fig 1.6. However, when the component cannot withstand the compressive stresses, local buckling can occur. This is generally the case when the thickness of the component is small. The BM can be broken down in three steps:

1. The absorbed laser energy results in an almost uniform temperature profile over the thickness of the component (Fig 1.6a). The thermal expansion is impeded by the (cold) surrounding material and induces compressive stresses in the heated volume.

2. The compressive stresses cause bucking of the component. The yield stress is lowered in the heated volume, resulting in a plastic deformation in the heated area, while the bent volume outside the heated region deforms elastically (Fig 1.6b). 
3. After laser irradiation and upon cooling down, the yield stress rises, resulting in a permanent bending, away from the laser beam (Fig 1.6c).

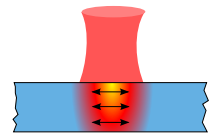

a

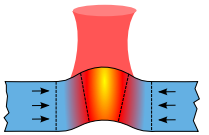

$\mathrm{b}$

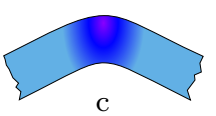

$\mathrm{C}$

Fig. 1.6: Buckling Mechanism (BM).

Non-thermal laser forming mechanisms include the Removal of Compressive Layers Mechanism (RCLM), and the Laser Shock Forming Mechanism (LSF). For the RCLM, the workpiece is coated with a layer that introduces compressive stresses in the top layer [24]. This layer can locally be removed by ultra short laser pulses, see Fig. 1.7. This introduces small local deformations towards the laser beam. However, this process can not be repeated at the same location, making it less suitable for iterative high precision alignment.

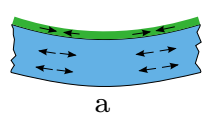

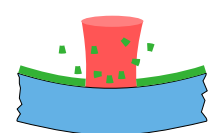

$\mathrm{b}$

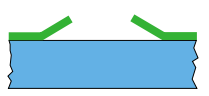

c

Fig. 1.7: Removal of Compressive Layers Mechanism (RCLM)

For LSF, an ultra short pulsed laser with pulse durations in the femtosecond regime is used to ablate material from the top surface. The formation of a high density and high pressure plasma results in a rapid expansion of the plasma, causing a short but intense shockwave. This shockwave causes expansion of the top layer, resulting in a micro bending away from the laser [24, 25], see Fig. 1.8. The LSF mechanism is not limited to a specific material, and can be used with silicon for example. However, such brittle materials cannot sustain repeated bending, and show dislocations and micro cracks.

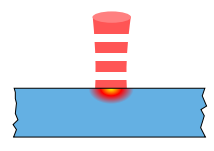

a



$\mathrm{b}$

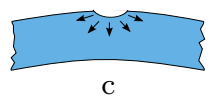

Fig. 1.8: Laser Shock Forming Mechanism (LSF) 


\subsection{High precision micro assembly using laser forming}

An application of laser forming that received substantial attention in the recent years, is the high precision alignment and assembly of (small) components. This process is often referred to as 'laser adjusting' [10] or 'laser hammering' [26, 27]. This process has been applied to several industrial applications where a sub-micron assembly accuracy was required [18, 27-30].

For these applications, the aim is to obtain small deformations in dedicated structures (or actuators). These deformations induce a displacement to the part or component to be aligned. Due to the limited deformation magnitude and repeatability per irradiation step, the alignment process is usually a multi-step process.

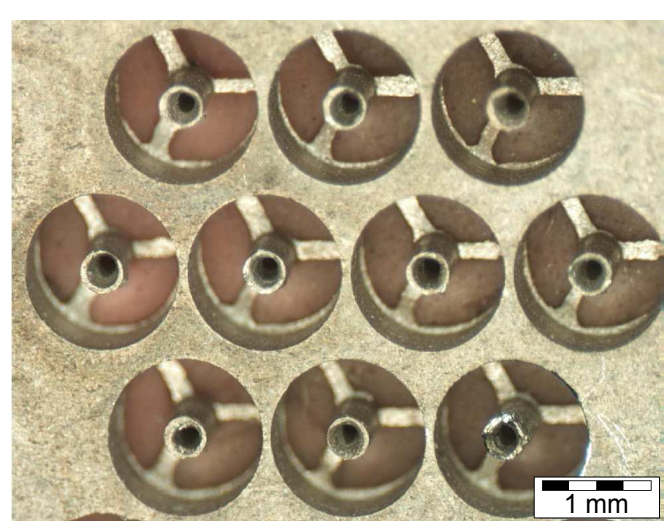

(a) 'Y actuators'.

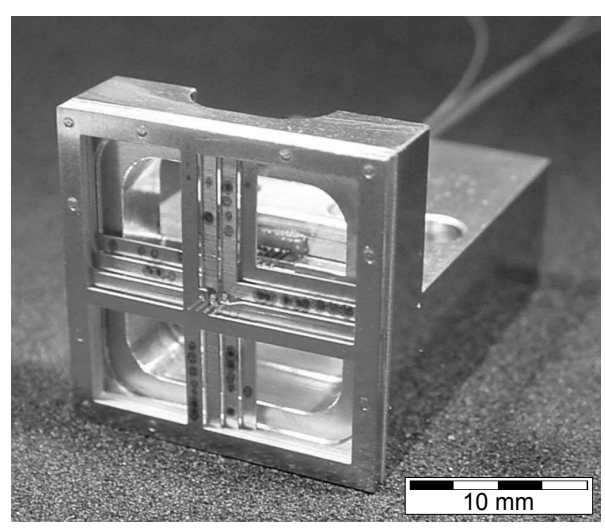

(b) '+ actuators'.

Fig. 1.9: (a):An array of ' $\mathrm{Y}$ ' shaped actuators for aligning optical fibers to a microlens array [31]. The smallest displacement achieved with this actuator was $0.2 \mu \mathrm{m}$. (b): Multiple fibers are aligned using four ' + ' shaped actuator windows [32]. The final fiber-tip position accuracy using this actuator was within $\pm 0.25 \mu \mathrm{m}$.

Stark et al. [31] used this method to align multiple fibers with respect to a microlens array with a pitch of $2 \mathrm{~mm}$, see Fig 1.9a. One actuator consists of three 'legs' in a ' $\mathrm{Y}$ ' shape, where each leg can be shortened by laser forming. A fiber is fixed in the center of each actuator. The authors achieved a minimum lateral step size of $0.2 \mu \mathrm{m}$ of the fiber. However, the heat input to the legs of this actuator requires careful planning of the irradiations to prevent excessive heating of the fiber and adhesives. Zandvoort et al. [32] aligned multiple optical fibers with respect to an optical chip, using the UM with four legs in a ' + ' shaped actuator, see Fig 1.9b. Multiple actuators were stacked to align an array of fibers individually, each with an accuracy of $0.25 \mu \mathrm{m}$. However, this actuator requires a large base frame of about $30 \mathrm{~mm} \times 30 \mathrm{~mm}$, which significantly increases the total packaged volume of such a device. 


\subsection{Problem definition}

Applications of optical devices that support short wavelengths into the UV spectrum include Raman spectroscopy, confocal microscopy, fluorescence microscopy [33], flowcytometry [34], DNA sequencing [35] or even high-throughput screening of food products [36]. Currently the optics in these devices include many discrete components like lenses and mirrors that need individual alignment. For those applications, the use of PIC chips (for example the ILBC mentioned in section 1.1) allows for a more robust 'plug-and-play' implementation of complex optical functions, as well as reduction of the weight, volume and cost. The recent developments in waveguide technology enable mass production of PIC chips for such short wavelengths [33], but new challenges arise in the micro-assembly and alignment of the optical fibers to these chips, see section 1.1. These challenges currently hinder the widespread adoption of photonic integrated circuits for short wavelengths into the UV spectrum.

When such sub-micron assembly accuracies are required, using an integrated onetime (re)alignment actuator using laser forming is a viable solution (see section 1.3). However, in order to use laser forming effectively for precision alignment, detailed knowledge of the amount of deformation in relation to the input parameters must be accurately known. Those input parameters include the laser power, laser spot size, pulse duration, as well as material properties and actuator dimensions. Numerous FEM models have been developed that can simulate the deformations due to laser forming successfully [13, 16, 17, 37, 38].

However, these models usually do not provide any information about the repeatability of the deformation for repeated irradiations. Such scattering in deformation is a result of irregularities of the process and the input parameters. While the latter are generally well controlled, irregularities in the process, like variations in the laser absorption coefficient, internal stresses, micro-structure changes [39] or differences in material batches are difficult to control or predict. Hennige et al. [40] identified the uncertainties in these parameters for laser plate bending and concluded that the final working accuracy of plate bending is limited by the variance of the bending angle.

To achieve accurate alignment despite these process uncertainties, the use of a feedback algorithm is required, that adapts the input parameters based on the measured distance to the target deformation. Such an algorithm makes the laser forming alignment an iterative process, that continues until the deformation has converged to the target within a specified accuracy. The use of such an algorithm can improve the accuracy of laser forming alignment from several microns to sub-micron accuracy.

Therefore, the problems which will be studied in this thesis are the characterization of the laser forming process repeatability and scattering, and improving the accuracy of laser forming actuators using control algorithms. The results will be applied to the PIC micro-assembly case, where a compact actuator is required to align an optical fiber to the chip after assembly. 


\subsection{Research objective and approach}

The problem definition, in the previous section, led to the formulation of the following research objectives for this thesis:

1. Explore and quantify the repeatability, sensitivity and range of motion to variations in the process and its parameters, of laser forming deformations.

2. Based on these insights, develop robust algorithms for aligning components with sub-micrometre accuracy using laser forming.

3. Develop a suitable laser forming actuator with an accompanying experimental setup, that can be applied for aligning an optical fiber with respect to an optical chip with sufficient accuracy.

4. Apply these algorithms and the actuator to the fiber alignment case and determine its performance by experiments.

To achieve these research objectives, a deeper understanding of the laser forming process is required. Therefore, first a planar three-bridge actuator is used to characterize the deformations for different bridge geometries, laser power and pulse durations. The 2D behavior of such an actuator allows for significant model simplifications for FEM and analytical models, aiding in the understanding of the process. These models are validated using an experimental setup that measures the deformation and temperature of the bridges during the laser pulse. The scattering in laser absorption as well as the scattering in resulting deformation is quantified by these experiments.

With the knowledge of the planar actuator, a more suitable actuator consisting of a tube, for aligning a single optical fiber is developed. For this tube actuator, an alignment algorithm is proposed that allows for fully unattended lateral alignment of the fiber tip. This algorithm is extended to the situation where the fiber tip position can not be measured, which is the case when the fiber is fully enclosed by the actuator and PIC chip. The performance of those actuators is verified be experiments, using an experimental setup that allows for real-time measurement of the deformation and control of the most important process parameters.

The actuator and algorithms presented in this thesis are designed for fiber alignment. However, the general methodology can be used for any micro-assembly case where laser forming is an option. 


\subsection{Outline}

The main part of this thesis consists of four journal articles, appearing as reprints in chapters 2 to 5 . While the chapters are self-contained and can be read independently, it is recommended to read them in the order presented. The content of these chapters is briefly outlined here.

In chapter 2 a planar, so-called three-bridge actuator is presented. A FEM model, as well as a reduced model to predict the motion of the actuator is presented and validated with experiments. Finally, an alignment algorithm is proposed for such an actuator which is simulated with the reduced model. This chapter addresses the topics of research objective 1 and 2 in section 1.5.

Chapter 3 introduces a laser forming actuator consisting of a simple tube. An optical fiber is concentric in the tube, and its tip can be aligned by laser-bending the tube. This chapter focuses on the development of an experimental setup that both measures this fiber tip displacement with an optical system, and is capable of positioning the laser spot on the tube surface. Experiments show that tube bending is accurate enough to align a fiber with the required precision when the input parameters are carefully chosen. This chapter addresses the topics of research objective 3 in section 1.5 .

In chapter 4 the selection of those input parameters is automated by an algorithm that minimizes the number of bending steps required to meet the desired alignment accuracy. This algorithm uses the statistical information gathered from previous bending steps to determine the optimal laser power and laser position. Three different tube geometries have been tested with this algorithm. A statistical comparison is made between the experiments and a simulation with thousands of alignment trials. This chapter addresses the topics of research objective 2 and 4 in section 1.5.

Chapter 5 focuses on the application of the algorithm developed in chapter 4 to the alignment of an optical fiber to a PIC chip. When such a chip is in place, the fiber tip is fully enclosed, and its position can not be measured. Therefore, a scanning algorithm is proposed that exploits the thermal expansion of the tube to move the fiber tip, without permanent deformation. This scanning algorithm finds the position that maximizes the optical coupling efficiency, which is then used in the alignment algorithm. This chapter addresses the topics of research objective 2 and 4 in section 1.5 .

Finally the conclusions are summarized in section 6.1 and a list of recommendations is presented in section 6.2. 


\title{
Chapter 2 \\ In-plane laser forming for high precision alignment
}

\begin{abstract}
Laser micro-forming is extensively used to align components with submicrometer accuracy, often after assembly. While laser-bending sheet metal is the most common laser forming mechanism, the in-plane upsetting mechanism is preferred when a high actuator stiffness is required. A three-bridge planar actuator made out of Invar36 sheet, was used to characterize this mechanism by experiments, FEM modeling and a fast reduced model. The predictions of the thermal models agree well with the temperature measurements, while the final simulated displacement after 15 pulses deviates up to a factor two from the measurement, using standard isotropic hardening models. Furthermore, it was found from the experiments and models that a small bridge width and a large bridge thickness are beneficial to decrease the sensitivity to disturbances in the process. The experiments have shown a step size as small as $0.1 \mu \mathrm{m}$, but with a spread of $20 \%$. This spread is attributed to scattering in surface morphology, which affects the absorbed laser power. To decrease the spread and increase the positioning accuracy, an adapted closed-loop learning algorithm is proposed. Simulations using the reduced model showed $78 \%$ of the alignment trials were within the required accuracy of $\pm 0.1 \mu \mathrm{m}$.
\end{abstract}

This chapter is reprinted with permission from SPIE from: Folkersma, K. G. P. Römer, G. R. B. E. Brouwer, D. M. Huis in 't Veld, A. J. "In-plane laser forming for high precision alignment". In: Optical engineering 53.12 (2014), pp. 126105-126105. DOI: $10.1117 / 1.0 \mathrm{E} .53 .12 .126105$. . 


\subsection{Introduction}

Laser micro-forming has been used in several applications in which high precision position adjustments to components are needed, often after component assembly [18, 20, 42, 43]. Applications are found in alignment of optics, diode laser packaging or optical fiber alignment, where the required positioning accuracy is in many cases below $1 \mu \mathrm{m}$. For these applications a stiff actuator is required for minimizing alignment errors due to external disturbances, for example due to external loads, thermal influences or vibrations. In this paper we research the use of laser forming for $0.1 \mu \mathrm{m}$ precision post-assembly adjustment.

\subsubsection{Laser forming mechanisms}

During laser forming the temperature profile, induced by the absorbed laser energy, results in a permanent deformation of the material under consideration. This deformation is a result of the generation of stress and strain fields by elevated local temperatures due to thermal expansion. That is, the material is heated (just) below the melting temperature, the compressive stress exceeds the yield stress, and a compressive plastic deformation with no spring-back is induced [22].

There are three types of direct thermal forming mechanisms, which are referred to as the Temperature Gradient Mechanism (TGM), the Upsetting Mechanism (UM) and the Buckling Mechanism (BM) [14, 22, 44]. The first two mechanisms are mostly applied for sub-micrometer resolution adjustments [18, 20, 30, 31].

The driving force for the TGM (also known as laser-bending) is a temperature gradient over the thickness of the substrate. The TGM is dominating over other mechanisms if the workpiece thickness is in the order of the laser beam diameter [22] and the interaction time is short, or in general, for small Fourier numbers. For the TGM several analytical and FEM models have been successfully developed, predicting the bending angle based on the (laser) processing parameters [22, 45-47]. However, since this mechanism is based on the bending of thin mechanical structures (or actuators), the stiffness in the actuation direction is low, which can cause alignment errors when external disturbances are present.

The UM is based on a small or no temperature gradient between the top and bottom surfaces of the irradiated material, see Figure 2.1. This near-uniform temperature distribution along the thickness occurs when the laser spot diameter is significantly larger than the thickness of the material [22] and/or the irradiation time is long and/or the thermal diffusivity of the material is large. That is, uniform heating of a cylindrical volume in the sheet is aimed at, resulting in an in-plane contraction of the (thin) mechanical structure. This can be exploited to create a stiff actuator. Therefore, the focus in this paper is on in-plane laser forming by the UM.

This mechanism has been exploited in actuators with multiple degrees of freedom $[30,31]$ and is the main mechanism occurring in laser-bending of tubes $[13,14,48]$. 


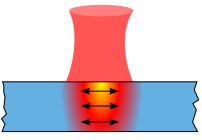

a
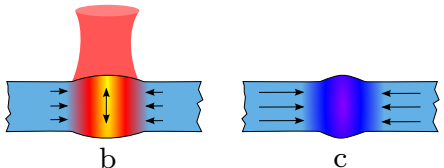

Fig. 2.1: The Upsetting Mechanism (UM). (a) Heating material with no or small temperature gradient in the thickness direction. (b) The thermal expansion causes compressive stresses that exceed the yield stress. (c) After laser irradiation, a contraction occurs as the material cools down.

Unfortunately, accurate prediction of the displacements of an actuator based on the UM is not trivial. Quite some research has been conducted to find relations between the input parameters (such as laser processing conditions, actuator geometry and material properties) and the obtained deformation [14, 48-50]. In a recent study it was shown that a minimum step size of $0.1 \mu \mathrm{m}$ can be achieved when a so-called "threebridge actuator" (see section 2.2) is used [51]. However, a relatively large spread of about $20 \%$ was found in the final position of the actuator, which was mainly attributed to scattering of the process parameters.

\subsubsection{Goal}

To the best of our knowledge, no study has been published on methods to improve the positioning accuracy of actuators based on in-plane laser adjusting by the UM. Therefore, in this paper models, experiments and control-algorithms are presented and discussed, aimed at the improvement of the positioning accuracy of actuators exploiting the in-plane laser adjusting. We want to use the UM in a feedback system, where the laser power is adapted, based on the incremental change of deformation. This approach has been successfully applied for laser bending [40, 52].

\subsubsection{Outline}

In section 2.3.1, a 3-D FEM model, relating the maximum occurring temperature and the resulting displacement, is presented and discussed, in order to investigate the resolution of the forming mechanism and the sensitivity to changes in geometry and laser parameters. Further, in section 2.3.2, a "reduced model" based on first principles, that allows the prediction of the displacements of the three-bridge actuator, is presented and discussed. Section 2.4 presents the experimental setup, which was used to validate the models, as well as to determine the spread in displacement. The latter is used to simulate the performance of a closed loop algorithm for a one-dimensional alignment 
problem. Section 2.5 presents the experimental and simulation results. Results of the reduced model and experiments are compared to results of the FEM model. The computational load of the reduced model is low, which allows statistical and robustness analysis of closed-loop algorithms. Using this reduced model, a new alignment algorithm is presented in section 2.6, that is robust for the disturbances in the laser forming process. Finally, section 2.7 summarizes the conclusions.

As mentioned before, the models, experiments and control-algorithms were developed for, and evaluated on, a three-bridge actuator. Therefore the characteristics and dimensions of this actuator are discussed in detail in the next section.

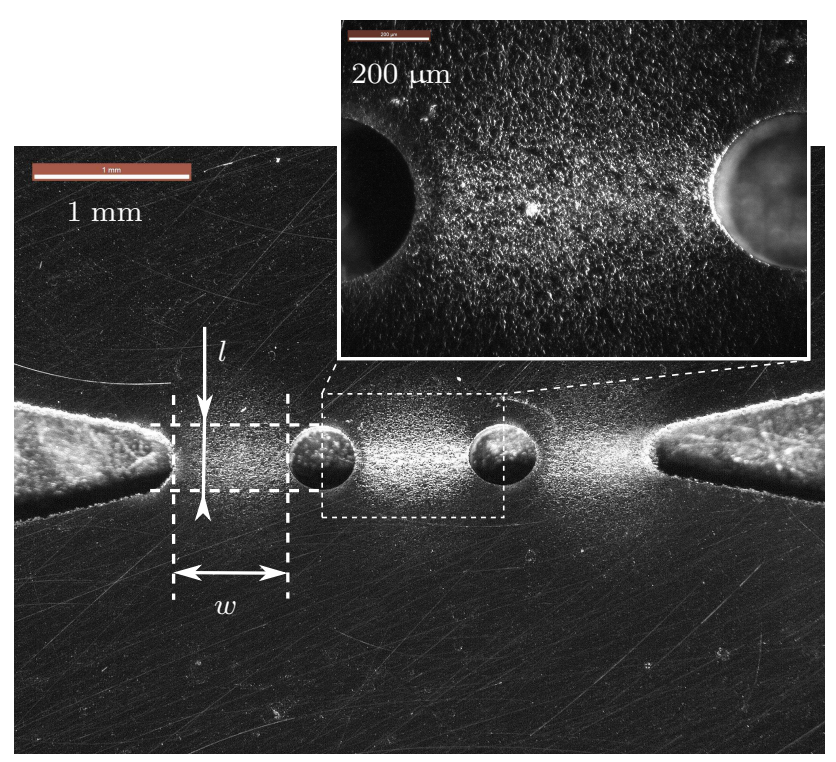

Fig. 2.2: Microscope image of three bridge actuator in Invar, after irradiation by several laser pulses. The areas on the bridges are bright due to laser-induced surface modifications. $l=500 \mu \mathrm{m}, w=750 \mu \mathrm{m}$.

\subsection{Three-bridge actuator}

In all laser forming mechanisms, a counteracting force, opposing the thermal expansion is a prerequisite for plastic deformation to occur in the material. Consequently, the deformation can only be a contraction of the heated material. These constraints need to be taken into account when designing an actuator structure. A common struc- 
ture is the "bridge actuator" $[30,50,53]$. It consists of multiple bridges (rods, bars) connecting the fixed part of the mechanism to the free part of the actuator structure, see Fig. 2.3. Heating one of the bridges, referenced to as A, B and C in Fig. 2.3, with a stationary laser beam causes thermal expansion, which is counteracted by the other bridges. The resulting compressive stress in the heated bridge causes compressive plastic deformation, shortening the bridge when cooling down. Such a structure has two actuation degrees of freedom; a bi-directional rotation $(\theta)$ (by shortening one of the outer bridges i.e. A or $\mathrm{C}$ ) and a translation $(y)$ in one direction (when shortening all bridges). In this paper we study a simple planar three-bridge actuator, see Fig. 2.3 and Fig. 2.2. For this research, the 3-bridge actuator is preferred over a 2-bridge actuator, since the stresses and strains in each bridge can be considered to be pure tensile or compressive, whereas the 2-bridge actuator also requires considering in-plane bending stress and strain in the bridges. The bridges were designed with radii to prevent stress concentrations in sharp corners.

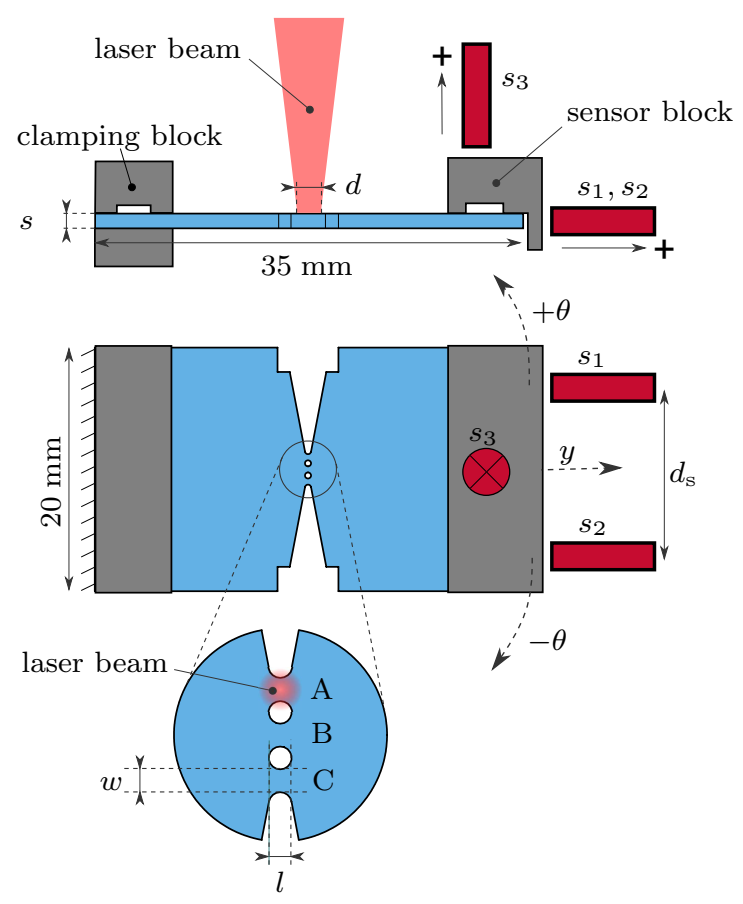

Fig. 2.3: Dimensions of the three bridge actuator studied in this paper. The directions of motion for a sequence of laser pulses on the respective bridges (A,B and C) are indicated by dashed arrows. 


\subsection{Models}

In this section, the 3D and 2D FEM models are presented, which were used to simulate thermal and mechanical behavior of the 3-bridge actuator. While these models are flexible in terms of geometry and thermal modeling, they are computationally intensive if multiple successive laser forming steps are required. This results in computation times that are unsuitable for statistical analysis of alignment algorithms. Therefore, a fast reduced model for the three-bridge actuator was developed to predict stresses and (plastic) strains from laser heating. This reduced model is outlined in section 2.3.2.

\subsubsection{FEM model}

To predict the deformation of the bridges from a set of process parameters, a timedependent 3D FEM model of the three bridge actuator was created in COMSOL MULTIPHYSICS.

The heat dissipation in the material due to deformation is very small compared to the heat induced by the laser. Therefore, the heat transfer and structural mechanics are only coupled by the thermal expansion of the material. The laser source was modeled as a surface heat flux with a Gaussian intensity profile $I$ in a polar coordinate system, defined by

$$
\begin{aligned}
I(r, \phi) & =I_{0} \exp \left(-\frac{8}{d^{2}} r^{2}\right), \\
\text { where } I_{0} & =\frac{8}{\pi d^{2}} P .
\end{aligned}
$$

Where $P$ is the laser power and $d$ the $1 / e^{2}$ spot diameter. The Von Mises yield criterion was implemented in the structural model. Isotropic strain hardening was used, with a bilinear stress-strain curve using the material tangent modulus. All structural material properties were assumed to be temperature-dependent, and obtained from [31]. A symmetric boundary condition was used for the geometry to reduce calculation time, see Fig. 2.4.

For thin planar structures, where the temperature gradient over the thickness is small, a 2D plane stress model suffices if the bending is not of interest. The 2D model predicts a displacement that is $2-20 \%$ less compared to the $3 \mathrm{D}$ model for the tested cases (see table 2.3), but shows a significant drop in computational load. 


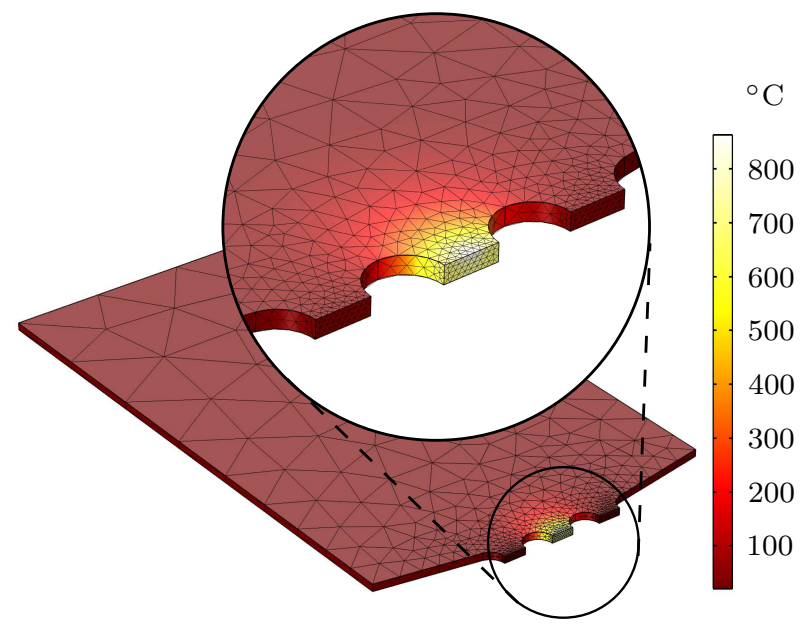

Fig. 2.4: A typical temperature distribution after one pulse on bridge B ( $s=250 \mu \mathrm{m}$, $\left.w=750 \mu \mathrm{m}, l=1000 \mu \mathrm{m}, d=560 \mu \mathrm{m}, P=7 \mathrm{~W}, t_{\text {pulse }}=300 \mathrm{~ms}\right)$. Note that the model has a symmetric boundary condition at the symmetry plane of the bridges.

\subsubsection{Reduced model}

To make the reduced model as simple and fast as possible, the geometry is reduced to three rectangles for the thermal model, and three hinged one-dimensional elastoplastic truss elements for the mechanical model, see Fig. 2.5. Furthermore, all physical properties are assumed to be uniform over the bridges, which implies that for example the laser intensity distribution is assumed to be uniform over the whole bridge. The simulated time is divided in small time-steps, which is necessary to incorporate the temperature dependent material properties (thermal conductivity $\kappa$, thermal expansion coefficient $\alpha_{\mathrm{th}}$, Young's modulus $E$ and yield stress $\sigma_{\mathrm{y}}$ ), which are updated each step. The step size $\Delta t$ was set to $0.125 \mathrm{~ms}$, as smaller time-step did not result in a significant change in the final displacement. This reduced model allows for an explicit solution of each time-step, and a low computational load.

The temperature $T_{i, k}$ of time step $i$ of bridge $k$ is obtained using the heat capacity of the bridge and the laser power. The conduction to the bulk material is modeled as a one-dimensional in heat flow to the bulk material:

$$
\begin{aligned}
\dot{Q}_{\text {cond }} & =-\kappa \cdot w \cdot s \frac{\left(T_{i-1, k}-T_{\mathrm{bulk}}\right)}{\frac{1}{2} l} \\
T_{i, k} & =T_{i-1, k}+\Delta t \frac{\left(P \cdot A+2 \dot{Q}_{\mathrm{cond}}\right)}{\rho c_{\mathrm{p}} V} .
\end{aligned}
$$



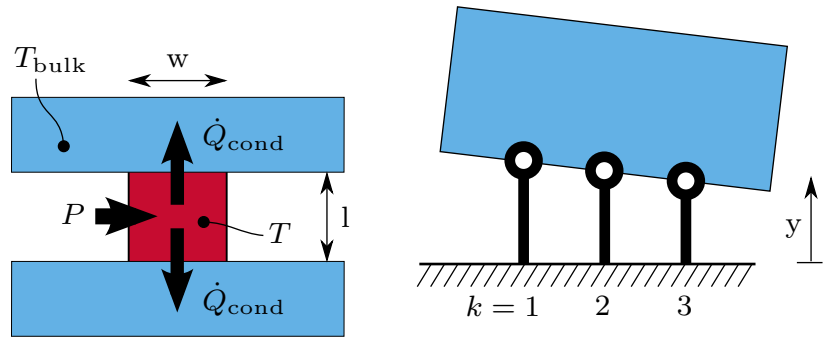

Fig. 2.5: Reduced model. (left) For the thermal model the bridges are assumed to be rectangular. (right) The mechanical model is an analogy to a system with three hinged bars, connected to a rigid block.

where $c_{\mathrm{p}}$ the specific heat and $\rho$ the density of the material. $A$ is the laser absorption coefficient and $V=w \cdot l \cdot s$ is the volume of a single bridge. The laser power $P$ is set to zero after $t>t_{\text {pulse }}$. $T_{\text {bulk }}$ is the temperature of the bulk material, which is approximated by a constant factor of the current bridge temperature by $T_{\text {bulk }}=0.25 T_{i-1, k}$. This factor was found empirically by comparing with the FEM model.

As mentioned before, the driving force for the laser adjusting displacement is thermal expansion. The thermal strain for time step $i$ of bridge $k$ equals

$$
\varepsilon_{i, k}^{\mathrm{th}}=\alpha_{\mathrm{th}} T_{i, k},
$$

The elastic strain can now be calculated from

$$
\begin{array}{r}
\varepsilon_{i, k}^{\mathrm{el}}-\varepsilon_{i_{0}, k}^{\mathrm{el}}=\Delta \varepsilon \cdot \beta_{k}, \\
\Delta \varepsilon=\varepsilon_{i, k}^{\mathrm{th}}+\varepsilon_{i-1, k}^{\mathrm{pl}}-\varepsilon_{i_{0}, k}^{\mathrm{pl}},
\end{array}
$$

where $\varepsilon^{\mathrm{pl}}$ is the plastic strain, $i_{0}$ is the initial time step of the current pulse and $\beta_{k}$ is the factor of elastic strain in bridge $k$ relative to the current difference in strain $\Delta \varepsilon$.

For a symmetric three-bridge structure this factor can be found by considering the force balance, assuming the strain in the other bridges is purely elastic.

$$
\begin{aligned}
\sum F & =F_{1}+F_{2}+F_{3}=0, \text { where } F_{1}=F_{3} \\
-F_{2} & =2 F_{1}=2 F_{3} \\
-\varepsilon_{2}^{\mathrm{el}} E_{2} & =2 \varepsilon_{1}^{\mathrm{el}} E_{1}=2 \varepsilon_{3}^{\mathrm{el}} E_{3}
\end{aligned}
$$

Where $F_{k}$ is the force in bridge $k$. For the current bridge $k=2$, we have an equal strain for all bridges due to symmetry, resulting in

$$
\varepsilon_{2}^{\mathrm{el}}+\Delta \varepsilon=\varepsilon_{1}^{\mathrm{el}}=\varepsilon_{3}^{\mathrm{el}} .
$$


Combining equations (2.5) and (2.6) gives:

$$
\varepsilon_{2}^{\mathrm{el}}=-\Delta \varepsilon \frac{1}{1+\frac{E_{2}}{2 E_{0}}},
$$

where $E_{0}$ is the Young's modulus of the other bridges (at room temperature). For $k=1$ we get the geometric relation:

$$
\varepsilon_{1}^{\mathrm{el}}+\Delta \varepsilon=2 \varepsilon_{2}^{\mathrm{el}}-\varepsilon_{3}^{\mathrm{el}}
$$

From equation (2.5) follows

$$
\begin{aligned}
& \varepsilon_{2}^{\mathrm{el}}=-2 \varepsilon_{1}^{\mathrm{el}} \frac{E_{1}}{E_{0}} \\
& \varepsilon_{3}^{\mathrm{el}}=\varepsilon_{1}^{\mathrm{el}} \frac{E_{1}}{E_{0}} .
\end{aligned}
$$

Substituting equations (2.8), (2.9) and (2.10):

$$
\varepsilon_{1}^{\mathrm{el}}=-\Delta \varepsilon \frac{1}{1+5 \frac{E_{1}}{E_{0}}}
$$

Due to symmetry the result is the same for $k=3$, so we get

$$
\begin{aligned}
& \beta_{1}=\beta_{3}=-\frac{1}{1+5 \frac{E}{E_{0}}}, \\
& \beta_{2}=-\frac{1}{1+\frac{E}{2 E_{0}}} .
\end{aligned}
$$

The stress $\sigma$ then follows from

$$
\sigma_{i, k}=\varepsilon_{i, k}^{\mathrm{el}} E,
$$

Assuming a perfect plastic material behavior (no hardening), the plastic strain is calculated as

$$
\varepsilon_{i, k}^{\mathrm{pl}}=\varepsilon_{i-1, k}^{\mathrm{pl}}+ \begin{cases}\frac{\sigma_{i, k}-\operatorname{sign}\left(\sigma_{i, k}\right) \sigma_{\mathrm{y}}}{E} & \text { if } \sigma_{i, k}>\sigma_{\mathrm{y}} \\ 0 & \text { if } \sigma_{i, k} \leq \sigma_{\mathrm{y}}\end{cases}
$$

Finally, the total strain $\varepsilon_{i, k}^{\text {tot }}$ in the $k$ th bridge is calculated, and multiplied with a constant vector $\boldsymbol{G}_{k}$ to obtain the total strain in the other bridges,

$$
\begin{aligned}
& \varepsilon_{i, k}^{\mathrm{tot}}=\varepsilon_{i, k}^{\mathrm{el}}+\varepsilon_{i, k}^{\mathrm{th}}+\varepsilon_{i, k}^{\mathrm{pl}}, \\
& \boldsymbol{\varepsilon}_{i}^{\mathrm{tot}}=\varepsilon_{i_{0}}^{\mathrm{tot}}+\left(\varepsilon_{i, k}^{\mathrm{tot}}-\varepsilon_{i_{0}, k}^{\mathrm{tot}}\right) \boldsymbol{G}_{k} .
\end{aligned}
$$


The vector $\boldsymbol{G}_{k}$ relates the total strain of all bridges to the known total strain of bridge $k$. This value is 1 for $k=2$, where all bridges have the same strain due to symmetry. For $k=3$ this vector can be found from the geometrical relation

$$
\varepsilon_{2}^{\mathrm{tot}}=\frac{\varepsilon_{1}^{\mathrm{tot}}+\varepsilon_{3}^{\mathrm{tot}}}{2}
$$

and from equation (2.4) we have

$$
-\varepsilon_{2}^{\text {tot }}=2 \varepsilon_{1}^{\text {tot }}
$$

Substituting equation (2.20) with equation (2.19) yields

$$
\begin{aligned}
& \varepsilon_{2}^{\mathrm{tot}}=\frac{2}{5} \varepsilon_{3}^{\mathrm{tot}} \text { and } \\
& \varepsilon_{1}^{\mathrm{tot}}=-\frac{1}{5} \varepsilon_{3}^{\mathrm{tot}} .
\end{aligned}
$$

A similar result is obtained for $k=1$. The resulting combined matrix $\boldsymbol{G}$ then reads

$$
\boldsymbol{G}=\left[\begin{array}{l}
\boldsymbol{G}_{1} \\
\boldsymbol{G}_{2} \\
\boldsymbol{G}_{3}
\end{array}\right]=\left[\begin{array}{ccc}
1 & \frac{2}{5} & -\frac{1}{5} \\
1 & 1 & 1 \\
-\frac{1}{5} & \frac{2}{5} & 1
\end{array}\right]
$$

The strains and stresses in the remaining bridges $k^{\prime}$ are calculated from

$$
\begin{aligned}
\varepsilon_{i, k^{\prime}}^{\mathrm{pl}} & =\varepsilon_{i-1, k^{\prime}}^{\mathrm{pl}} \\
\varepsilon_{i, k^{\prime}}^{\mathrm{th}} & =0 \\
\varepsilon_{i, k^{\prime}}^{\mathrm{el}} & =\varepsilon_{i, k^{\prime}}^{\mathrm{tot}}-\varepsilon_{i, k^{\prime}}^{\mathrm{pl}} \\
\sigma_{i, k^{\prime}} & =\varepsilon_{i, k^{\prime}}^{\mathrm{el}} E .
\end{aligned}
$$

For each subsequent laser pulse this process is repeated, where the strains and stresses from the final time-step are taken as initial values for the next pulse. The total strain is multiplied by $l$ to obtain the absolute displacement of each bridge.

An interesting result, following from this model and its assumptions, is that the geometry of the bridges is only of influence on the bridge temperature in equation (2.1). The relation between the temperature and strains is independent of the geometry. As a result, if the laser power or pulse time is scaled with the bridge width or thickness, the displacement per pulse will not change. Furthermore, the spacing between the bridges has no effect on the strains, however a larger spacing makes the angular motion of the actuator smaller. 


\subsection{Experimental setup}

To verify the FEM model, an experimental setup was designed and implemented that allows to measure the displacement of the actuator, during the laser adjusting process. The three-bridge actuator structure was cut from a plate by wire electrical discharge machining (EDM). A photo of the three bridges is shown in Fig. 2.2. The material used for the actuator was the low thermal expansion nickel alloy Invar 36 (FeNi36) [31]. Invar is chosen, because it has well-known temperature dependent material properties and has a small expansion coefficient at room temperature. The latter is beneficial for the stability of the alignment of components at room temperature. Above $200{ }^{\circ} \mathrm{C}$, the thermal expansion coefficient of Invar increases sharply with temperature, which allows for the thermal expansion stresses to exceed the yield stress, without exceeding the melting temperature of $1450{ }^{\circ} \mathrm{C}$. The Invar samples were polished in 5 steps to a surface roughness of $1 \mu \mathrm{m}$ and cleaned with alcohol before each experiment. Argon was used as a shielding gas, to prevent oxidation of the surface during the heating cycle. Two capacitive sensors measured the in-plane translation and rotation of the actuator, and a third capacitive sensor measured the out-of-plane bending of the sample, see Fig. $2.3 ; s_{1}$ to $s_{3}$. The samples were clamped to a base plate at one end, while at the free end, a brass block was mounted to create a measuring surface for the capacitive sensors, see Fig. 2.6.

A $100 \mathrm{~W}, 1080 \mathrm{~nm}$ fiber laser (JK Lasers JK100FL) was used to heat the bridges. A single-mode fiber and beam delivery optics delivered a Gaussian intensity profile near the focus of the beam. A variable working distance allows for an adjustable spot size. The intensity profile was measured (using the Primes FocusMonitor) for the used spot sizes and can be considered Gaussian [51].

During the process, the spatial maximum temperature at the surface was measured by a high-speed two-color pyrometer (Sensortherm Metis HQ22). The intensity is measured at $1450 \mathrm{~nm}$ and $1800 \mathrm{~nm}$ wavelength, which makes it insensitive to the laser reflection. This pyrometer has an absolute temperature range of $500{ }^{\circ} \mathrm{C}$ to $1300{ }^{\circ} \mathrm{C}$ and a response time of $80 \mu \mathrm{s}$. The pyrometer optics were aligned such as to cover roughly the same area as the laser spot on the bridges. The emissivity slope of the material was found by heating a sample in an oven, while measuring the surface temperature with a thermocouple as well as with the pyrometer. The signals of the displacement sensors and the pyrometer were captured by a data acquisition system running Matlab xPC, sampling at a frequency of $10 \mathrm{kHz}$. The same system was used to control the laser power and triggering, as well as controlling the stage motion, allowing positioning of the sample relative to the laser beam.

The direction of the in-plane rotation can be set by the sequence of heating the bridges (see Fig. 2.2). This sequence was chosen to be repeating B-A-C in all experiments, which results in a combination of in-plane rotation and translation of the free end of the actuator. 


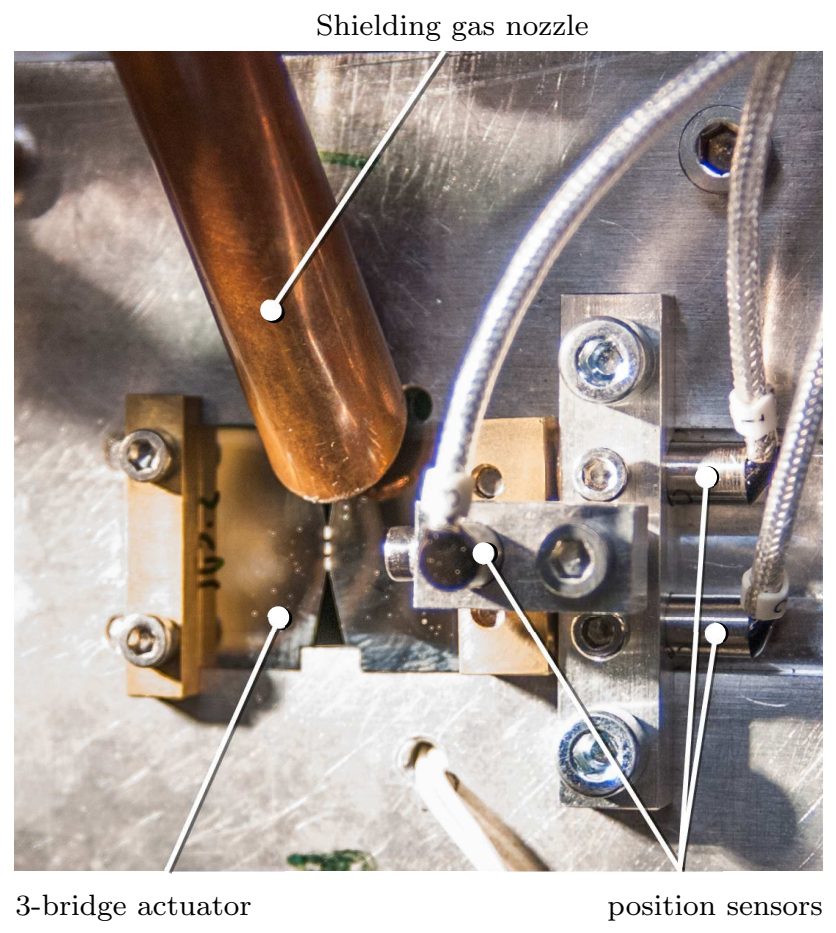

Fig. 2.6: Photo of the sample clamping and position measurement in the experimental setup.

\subsection{Results}

\subsubsection{Temperature measurements}

The driving force for the laser forming mechanism is the temperature change in a bridge over time. Therefore, accurate temperature measurements are the key to understanding the forming mechanism. The reproducibility of the temperature measurement was checked by repeated laser pulses of $300 \mathrm{~ms}$ on a fixed position on an Invar plate. After 6 pulses, the plate was moved to a new (virgin) location. It has been found that the repeatability of the temperature cycle strongly depends on the surface morphology of the Invar plate. Fig. 2.7 shows a typical temperature cycle of a polished surface with a roughness of about $1 \mu \mathrm{m}$. The standard deviation of the maximum temperature of 36 heating cycles was found to be $12{ }^{\circ} \mathrm{C}$, which is $1.3 \%$ of the average maximum temperature. Similar tests with an approximated surface roughness of $3 \mu \mathrm{m}, 6 \mu \mathrm{m}$ and $18 \mu \mathrm{m}$ showed a standard deviation of $9{ }^{\circ} \mathrm{C}(1.1 \%), 65{ }^{\circ} \mathrm{C}(6.2 \%)$ and $110{ }^{\circ} \mathrm{C}(9 \%)$ respectively. 


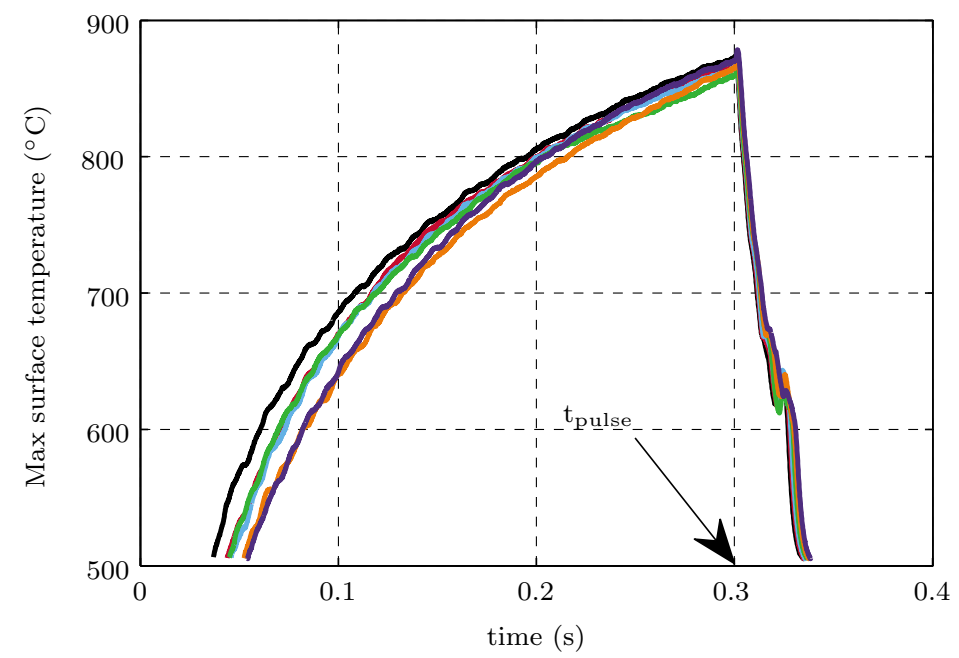

Fig. 2.7: Measured temperature cycle of 6 subsequent laser pulses on different locations on the polished Invar plate. $s=220 \mu \mathrm{m}, P=43 \mathrm{~W}, d=730 \mu \mathrm{m}$.

This indicates that a surface roughness of less than $4 \mu \mathrm{m}$ is required for a repeatability better than $5 \%$. The surface roughness appearing at the surface after irradiation (see Fig. 2.2), also affects the laser absorption after several pulses.

However, when the same measurements are carried out on the bridges of the 3-bridge actuator, the repeatability of the measured temperature decreases strongly, see Fig. 2.8 for a typical measurement of 3 pulses on each bridge. The standard deviation in this figure is $42{ }^{\circ} \mathrm{C}(4.3 \%)$. However, with a different actuator geometry (width and thickness of the bridges) and laser parameters, this deviation may even increase up to $130{ }^{\circ} \mathrm{C}(12.5 \%)$. Notice that the temperature spread for a single bridge is much less than for all bridges combined. The small deviations in geometry of the bridges due to the manufacturing process may contribute to this spread, but this does not account for the large temperature differences. This indicates that the laser absorption varies between the bridges, even after polishing. This can be attributed to poor polishing at the edges of the actuator structure in combination with the large overlap of the laser spot over these edges of the bridges.

Due to this large spread in temperature, the absorption coefficient can not be considered constant for all bridges. Therefore, the temperature measurement and not the actual laser power, was taken as the input for the FEM model of the forming mechanism. This allows for direct comparison of samples with different surface qualities, and the model validation is therefore less sensitive to the polishing process. 


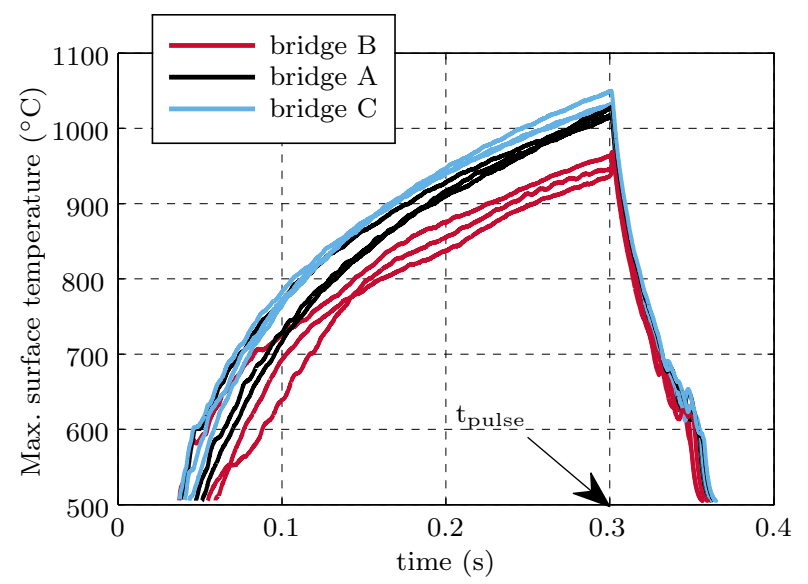

Fig. 2.8: Measured temperature cycle of 3 laser pulses on each bridge of the polished actuator. $w=750 \mu \mathrm{m}, s=220 \mu \mathrm{m}, l=500 \mu \mathrm{m}, P=50 \mathrm{~W}, t_{\text {pulse }}=300 \mathrm{~ms}$, $d=1000 \mu \mathrm{m}$.

\subsubsection{Displacement measurements}

The displacement of the free end of the actuator sample was measured by capacitive sensors. Sensors $s_{1}$ and $s_{2}$ measured the in-plane deformation and $s_{3}$ the out-of-plane bending angle, see Fig. 2.3. The distance $d_{\mathrm{s}}$ between $s_{1}$ and $s_{2}$ is $12 \mathrm{~mm}$ and $s_{3}$ is located at $15 \mathrm{~mm}$ from the center of the sample. The material surrounding the bridges is assumed to be rigid and the rotations are assumed to be small. Therefore, the displacement of each bridge can be calculated from the two displacement measurements. The displacement of bridge $\mathrm{B}$ is the average of $s_{1}$ and $s_{2}: y_{\mathrm{B}}=\left(\frac{s_{1}+s_{2}}{2}\right)$. The displacement of bridge $\mathrm{A}$ and $\mathrm{C}$ are then calculated from $y_{\mathrm{A}}=\frac{s_{2}-s_{1}}{d_{\mathrm{s}}}(w+l)+y_{\mathrm{B}}$ and $y_{\mathrm{C}}=\frac{s_{1}-s_{2}}{d_{\mathrm{s}}}(w+l)+y_{\mathrm{B}}$ respectively.

Fig. 2.9a shows the measured displacement during and after the first laser pulse on bridge $\mathrm{B}$. The thermal expansion causes expansion up to $t=t_{\text {pulse }}$. After cooling, the shortening of all bridges is equal due to the symmetry. The displacement at $t=0$ is re-zeroed for each pulse, and therefore the compression results in a negative displacement. After the pulse, a tensile stress is present in the irradiated bridge B, while a compressive stress is present in bridge $\mathrm{A}$ and $\mathrm{C}$.

Due to this first shot on bridge B, a small rotation of the free end of the actuator is always present. The rotation is noticed by a difference between sensor readings $s_{1}$ and $s_{2}$ (not visible in Fig. 2.9a), which can be caused by a misalignment of the laser spot with respect to the bridges, sample geometry imperfections or initial internal stresses in the material. A pulse on bridge $\mathrm{A}$ and $\mathrm{C}$ (Fig. 2.9b and 2.9c) results in a shortening of those bridges, causing a combination of in-plane rotation and a translation of the actuator. 


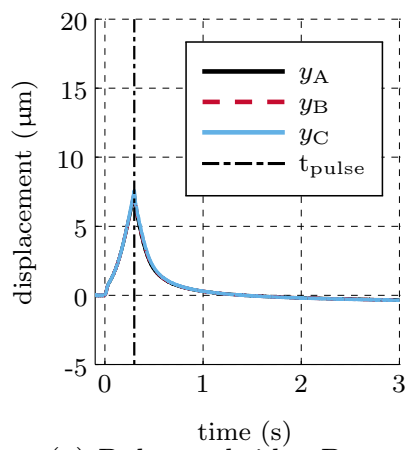

(a) Pulse on bridge $B$

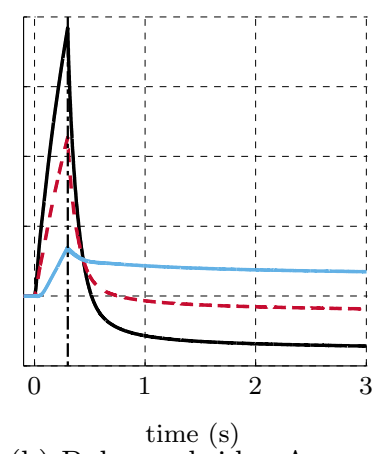

(b) Pulse on bridge A

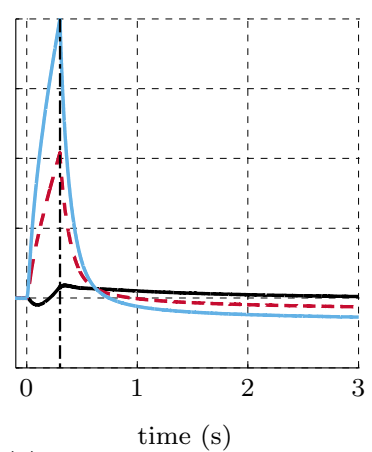

(c) Pulse on bridge $\mathrm{C}$

Fig. 2.9: Measured displacement due to the first laser pulse on each bridge in the sequence B-A-C. $s=220 \mu \mathrm{m}, w=750 \mu \mathrm{m}, l=500 \mu \mathrm{m}, d=1000 \mu \mathrm{m}$, $P=50 \mathrm{~W}, t_{\text {pulse }}=300 \mathrm{~ms}$.

This process can be repeated in the same sequence (here B-A-C) to induce larger deformations. Here, the final deformation (after $20 \mathrm{~s}$ cooling time) of each pulse was gathered. Fig. 2.10 and 2.11 show the cumulative displacement of the first $5 \times 3$ laser pulses on two different bridge geometries and corresponding laser settings. The first 3 pulses result in a larger displacement than the subsequent pulses, because there is no initial stress in the (virgin) material of each bridge. After the first three pulses, one on each bridge, the subsequent iterations of the same sequence show a constant deformation with each series of pulses.

Significant bending, measured by sensor $s_{3}$, has been found in samples with a thickness over $500 \mu \mathrm{m}$. This implies that the temperature gradient over the thickness of the sample was significantly high for the TGM to occur. However, in a carefully designed actuator, this bending is suppressed by the rest of the structure. The bending is therefore not considered in this paper. While the sensors $s_{1}$ and $s_{2}$ are located in the neutral axis of the actuator plate (see Fig. 2.3), there was still a small coupling between the bending of the sample and the displacement measured by sensors $s_{1}$ and $s_{2}$. Therefore, a linear correction was applied to decouple the bending from the in-plane displacement, using the information from $s_{3}$.

\subsubsection{FEM model validation}

To validate the FEM model, model predictions were compared to the experimental results. The heat transfer model was checked independently from the forming process, by using data from the pyrometer. 


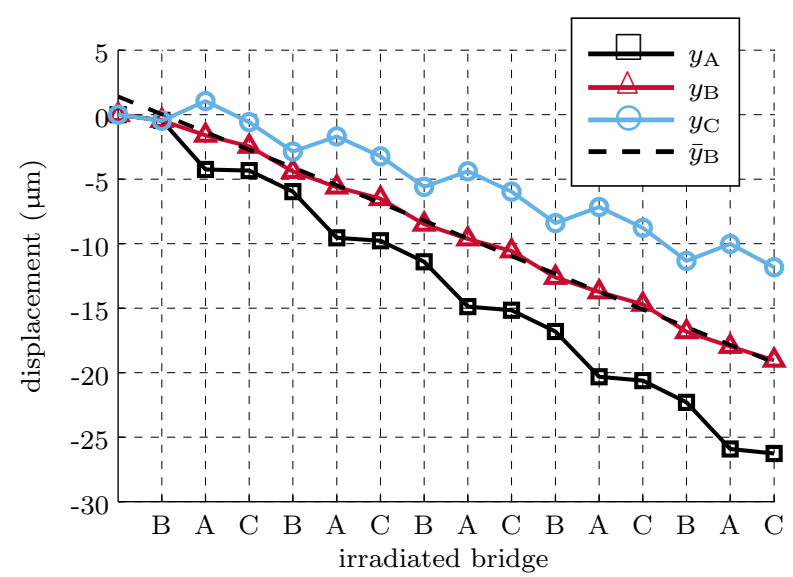

Fig. 2.10: Measured cumulative displacement of bridges A, B and C for 15 pulses. $s=220 \mu \mathrm{m}, w=750 \mu \mathrm{m}, l=500 \mu \mathrm{m}, d=1000 \mu \mathrm{m}, P=50 \mathrm{~W}, t_{\text {pulse }}=300 \mathrm{~ms}$

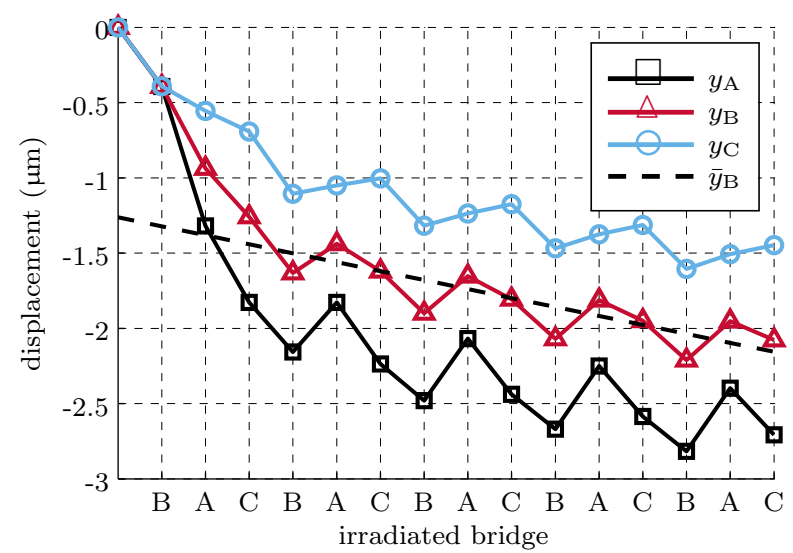

Fig. 2.11: Measured cumulative displacement of bridges A, B and C for 15 pulses. $s=560 \mu \mathrm{m}, w=500 \mu \mathrm{m}, l=500 \mu \mathrm{m}, d=730 \mu \mathrm{m}, P=40 \mathrm{~W}, t_{\text {pulse }}=300 \mathrm{~ms}$

\section{Heat transfer model}

Polished Invar plates with a thickness of $220 \mu \mathrm{m}$ and $480 \mu \mathrm{m}$ were heated by a stationary laser spot with a pulse duration of $300 \mathrm{~ms}$. The pyrometer does not provide measurements below $500{ }^{\circ} \mathrm{C}$, therefore an extrapolation algorithm was used that fits a 6 th order polynomial to the measurement signal with constraints $T(0)=23{ }^{\circ} \mathrm{C}$ and $T\left(t_{\text {pulse }}\right)=T_{\max }$, where $T_{\max }$ is the maximum measured temperature. The 
measurements were simulated by the 3D FEM model, using the measured intensity profile of the laser in the center of a $10 \mathrm{~mm}$ by $10 \mathrm{~mm}$ plate.

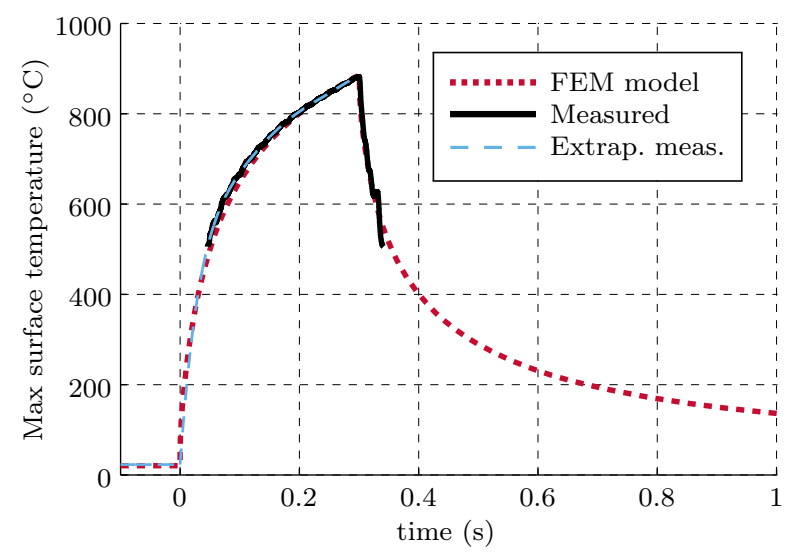

Fig. 2.12: Simulated and measured temperature cycle on Invar plate. $s=220 \mu \mathrm{m}$, $d=1000 \mu \mathrm{m}, P=50 \mathrm{~W}, t_{\text {pulse }}=300 \mathrm{~ms}$.

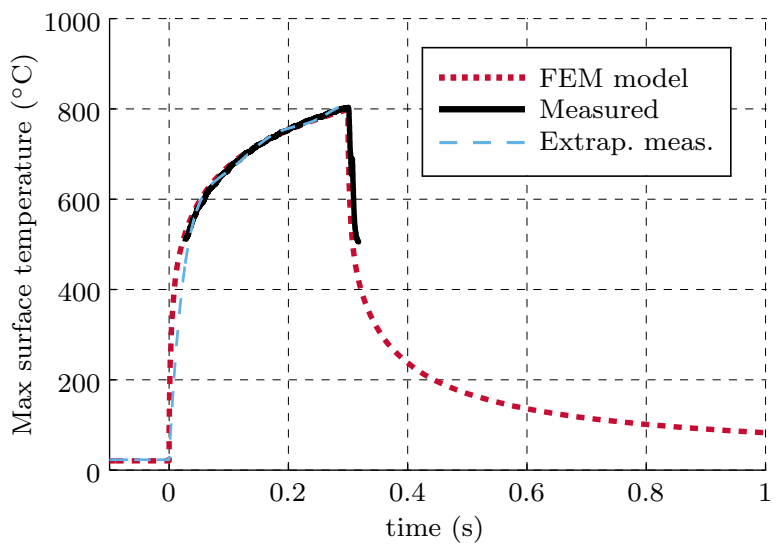

Fig. 2.13: Simulated and measured temperature cycle on Invar plate. $s=480 \mu \mathrm{m}$, $d=730 \mu \mathrm{m}, P=60 \mathrm{~W}, t_{\text {pulse }}=300 \mathrm{~ms}$.

The absorption coefficient in the model was found iteratively by matching the maximum temperature with the measurement from the pyrometer. For a polished Invar plate with a surface roughness of about $1 \mu \mathrm{m}$, this absorption coefficient was 
found to equal 13\%. As can be observed from two test cases in Fig 2.12 and 2.13, the simulations match well with the measured temperature.

\section{Mechanical model}

To verify the mechanical model independently from the spread in temperature observed in the experiments, the temperature measurements are taken as an input for the FEM model. To prescribe a temperature distribution in the heat transfer model without knowledge of the absorption coefficient, the laser power in the FEM model was automatically adjusted each time step, to obtain the same spatial maximum temperature as in the measurements. Fig. 2.14 shows a comparison of the simulated displacement at the sensor locations with a measurement, for 8 pulses. A cooling time of $20 \mathrm{~s}$ per laser shot was used, however data has been cut-off after each $5 \mathrm{~s}$ for clarity.

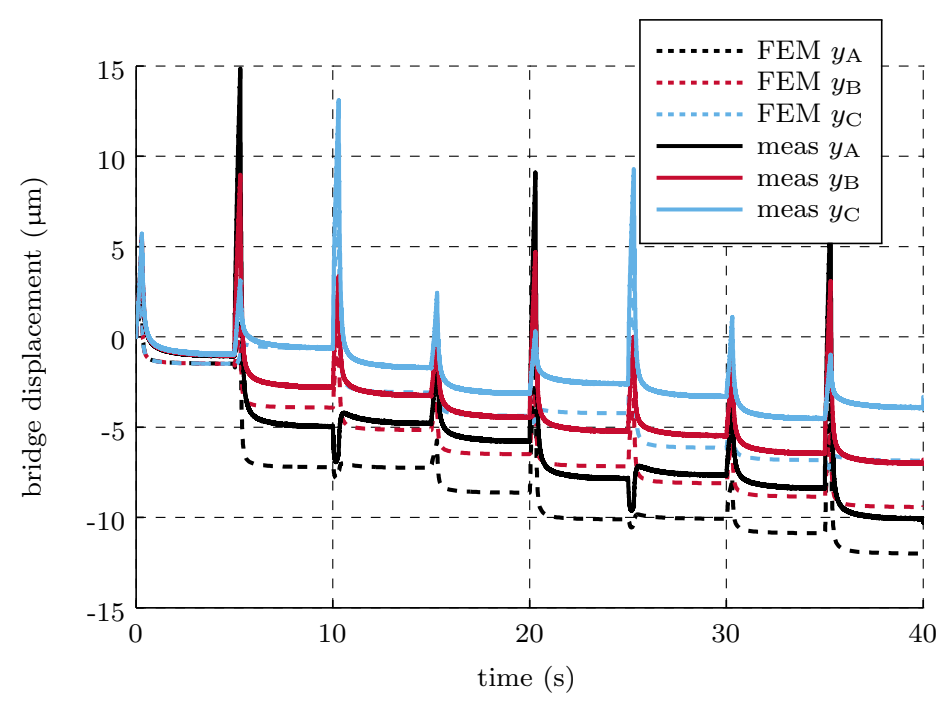

Fig. 2.14: Example of a comparison of measured and simulated displacement at the sensor positions, for 8 laser pulses. $s=220 \mu \mathrm{m}, w=500 \mu \mathrm{m}, l=500 \mu \mathrm{m}$, $d=730 \mu \mathrm{m}, P=32 \mathrm{~W}, t_{\text {pulse }}=300 \mathrm{~ms}$.

While the displacement from the model shows the same trends as the experiments, the absolute displacement error after the 8 pulses is $35 \%$. For other parameter sets this error can be as high as $100 \%$ (i.e. the simulated displacement is twice the measured displacement). The main cause of this error is likely to be found in the chosen hardening model. While isotropic hardening is often used in laser-bending (TGM) models with success $[13,54,55]$, it may not suffice for the in-plane laser-forming process, where 
more stress relaxation may occur due to the high temperatures. Moreover, hardening models require the temperature-dependent tangent modulus, which is scarcely available for most materials. Another cause may be a change in grain size due to laser irradiation leading to a change in yield stress, as proposed by Shen et al. [56].

\subsubsection{Deformation sensitivity}

To study the effect of different bridge geometries and the effect of laser parameters, the deformation sensitivity of the three-bridge actuator is defined as the deformation of bridge B per pulse for a repeated B-A-C sequence. Therefore, the cumulative deformation of bridge B in Fig. 2.10 was fitted by a linear least-squares fit. The first three pulses were omitted, to remove the start-up effects and initial stresses. The slope of this fit $\bar{y}_{\mathrm{B}}$ is the deformation sensitivity in $\mu \mathrm{m}$ per pulse. This deformation sensitivity was calculated from experiments with different three-bridge actuator geometries. The dimensions of the actuators and laser parameters used in the experiments are listed in Table 2.1. The bridge length was fixed to $500 \mu \mathrm{m}$, since the effect of this parameter was found to be small in the FEM model. The laser spot diameter was chosen to be about 140\% larger than the bridge width. This makes the laser beam alignment less critical. However, about $10 \%$ of the incident power is lost at the sides of the bridge in this setting. To ensure small temperature gradients over the thickness, in order to prevent excessive bending of the actuator, the pulse duration has to be chosen sufficiently long and has been set to $300 \mathrm{~ms}$. For longer pulses, heat flowing to the surrounding bridges can not be ignored and will influence the results.

Table 2.1: Actuator dimensions and laser parameters used in the experiments

\begin{tabular}{|c|c|c|c|c|c|}
\hline $\begin{array}{l}\text { number of } 3 \\
\text { bridge actuators }\end{array}$ & $\begin{array}{l}\text { thickness } \\
s(\mu \mathrm{m})\end{array}$ & $\begin{array}{l}\text { bridge width } \\
w(\mu \mathrm{m})\end{array}$ & $\begin{array}{l}\text { bridge length } \\
l(\mu \mathrm{m})\end{array}$ & $\begin{array}{l}\text { spot diam. } \\
d(\mu \mathrm{m})\end{array}$ & $\begin{array}{l}\text { laser power } \\
P\end{array}$ \\
\hline 6 & 250 & 400 & 500 & 590 & $3 \times 25 \mathrm{~W}, 3 \times 28 \mathrm{~W}$ \\
\hline 6 & 250 & 500 & 500 & 730 & $5 \times 30 \mathrm{~W}, 1 \times 35 \mathrm{~W}$ \\
\hline 6 & 250 & 750 & 500 & 1000 & $4 \times 45 \mathrm{~W}, 2 \times 25 \mathrm{~W}$ \\
\hline 6 & 500 & 500 & 500 & 730 & $6 \times 40 \mathrm{~W}$ \\
\hline 3 & 500 & 750 & 500 & 1000 & $3 \times 55 \mathrm{~W}$ \\
\hline
\end{tabular}

The experimental results are shown in Fig. 2.15 for the different actuator geometries. On the horizontal axis the maximum temperature at the end of the pulse, averaged over all 15 pulses for the sample under consideration is plotted. The spread of this temperature showed a standard deviation of $50{ }^{\circ} \mathrm{C}$, averaged over all measurements. Error bars for this spread are not shown here for clarity. A linear least-squares fit through the measurements shows the relation between the maximum temperature and the displacement per laser pulse. 


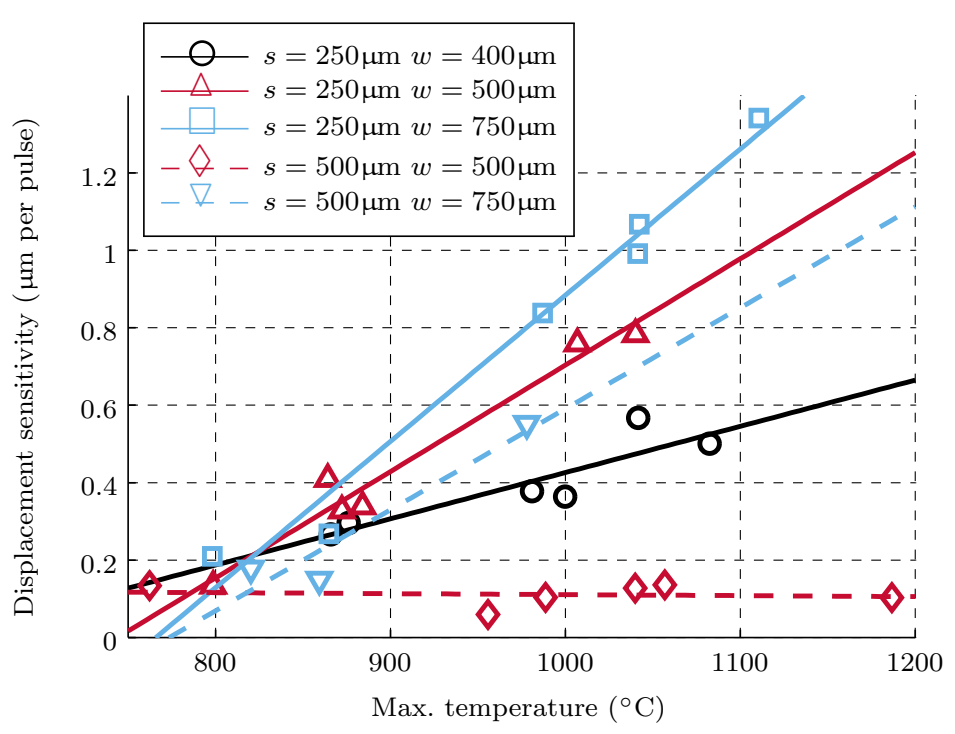

Fig. 2.15: Displacement sensitivity: Average measured step size of $y_{\mathrm{B}}$ per shot versus the maximum measured temperature.

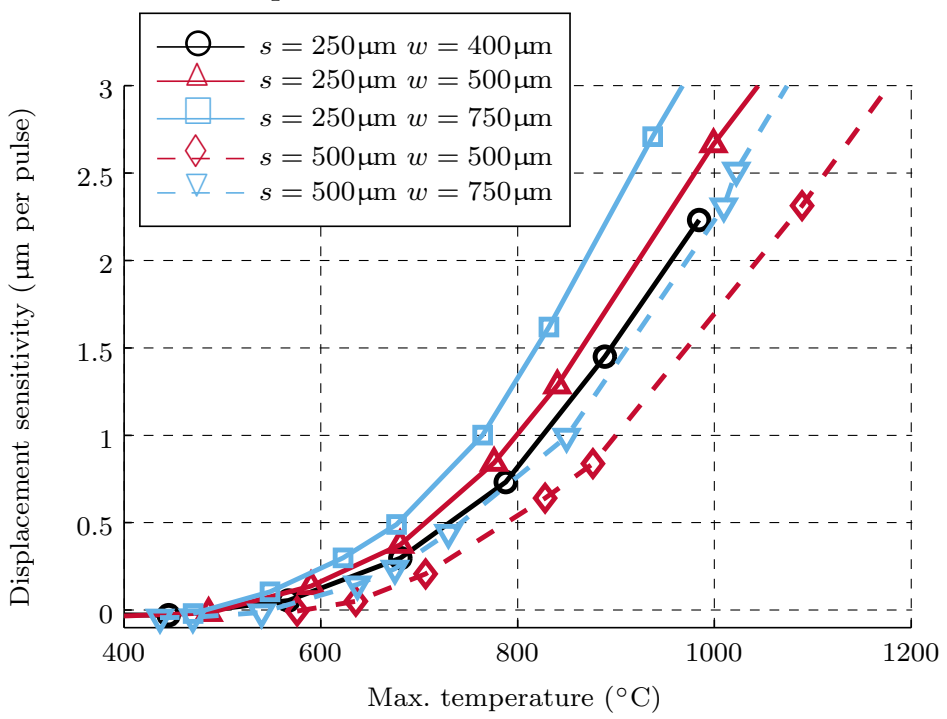

Fig. 2.16: Average step size of $y_{\mathrm{B}}$ per shot versus the maximum occurring temperature, derived from the 3D FEM model. 
If small displacement steps are desired for an actuator, a low sensitivity to temperature variation is preferred. This makes the displacement more predictable when the absorbed laser power is not constant. However, when a large range of motion is required, a small sensitivity requires more successive laser pulses or higher temperatures. The minimum repeatable step size was found to be $0.1 \mu \mathrm{m}$ for a bridge width of $500 \mu \mathrm{m}$ and a thickness of $500 \mu \mathrm{m}$. For the measurements with these dimensions, the sensitivity is independent of the maximum temperature. To reach an even lower sensitivity, it is possible to use lower laser power, as long as the threshold for plastic deformation is reached.

In these experiments, a small sensitivity is generally achieved with a small bridge width. This is the result of the relatively low thermal flow in the length direction of the bridge for narrow bridges. This makes the effective heated length smaller for the same maximum temperature, resulting in less deformation. On the other hand, the actuators with a larger thickness show a lower sensitivity compared to the thin actuators. This is a result of the temperature gradient in the z-direction that is present in the thicker samples. Due to this gradient, the average temperature over the $\mathrm{z}$ direction is considerably lower as the measured surface temperature, and therefore the total in-plane deformation is smaller.

The FEM model was applied for the same conditions as the measurements in Fig. 2.15, and the simulated sensitivity is shown in Fig. 2.16. The displacement sensitivity calculated in the model is much larger than the sensitivity found in the experiments. Possible causes are explained in section 2.5.3. Moreover, the measurements show a sensitivity that is linearly dependent on the surface temperature, which is not the case for the FEM model below $800{ }^{\circ} \mathrm{C}$. Nevertheless, in both figures the same trends can be observed; the sensitivity increases with increasing bridge width, and the sensitivity decreases with increasing bridge thickness.

\subsubsection{Model comparison}

The 3D and 2D models (outlined in section 2.3.1), a 2D FEM verification model and the reduced model (outlined in section 2.3.2) are compared using 6 benchmark cases listed in table 2.2. For each case, 15 pulses are simulated, and all models assume perfect plastic material behavior (no hardening). The verification FEM model uses the same geometrical simplifications as the reduced model, with rectangular bridges, which are mechanically connected by rigid bulk material. The radii of the bridges in the full models make the bridge volume larger than the rectangular bridges in the reduced model, which has a significant influence on the mean bridge temperature. Therefore, since the bridge width only appears in the thermal part of the reduced model, the bridge width $\hat{w}$ in the reduced model and verification model is adjusted to $\hat{w}=w+\left(1-\frac{1}{4} \pi\right) l$, which is the mean bridge width of geometry including the radii. To models are compared by the temperature at $t=t_{\text {pulse }}$, the final translation $y_{\mathrm{B}}$ and 
the final rotation $\theta$ after 15 pulses. The temperature is the spatial mean temperature over a rectangular volume with dimensions $w \times l \times s$.

Table 2.2: Parameters used in the test cases for the models. The bridge length $l$ is $1000 \mu \mathrm{m}$ for all cases.

\begin{tabular}{lllllll}
\hline & $\begin{array}{l}\text { bridge } \\
\text { thickness } \\
\text { case }\end{array}$ & $\begin{array}{l}\text { bridge } \\
\text { width } \\
w(\mu \mathrm{m})\end{array}$ & $\begin{array}{l}\text { laser spot } \\
\text { diameter } \\
d(\mu \mathrm{m})\end{array}$ & $\begin{array}{l}\text { laser } \\
\text { power } \\
P(\mathrm{~W})\end{array}$ & $\begin{array}{l}\text { pulse } \\
\text { length } \\
t_{\text {pulse }}(\mathrm{ms})\end{array}$ & $\begin{array}{l}\text { pulse } \\
\text { sequence }\end{array}$ \\
\hline 1 & 500 & 500 & 375 & 13.8 & 300 & B-A-C \\
2 & 250 & 500 & 375 & 7.8 & 100 & B-A-C \\
3 & 250 & 500 & 375 & 6.75 & 300 & B-A-C \\
4 & 250 & 750 & 560 & 11.3 & 100 & B-A-C \\
5 & 250 & 500 & 375 & 5.3 & 300 & B-A-C \\
6 & 500 & 500 & 375 & 13.8 & 300 & B-A-C-B-C-A \\
\hline
\end{tabular}

The results are listed in table 2.3, where "verif." and "red." denote the verification 2D FEM model and the reduced model, respectively. For case 2, a comparison between the bridge displacements of the verification model and the reduced model is shown in Fig. 2.17. The average difference between those models is $4 \%$ for the temperature, $11 \%$ for the translation and $-1 \%$ for the rotation. This deviation is a result of the Gaussian heat input in the FEM model, while the reduced model has an averaged heat input for the whole bridge. In practice the plastic deformation is concentrated in the center of the irradiated zone, but when only displacement is of interest, this lumped approach is found to be a good approximation.

When comparing the reduced model to the $2 \mathrm{D}$ or $3 \mathrm{D}$ model, the error is close to constant for all 6 cases. In other words, the reduced model consistently predicts the bridge displacements to be $42 \%$ smaller (with a standard deviation of $3 \%$ ) compared to the $3 \mathrm{D}$ FEM model. This is a result of the rectangular bridge approximation, and the lack of a hardening rule in the reduced model. However, once this factor is known for a given material and bridge length, the displacement of all subsequent pulses can be predicted by the reduced model using the correction factor. This significantly reduces the computation time compared to solving the full 3D FEM model.

\subsection{Simulations of closed-loop alignment algorithms}

The reduced model, combined with a closed loop strategy, was used to simulate the fine adjusting for an alignment problem, where the actuator must be positioned to a predefined position, with a predefined accuracy. This alignment algorithm must be robust enough to compensate for the spread in sensitivity between samples, as observed in the experiments. With the reduced model it is possible to simulate a large number of alignment cases in a limited amount of time, which makes it possible 


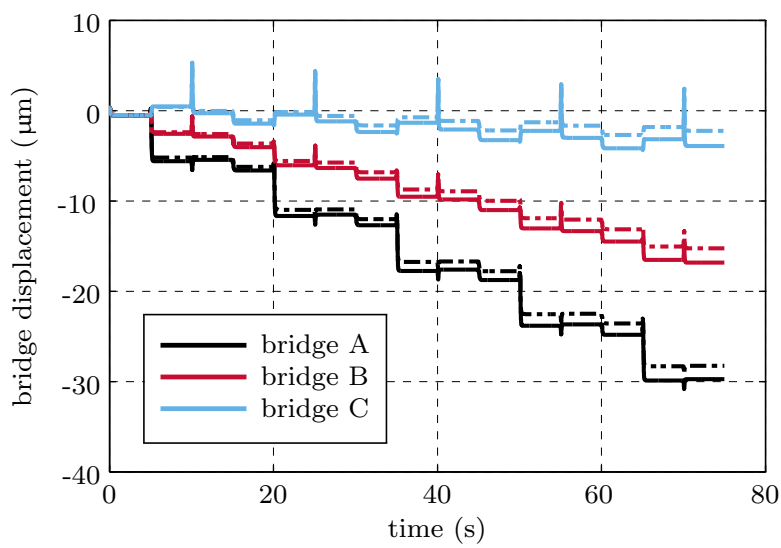

Fig. 2.17: Comparison of displacement from the reduced model (solid line) with the validation FEM model (dashed line) for case 2 (see table 2.2)

Table 2.3: Maximum temperature and final displacement and rotation of the threebridge actuator after 15 pulses, for each test case. "red." and "verif." denote the reduced and verification model, respectively. "SD" denotes the standard deviation.

\begin{tabular}{|c|c|c|c|c|c|c|c|c|c|c|c|c|}
\hline \multirow[b]{3}{*}{ case } & \multicolumn{4}{|c|}{ temperature $\left({ }^{\circ} \mathrm{C}\right)$} & \multicolumn{4}{|c|}{ translation $y_{\mathrm{B}}(\mu \mathrm{m})$} & \multicolumn{4}{|c|}{ rotation $\theta(\mathrm{mrad})$} \\
\hline & \multicolumn{3}{|c|}{ FEM } & \multirow[b]{2}{*}{ red. } & \multicolumn{3}{|c|}{ FEM } & \multirow[b]{2}{*}{ red. } & \multicolumn{3}{|c|}{ FEM } & \multirow[b]{2}{*}{ red. } \\
\hline & $3 \mathrm{D}$ & $2 \mathrm{D}$ & verif. & & $3 \mathrm{D}$ & $2 \mathrm{D}$ & verif. & & $3 \mathrm{D}$ & $2 \mathrm{D}$ & verif. & \\
\hline 1 & 749 & 743 & 749 & 725 & $-35,8$ & $-30,9$ & $-18,2$ & $-20,1$ & 20,0 & 17,9 & 9,4 & 10,2 \\
\hline 2 & 603 & 607 & 603 & 63 & $-26,8$ & $-21,7$ & $-15,2$ & $-16,8$ & 13,7 & 13,8 & 7, & 7,5 \\
\hline 3 & 722 & 722 & 736 & 714 & $-33,4$ & $-28,6$ & $-17,9$ & $-20,1$ & 19,8 & 18,5 & 9 , & 9,5 \\
\hline 4 & 656 & 654 & 639 & 679 & $-32,1$ & $-27,1$ & $-16,2$ & $-19,2$ & 14,2 & 13,9 & 7,2 & 7,2 \\
\hline 5 & 591 & 594 & 604 & 595 & $-25,7$ & $-21,9$ & $-14,9$ & $-14,5$ & 13,8 & 14,1 & 7,4 & 6,8 \\
\hline 6 & 748 & 752 & 749 & 725 & $-36,4$ & $-35,8$ & $-18,2$ & $-20,1$ & 4,1 & 3,9 & 1,9 & 2,0 \\
\hline \multicolumn{13}{|c|}{ error with respect to FEM 3D } \\
\hline & - & $0 \%$ & $0 \%$ & $0 \%$ & 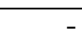 & -13 & $-47 \%$ & $-42^{\circ}$ & & -49 & -50 & $-50 \%$ \\
\hline SD & . & $1 \%$ & $2 \%$ & $3 \%$ & - & $5 \%$ & $3 \%$ & $3 \%$ & - & $4 \%$ & $4 \%$ & $2 \%$ \\
\hline
\end{tabular}

to do statistical analysis on hundreds of simulated alignment trials. First, a closed loop strategy for laser bending, proposed by Henninge et al. [40], was modified for the three bridge actuator. Based on the observed shortcomings of applying this strategy for the three-bridge actuator, an improved algorithm was developed and tested.

\subsubsection{Test case}

A test case for a three-bridge actuator was used, with an irradiation sequence B-AC-B-C-A. This sequence results in an equal shortening of all bridges. As a result, 
the actuator is characterized by one effective degree of freedom. A random desired position of $-30 \mu \mathrm{m} \leq y_{\mathrm{d}} \leq-20 \mu \mathrm{m}$ was chosen for each trial, and it is assumed that the current position $y_{\mathrm{i}}$ (and therefore the remaining error $e_{i}=y_{\mathrm{d}}-y_{\mathrm{i}}$ ), after irradiation step $i$, is known at all times. The motion can only be negative (contraction), which means that if the current position is beyond the destination, it can not be corrected. Furthermore, the maximum number of laser pulses was limited to 50, to prevent excessive process time in practice. The spread in laser absorption and displacement found in the experiments was used in the simulation. This was modeled as a random spread of $\pm 10 \%$ per bridge plus a $\pm 5 \%$ spread between actuators, around the nominal laser power.

\subsubsection{Adapted plate bending algorithm}

The algorithm proposed by Henninge uses the first two irradiations to find a linear relation between the used power and the displacement:

$$
\Delta y_{\mathrm{i}} \frac{P_{i}}{P_{\max }}=c\left(P_{i}-P_{\min }\right)
$$

where $c[\mu \mathrm{m} / \mathrm{W}]$ is the sensitivity to the laser power, $P_{i}$ is the laser power and $P_{\max }$ is the maximum power that can be used without damaging the actuator. For a three-bridge actuator, using the $\mathrm{B}-\mathrm{A}-\mathrm{C}-\mathrm{B}-\mathrm{C}-\mathrm{A}$ sequence, the step size $\Delta y_{\mathrm{i}}$ is not constant for two subsequent irradiations (similar to the B-A-C sequence in Fig. 2.11). However, the step size is constant with three steps in between (i.e. for $i=1,4,7 \ldots$, $i=2,5,8 \ldots$ and $i=3,6,9 \ldots)$. Therefore, at each third step, the step size $\Delta y$ was averaged to calculate $\Delta \hat{y}$. $c$ was calculated after two complete sequences (the 12 th step), using $P_{\max }$ for the first 6 pulses, and $0.75 \cdot P_{\max }$ for the 6 th to 12 th pulse:

$$
\begin{array}{r}
c=\frac{\left(\Delta \hat{y}_{6}-\Delta \hat{y}_{12}\right)}{0.25 P_{\max }} \\
P_{\min }=P_{\max }-\frac{\Delta \hat{y}_{6}}{c}
\end{array}
$$

The total number of steps $i_{\text {min }}$, assuming the step size will not change, is estimated using the remaining error after the 12 th pulse $e_{12}$ from

$$
i_{\min }=\frac{e_{12}}{P_{\max } \cdot c\left(1-\frac{P_{\min }}{0.8 P_{\max }}\right)}+12, i_{\min } \in N
$$

The number of steps was calculated with $80 \%$ of the maximum power, allowing a correction of the laser power if the sensitivity was lower than expected. For the remaining steps, the optimal step size was defined as: 


$$
\Delta y_{\mathrm{opt}}=\frac{e_{12}}{i_{\min }-12}
$$

The laser power was changed once every 3 irradiations, and was defined by

$$
P_{i}=P_{\min }+\left(\Delta y_{\mathrm{opt}}+\frac{\gamma\left(\Delta y_{\mathrm{opt}}-\Delta \hat{y}_{i-1}\right)}{c}\right.
$$

The difference between the expected and the obtained step size multiplied by a factor $\gamma=0.5$ is added to the optimal step size, correcting for deviations from the expected step size. This strategy is repeated until the error $e$ is within a fixed accuracy of $\pm 0.1 \mu \mathrm{m}$.

When this algorithm was tested with the reduced model, it was found that the position $y$ was overshooting the desired position $y_{\mathrm{d}}$ frequently $(87 \%)$, because the algorithm can not correct in advance for the spread in step size due to the random spread in absorbed laser power. Therefore the optimal step size for the last 6 shots was changed to $\Delta y_{\mathrm{opt}}=0.3 e_{i-1}$. Furthermore $P_{\min }$ was updated to the current power $P_{i}$ whenever $\Delta \hat{y}_{i}<0.01 \mu \mathrm{m}$. This prevents the algorithm from using a power level, where the deformation is purely elastic, when the initial approximation in eq. 2.28 was too low. The final error for 200 trials is shown in a histogram in Fig. 2.18. Only $58 \%$ of the trials is within the goal of $\pm 0.1 \mu \mathrm{m}$, while the remaining $42 \%$ are still overshooting the destination. For the successful trials, the average number of irradiations required is 27. This means that the last few steps were too large, despite the corrections made for the last 6 irradiations. It turns out that the mismatch between the expected step size and the obtained step size is much larger than the desired final accuracy, which means that the linear prediction for the required power on basis of the first two sequences is not accurate enough, despite the on-line correction based on the previous step.

\subsubsection{Improved algorithm}

Based on these findings, a new algorithm was developed. This algorithm uses the first 15 pulses to learn the sensitivity of displacement $\Delta y$ to laser power $P$. The power for these 15 pulses is $P_{\max }$ to $0.6 P_{\max }$, with equal power for three subsequent pulses. Before every next pulse, sensitivity is obtained with a linear least-squares fit through the history of used power and the resulting displacement. Three separate fits are made for for $i=1,4,7 \ldots, i=2,5,8 \ldots$ and $i=3,6,9 \ldots$, instead of averaging over three steps. The optimal step size was defined as $\Delta y_{\text {opt }}=0.4 e_{i-1}$, but is limited by the maximum displacement that was measured during the first 15 pulses. The power for the next pulse is obtained from the corresponding fit and the desired step size. Again, when the step size is too small, the power for the next pulse is increased by $5 \%$. When tested with the same conditions as with the algorithm proposed by Henninge et al., the histogram shows that $78 \%$ of the 200 trials is within the goal of $\pm 0.1 \mu \mathrm{m}$. The average number of steps to reach the destination is 38 . This improvement is a 


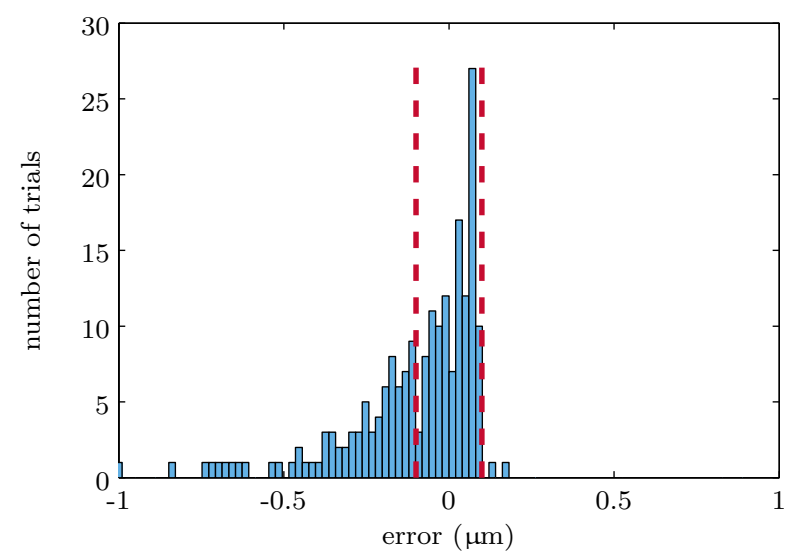

Fig. 2.18: Histogram of the final error of 200 repetitions for the adapted algorithm by Hennige et al. $58 \%$ of the trials is within the goal of $\pm 0.1 \mu \mathrm{m} \mathrm{A}$ negative error represents an overshoot of the desired position, which can not be corrected. A positive error remains when the maximum number of steps is exceeded.

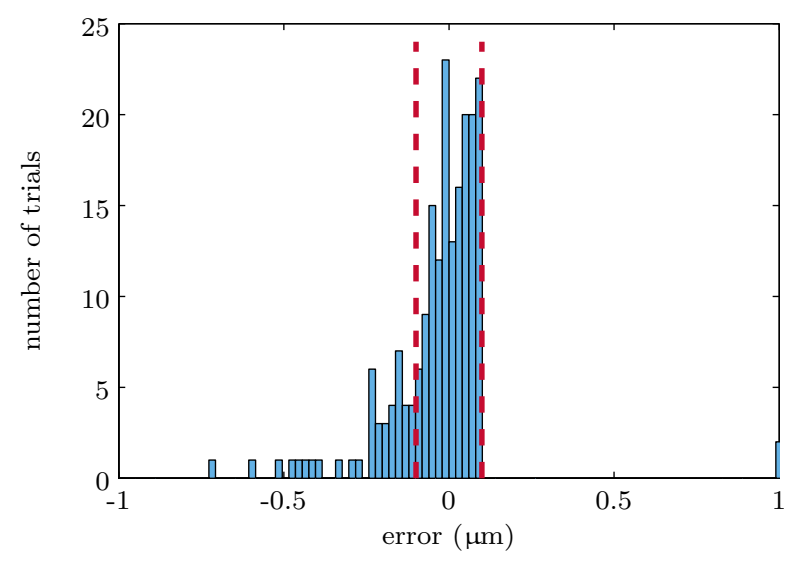

Fig. 2.19: Histogram of the final error of 200 repetitions for the proposed algorithm. $78 \%$ of the trials is within the goal of $\pm 0.1 \mu \mathrm{m}$

direct result of the more accurate and constantly updated estimations of the three displacement sensitivities. 


\subsection{Conclusion}

In-plane laser forming, using the Upsetting Mechanism, can be used for high precision alignment of components where a high actuator stiffness is required. A three-bridge actuator fabricated in Invar36 sheet metal was studied. FEM models and experiments were used to find the relation between maximum surface temperature and the displacement step size for different bridge geometries. FEM models showed a good match with the measured temperature in the experiments. However, when multiple pulses are considered, the simulated displacement shows deviations up to a factor of two compared to the measurements. This deviation was mainly attributed to limitations in the isotropic hardening model.

Generally when high precision is required, sensitivity of the step-size to changes in temperature should be low, at the cost of a limited range of motion. Experiments showed that this is achieved with a small bridge width and large thickness of the actuator. A minimum step size of $0.1 \mu \mathrm{m}$ was achieved in the experiments. However, a spread of about $20 \%$ was found in the final position of the actuator, which was attributed to scattering in process parameters. Due to this spread, a closed loop algorithm is required to reach a desired position with high precision. A fast reduced model was developed to test such alignment algorithms for robustness and accuracy. This model assumed the bridges to be square and to have uniform temperature, stress and strain distribution over the bridges. This was found to be a good approximation by comparing it with the FEM models.

An existing algorithm for laser bending was adapted, that uses the measurements of the actual position after each pulse, and adapts the laser power for the next pulse. The algorithm is robust to disturbances that were found in the experiments. $78 \%$ of the simulated alignment trials were within the required accuracy of $\pm 0.1 \mu \mathrm{m}$. 
2 


\title{
Chapter 3 \\ Micro tube laser forming for component alignment
}

\begin{abstract}
A micro actuator for precision alignment, using laser-forming of a tube, is presented. Such an actuator can be used to align components after assembly. The positioning of an optical fiber with respect to a waveguide chip is used as a test case, where a sub-micron lateral alignment accuracy is required. A stainless steel micro tube with an outer diameter of $635 \mu \mathrm{m}$ was used as a simple and compact actuator, where the fiber is mounted concentrically in the tube. An experimental setup has been developed to measure the fiber displacement in real-time with a resolution better than $0.1 \mu \mathrm{m}$. In addition, this setup allows the axial and radial positioning of the laser spot over the surface of the tube. Several tube samples were (de)formed to move a fiber to a predefined position, using a laser with a wavelength of $1080 \mathrm{~nm}$, a pulse length of $200 \mathrm{~ms}$ and a power between $4 \mathrm{~W}$ and $10 \mathrm{~W}$. On average of 18 laser pulses were required to reach the targeted position of the fiber with an accuracy of $0.1 \mu \mathrm{m}$. It has been found that increasing the laser power not only results in a larger bending angle, but also in a larger uncertainty of this angle. The opposite is true for the radial bending direction, where the uncertainty decreases with increasing laser power.
\end{abstract}

This chapter is reprinted from: Folkersma, K. G. P. Brouwer, D. M. Römer, G. R. B. E. "Micro tube laser forming for precision component alignment". In: - (2015). Submitted for publication. 

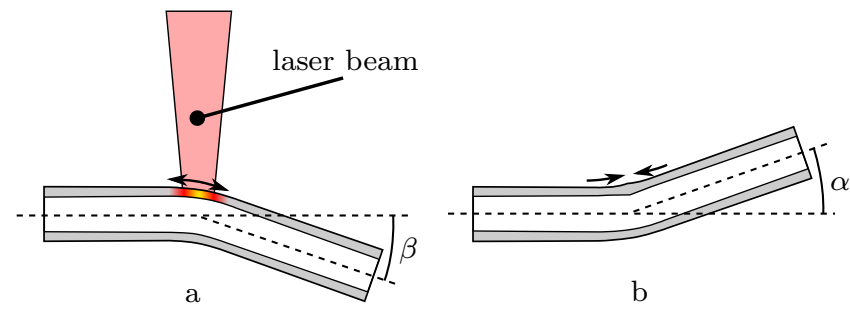

Fig. 3.1: Tube laser bending. a: Heating due to absorbed laser energy induces a bending of angle $\beta$ 'away' from the laser. b: after cooling, the tube bends 'towards' the laser, finally getting at an angle of $\alpha$.

\subsection{Introduction}

Laser micro-forming has been used widely in applications where high precision position adjustments are needed. Different actuator configurations are extensively studied, including two- and three bridge actuators [30, 41, 50], plate bending actuators [40] or star actuators $[31,32,43]$. Those actuators allow for position adjustments in one or more directions with sub-micrometer accuracy. However, these actuators require dedicated structures to be included with the components that require alignment. Many applications require a more compact actuator with a low cost per product. Such an application is the alignment of optical fibers to waveguides in silicon chips. Often multiple fibers in one array need to be fixed to a chip, but require individual alignment to the chip with a sub-micron accuracy after assembly. With a fiber pitch in the order of $1 \mathrm{~mm}$, the available space for actuators is limited.

A common application of laser forming is the bending of tubes[14, 48, 58-60]. This mechanism is activated by heating of one side of the tube, either by a stationary laser spot or by scanning the spot in the axial or radial direction. The resulting thermal strain in the tube wall introduces a compressive stress that exceeds the yield stress. If the tube wall thickness is high enough to prevent buckling, this results in a compressive plastic strain, and when the tube cools down, the heated portion of the tube wall will effectively contract. The result is a bending of the tube towards the laser, see Fig. 3.1. This process can be repeated several times to increase the deformation angle $\alpha$ and iteratively converge to a desired angle. The simple continuous tube geometry offers great potential for fiber alignment.

Laser tube bending for relatively large diameter tubes $(>10 \mathrm{~mm})$ has been studied experimentally, by FEM models [13, 14, 48, 58] and analytical models [59] with good results. However, to our best knowledge, no significant experimental studies have been done regarding micro tube bending (diameters $<1 \mathrm{~mm}$ ), with a focus on positioning accuracy. 


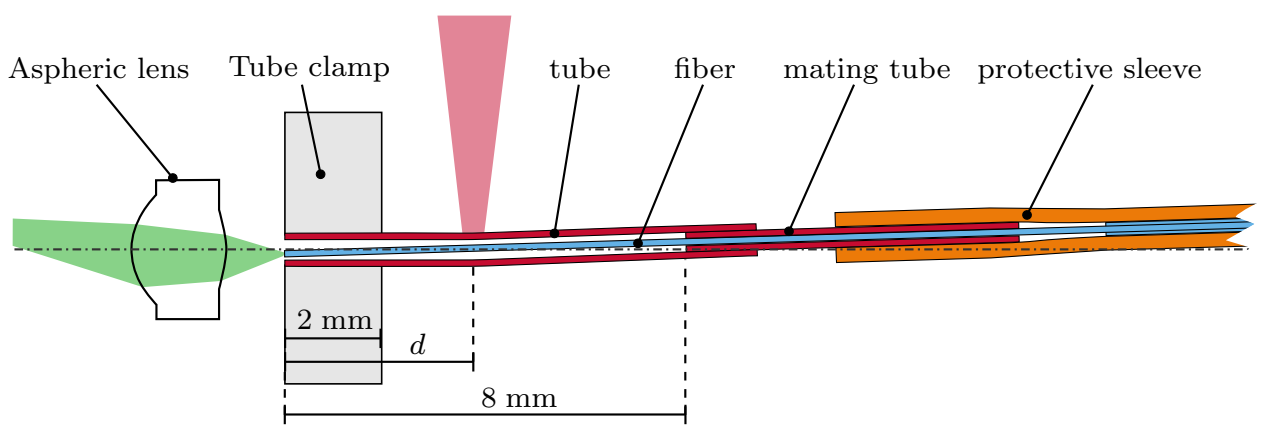

Fig. 3.2: Optical fiber and tube assembly.

Therefore the goal of this research is to use a simple micro tube as a 3-D micro actuator for aligning an optical fiber in two directions. For the case of aligning to a waveguide chip, the lateral alignment accuracy should be better than $0.4 \mu \mathrm{m}$ to obtain an acceptable optical coupling loss of the fiber-chip connection. The minimum reliable step size should smaller than $0.2 \mu \mathrm{m}$, and the total range of motion should be at least $50 \mu \mathrm{m}$. While the tilt angles and axial translation of the fiber also require accurate alignment, this research focuses on the lateral $(X, Y)$ displacement of the fiber tip.

\subsection{Method}

Measuring displacements in the order of $0.1 \mu \mathrm{m}$ in real-time requires a dedicated setup with a resolution and long-term stability in the same order. Such a setup was designed and is outlined in section 3.3. The experimental results are given and discussed in section 3.4.

Previous results on laser forming [41], and preliminary tests on tube bending showed that it is not useful to predict the exact response of the displacement to the incident laser power when multiple laser forming steps (i.e. multiple laser pulses) are used. The bending angle shows a large spread due to variations in absorption of laser energy and initial stress states induced by earlier deformations. Therefore, the focus is on the empirical estimation of the bending angle in relation to the laser power.

Additionally, a strong correlation between the radial position of the laser spot on the tube, and the direction of motion of the tube is beneficial for the controllability of the fiber tip position. The radial position of the laser can be obtained from the direction of thermal expansion. Therefore, the difference between the direction of thermal expansion and resulting motion is measured to determine the repeatability for the bending direction. 
To capture the rapid motion induced by the thermal expansion without disturbing the bending process, a real-time and contact-less measurement of the tube deformation is required. The measurement system is designed to measure three translations $(X, Y, Z)$, and two rotations $(r X, r Y)$. This is achieved by fixing an optical fiber in the tube and measuring the position and direction of the laser light emitted from the fiber end. The fiber is fixed concentric at one end of the tube, while the tip is free to move at the other end, see Fig. 3.2. A bending angle $\alpha$ at a distance from the tip $d$ will induce a translation of the tip of $\delta_{\mathrm{r}} \approx d \cdot \alpha$.

\subsection{Experimental setup}

An experimental setup has been developed that is capable of measuring the tube deformation in real-time, see Fig. 3.3 and Fig 3.4. The laser power and modulation, beam position and focus, and the tube position are computer controlled in a Matlab Simulink Real-time environment. All sensor data is acquired at a sample rate of $5 \mathrm{kHz}$, which is high enough to capture the dynamics of the motion during the laser pulse.

The setup consists of three parts, which are detailed in the following sections. Section 3.3.1 describes the assembly of the tube and fiber samples and how it is fixed in the setup. Section 3.3.2 explains the laser system and positioning of the laser beam on the tube. The measurement of the tube deformation is detailed in section 3.3.3, including the calibration procedures.

\subsubsection{Tube sample and clamping}

The tube samples have an outer diameter of $635 \mu \mathrm{m}$, a wall thickness of $153 \mu \mathrm{m}$ and a length of $10 \mathrm{~mm}$. The tubes manufactured by Vita Needles are TIG welded, plug drawn from 304 stainless steel, and received a hard temper treatment. At one end, a mating tube was inserted and fixed with adhesive to the outer tube and the fiber, see Fig. 3.2. The fiber has an outer diameter of $125 \mu \mathrm{m}$. A protective sleeve was attached to the fiber and mating tube for strain-relief, while handling the samples. The tubes have been clamped over $2 \mathrm{~mm}$ length in a custom clamp (Fig. 3.3 \#7). The clamp and tube can be moved in 5 directions with respect to the measuring unit for centering and calibration purposes (see section 3.3.3). The translations $X, Y$ and $Z$ are motorized, while the $r X, r Y$ rotations around the fiber tip are set with a manual goniometer (Fig. 3.3 \#12).

The free end of the fiber is susceptible to sag due to gravity. This sag can be estimated using basic beam theory, with a distributed load $q$ on the fiber

$$
q=\frac{\rho \pi r^{2} l g}{l}=2.65 \cdot 10^{-4} \mathrm{~N} / \mathrm{m}
$$




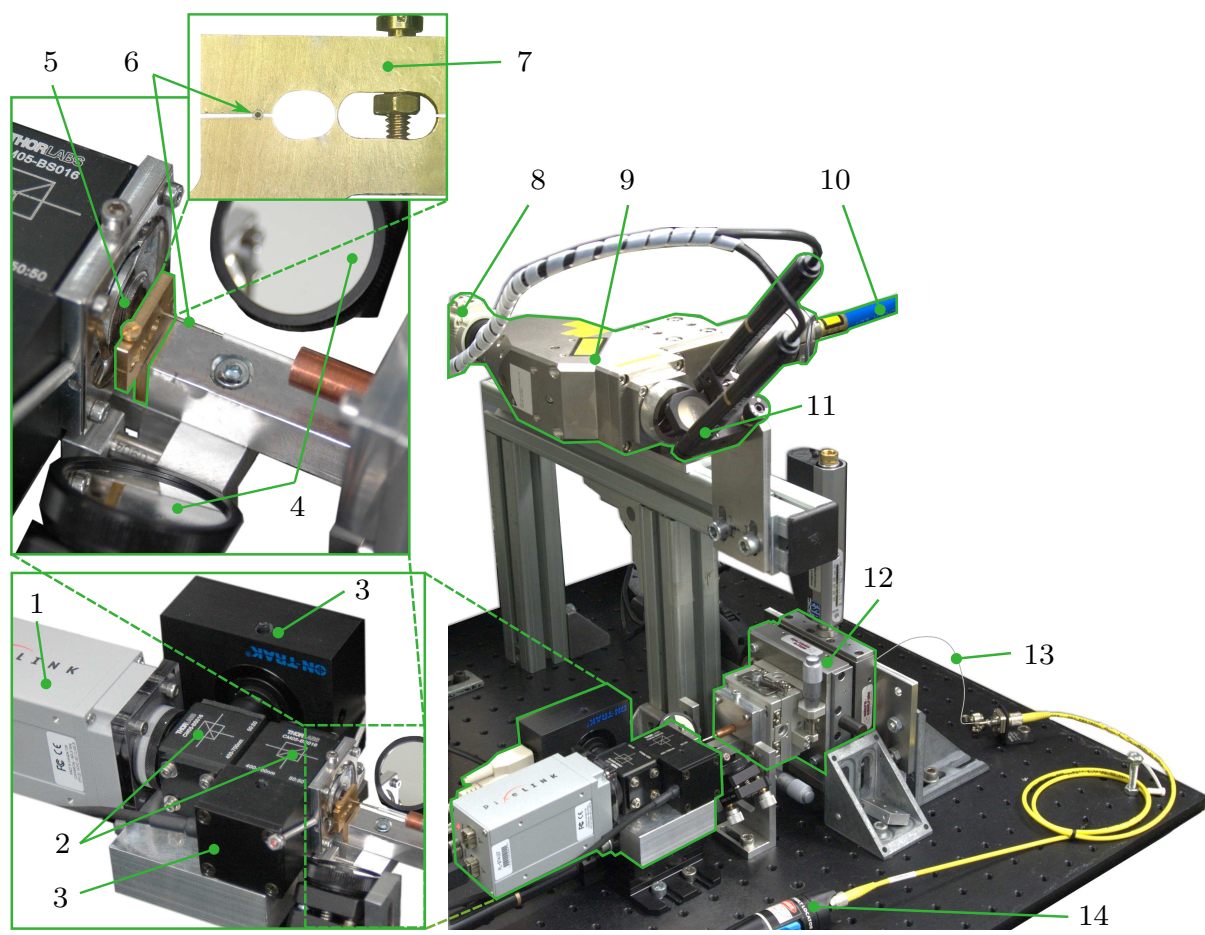

Fig. 3.3: The experimental setup.

1. Camera for focus measurement

2. 50:50 beam splitter

3. Position Sensing Detectors (PSD)

4. Fixed mirrors

5. Aspheric lens (see Fig. 3.2)

6. Tube with fiber (see Fig. 3.2)

7. Tube clamp (see Fig. 3.2)
8. Beam alignment camera for laser

9. Focusing optics

10. High power laser input

11. Motorized Tip/tilt mirror

12. Positioning stages for tube

13. Fiber to align

14. Position measurement laser

where $r=62.5 \mu \mathrm{m}$ is the fiber radius, $l=8 \mathrm{~mm}$ the free length of the fiber, $\rho=$ $2200 \mathrm{~kg} / \mathrm{m}^{3}$ the density of the fiber and $g=9.81 \mathrm{~m} / \mathrm{s}^{2}$ the gravitational constant. The sag $\delta_{\mathrm{g}}$ is now obtained by

$$
\delta_{\mathrm{g}}=\frac{q l^{4}}{8 E I_{\mathrm{a}}}=0.15 \cdot 10^{-6} \mathrm{~m}
$$

where $E=2200 \mathrm{~N} / \mathrm{m}^{2}$ is the Young's modulus and $I_{\mathrm{a}}=\frac{\pi}{4} r^{4}=1.2 \cdot 10^{-17} \mathrm{~m}^{4}$ the second moment of area of the fiber. The sag of $0.15 \mu \mathrm{m}$ is in the same order as 
the minimum desired step size, and can therefore not be neglected. However, this displacement is a constant offset, and has no effect on the relative displacement measurements. Since $\delta_{\mathrm{g}}$ is proportional to the fourth power of the fiber free length, the tube can be shortened to decrease the sag, at the cost of a smaller total stroke.

\subsubsection{Laser setup}

The laser source which was employed is a JK-100FL $100 \mathrm{~W}$ fiber laser with a wavelength of $1080 \mathrm{~nm}$ showing a Gaussian intensity profile. A motorized tip/tilt mirror (Fig. 3.3 \#11) is used to control the beam position. The beam was either focused directly on the tube, or via two fixed mirrors near the tube, see Fig. 3.4. Using the tip/tilt mirror, three radial positions $120^{\circ}$ from each other, and the complete tube length is accessible by the laser. Additionally, since the spot size of $400 \mu \mathrm{m}$ is smaller than the tube diameter, a small deviation of $\pm 35^{\circ}$ from these radial positions is achievable. This allows for more freedom in selecting the bending direction of the tube.

The laser is focused on the tube by an focusing head (Fig. (3.3 \#9) with a focal length of $300 \mathrm{~mm}$. The head is mounted on a motorized stage. This is required to re-focus the laser when changing radial position, and allows for an on-line variable spot size. For the experiments in this paper the laser spot size on the tube was fixed to $400 \mu \mathrm{m}$. A co-axial camera is mounted on the focusing head for beam alignment with respect to the tube.

\subsubsection{Fiber tip position measurement}

For the purpose of measuring the tube deformation, a single-mode optical glass fiber (Thorlabs SM600) was fixed to the tube (see Fig 3.2), and the other end was connected to a low power laser source $(2 \mathrm{~mW}, 650 \mathrm{~nm})$, see Fig. 3.5 and Fig. 3.3 \#14. The beam emitted from the fiber was focused with an aspheric lens with a focal length of $4.6 \mathrm{~mm}$, see Fig 3.2. The beam position was measured with two duo-lateral Position Sensing Detectors (PSD) (On-Trak PSM 2-4 and PSM 2-10, see Fig. 3.3 \#3) and a CMOS camera (Pixelink B741, see Fig. 3.3 \#1), using two 50:50 beam splitters (Fig. 3.3 \#2). A translation of the fiber results in an opposite translation of the beam on the PSDs, with a different gain for both. A tilt of the fiber tip results in a signal change that is approximately equal on both PSDs. The camera is used to measure the spot size, which is proportional to the Z-translation of the fiber with respect to the lens. Furthermore, the location of the tube clamp with respect to the lens was measured by 5 capacitive sensors (Lion Precision CPL290 with C6D probes), to correct for any external disturbances on the frame in real-time. These sensors have a resolution of $50 \mathrm{~nm}$ and have been corrected for non-linearity (by calibrating with an 


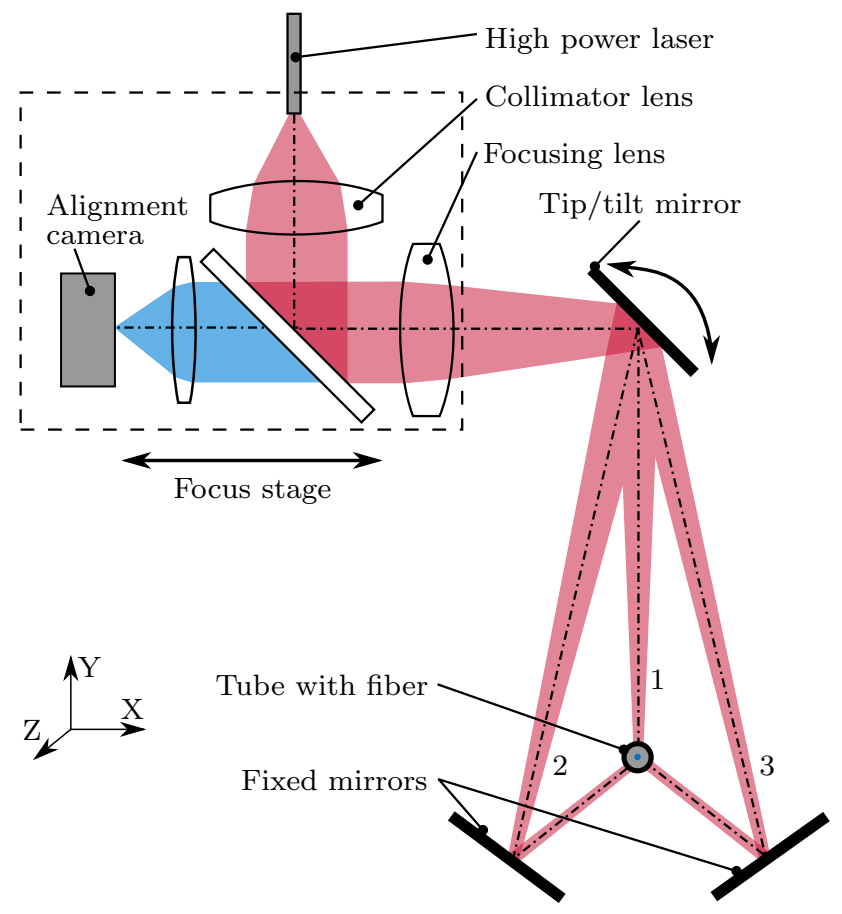

Fig. 3.4: Beam manipulation schematic. The laser can reach the tube from three directions using the tip/tilt mirror. 1: Direct path from above, 2/3: Via fixed mirrors. The focus stage is used to keep the spot-size on the tube constant.

Aerotech ABL10100LT precision stage) and tilt misalignment with respect to their target. The displacement measured by the these sensors was translated to the fiber tip by a geometrical transformation matrix, giving the coordinates of the fiber tip $\left(\left[X_{\mathrm{c}}, Y_{\mathrm{c}}, Z_{\mathrm{c}}, r X_{\mathrm{c}}, r Z_{\mathrm{c}}\right]\right)$.

This setup is capable of measuring both the fiber tip translations and the tip/tilt, by combining the PSD and camera info. However, for this study, only the $X$ and $Y$ translations were measured using both PSDs. This improves the accuracy, because both PSD signals are effectively averaged. The tube bending angle $\alpha$ can be calculated from the translation measurement and the known distance $d$ from to the fiber tip, see Fig. 3.2.

The relation of the four PSD signals $\boldsymbol{X}_{\mathrm{PSD}}=\left[X_{\mathrm{PSD} 1}, Y_{\mathrm{PSD} 1}, X_{\mathrm{PSD} 2}, Y_{\mathrm{PSD} 2}\right]$ to the fiber tip position was found by moving the tube with the fiber randomly over a $7 \times 7$ grid on the $X Y$ plane with a total size of $50 \mu \mathrm{m} \times 50 \mu \mathrm{m}$, using the motorized stages. For the calibration, the signals $\boldsymbol{X}_{\mathrm{c}}=\left[X_{\mathrm{c}}, Y_{\mathrm{c}}\right]$ and $\boldsymbol{X}_{\mathrm{PSD}}$ have been averaged over $0.5 \mathrm{~s}$ for each grid point. This is repeated 3 times, resulting in $N=147$ measurements. The 


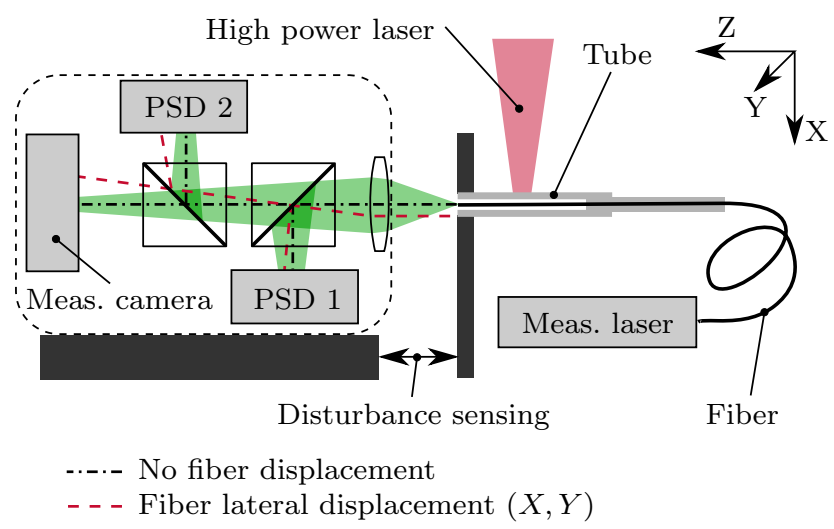

Fig. 3.5: Measurement of the fiber tip position. Laser light emitted from the fiber is collimated and projected on two duo-lateral PSDs and a camera via two beamsplitters. A translation of the fiber results in a rotation of the beam, measured by the PSDs.

relation was found by multivariate linear regression, with the regression matrix $\boldsymbol{\Phi}_{N}$ and the output measurements $\boldsymbol{Y}_{\boldsymbol{N}}$ gathered as:

$$
\begin{aligned}
\boldsymbol{\Phi}_{\boldsymbol{N}} & =\left(\begin{array}{ccc}
1 & \boldsymbol{X}_{\mathrm{PSD}}(1) & \boldsymbol{X}_{\mathrm{PSD}}^{2}(1) \\
\vdots & \vdots & \vdots \\
1 & \boldsymbol{X}_{\mathrm{PSD}}(N) & \boldsymbol{X}_{\mathrm{PSD}}^{2}(N)
\end{array}\right) \\
\boldsymbol{Y}_{\boldsymbol{N}} & =\left(\begin{array}{c}
\boldsymbol{X}_{\mathrm{c}}(1) \\
\vdots \\
\boldsymbol{X}_{\mathrm{c}}(N)
\end{array}\right)
\end{aligned}
$$

The estimate matrix $\boldsymbol{\Psi}$ can be found, using the least squares estimate, by

$$
\Psi=\Phi_{N}^{\dagger} Y_{N}
$$

Where $\Phi^{\dagger}$ is the pseudo-inverse of $\Phi$.

The fiber tip position $\boldsymbol{X}_{\mathrm{f}}$ as measured by the PSDs can now be found using

$$
\boldsymbol{X}_{\mathrm{f}}=\left[X_{\mathrm{f}}, Y_{\mathrm{f}}\right]=\boldsymbol{\Phi}_{N} \boldsymbol{\Psi} .
$$

The measurement accuracy was verified by an independent measurement, moving randomly over a $5 \times 5$ grid, with a total size of $40 \mu \mathrm{m} \times 40 \mu \mathrm{m}$, and repeating this 5 times. The error has been defined as $e=\left\|\boldsymbol{X}_{\mathrm{f}}-\boldsymbol{X}_{\mathrm{c}}\right\|$. This calibration and verification 


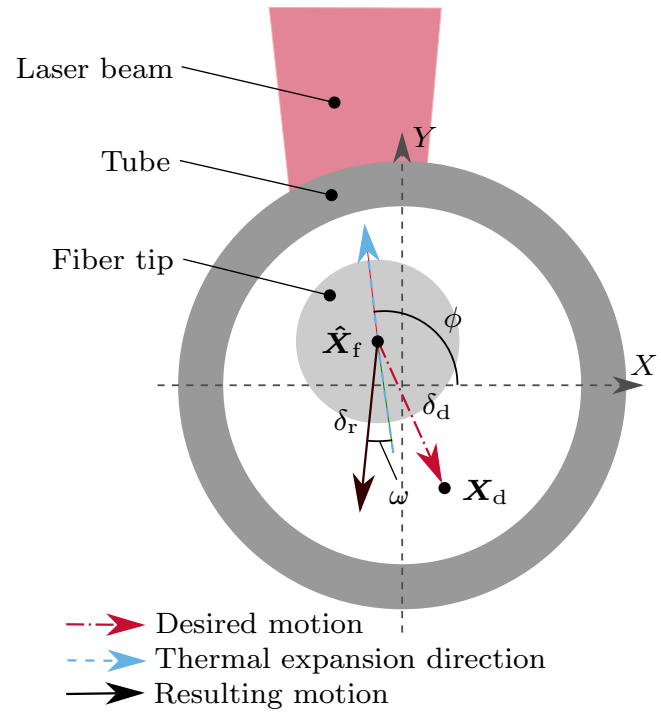

Fig. 3.6: Translation coordinates at the fiber tip.

process was repeated for each new tube sample. The maximum absolute measurement error was $0.2 \mu \mathrm{m}$, with a repeatability better than $0.1 \mu \mathrm{m}$.

After calibration, the corrected fiber tip displacement $\hat{\boldsymbol{X}}_{\mathrm{f}}$ was obtained by subtracting the disturbance signal from the position signal as $\hat{\boldsymbol{X}}_{\mathrm{f}}=\boldsymbol{X}_{\mathrm{f}}-\boldsymbol{X}_{\mathrm{c}}$. This eliminates long-term $(<60 \mathrm{~s})$ thermal drift and reduces the sensitivity to external vibrations.

\subsection{Experimental results}

Each experiment is an alignment trial, where the process settings (laser power and laser spot position on the tube), are adjusted by hand, in order to reach a desired location of the fiber tip with a minimal number of laser pulses. For each experiment, a new tube and fiber has been inserted in the setup, and a random destination location $\boldsymbol{X}_{\mathrm{d}}$ was chosen (see Fig. 3.6). The starting location, after calibration, is defined as $(0,0)$. It should be noted that this is not always the exact tube center, due to inaccuracies in the sample assembly.

The laser radial laser position has been set to the direction of the vector $\hat{\boldsymbol{X}}_{\mathrm{f}}-\boldsymbol{X}_{\mathrm{d}}$, which is opposite to the desired direction of motion. When the distance to the target $\left(\delta_{\mathrm{d}}=\left\|\hat{\boldsymbol{X}}_{\mathrm{f}}-\boldsymbol{X}_{\mathrm{d}}\right\|\right)$ was large, a large axial distance from the tip $(5 \mathrm{~mm} \leq d \leq 7 \mathrm{~mm})$ was chosen (see Fig. 3.2), this results in a larger translation at the tip, for a given bending angle $\alpha$. Moreover, the laser power was chosen relatively high $(7 \mathrm{~W} \leq P \leq$ $10 \mathrm{~W})$, to heat just below the melting point of the stainless steel. When $\delta_{\mathrm{d}}$ was small, 
a location closer to the tip $(3 \mathrm{~mm} \leq d \leq 5 \mathrm{~mm})$ and a lower power $(4 \mathrm{~W} \leq P \leq 7 \mathrm{~W})$ were chosen, to avoid overshooting the target location. After irradiating the tube for $200 \mathrm{~ms}$, the tube was allowed to cool for $60 \mathrm{~s}$ to ensure a stationary situation. The new location of the fiber has been used to plan the next bending step, and the process was repeated. When $\delta_{\mathrm{d}} \leq 0.1 \mu \mathrm{m}$, this iteration was stopped.
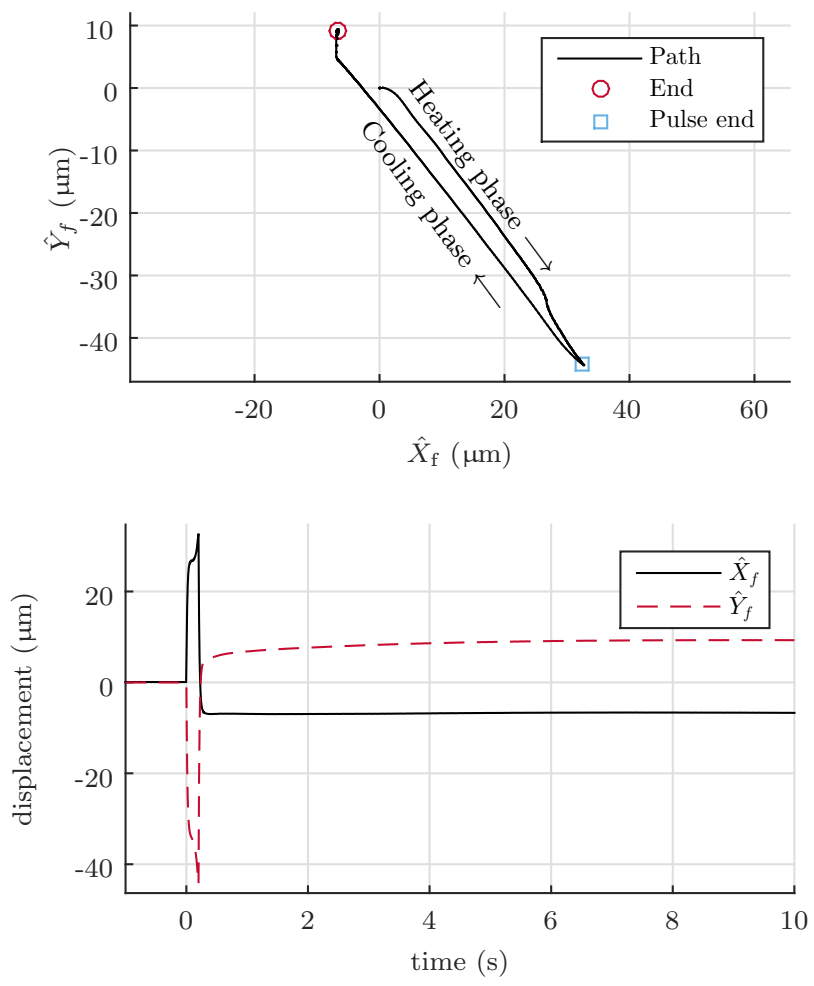

Fig. 3.7: Displacement of the fiber tip during heating $(0 \mathrm{~s}$ to $0.2 \mathrm{~s})$ and cooling $(0.2 \mathrm{~s}$ to $60 \mathrm{~s})$ at $P=10 \mathrm{~W}$ and $d=7 \mathrm{~mm}$. The final displacement is $11.3 \mu \mathrm{m}$ Top: $(X, Y)$ path plot. Bottom: Time-displacement of the same measurement.

An example of the displacement during one heating and cooling phase is shown in Fig. 3.7. In this figure the starting location is set to zero, and the final displacement equals $11.3 \mu \mathrm{m}$. The displacement due to thermal expansion can be up to a factor 100 larger than the final displacement, and is $55 \mu \mathrm{m}$ in this figure.

The process settings for these experiments are listed in Table 3.1. A typical path of the fiber tip towards the target when using multiple laser pulses (steps) is shown in Fig. 3.8. In this figure, each dot, connected by straight lines, represents a stationary position after a bending step. The red dashed lines indicate the measured direction $(\phi)$ of the thermal expansion at that step, which coincides with the radial laser position. 


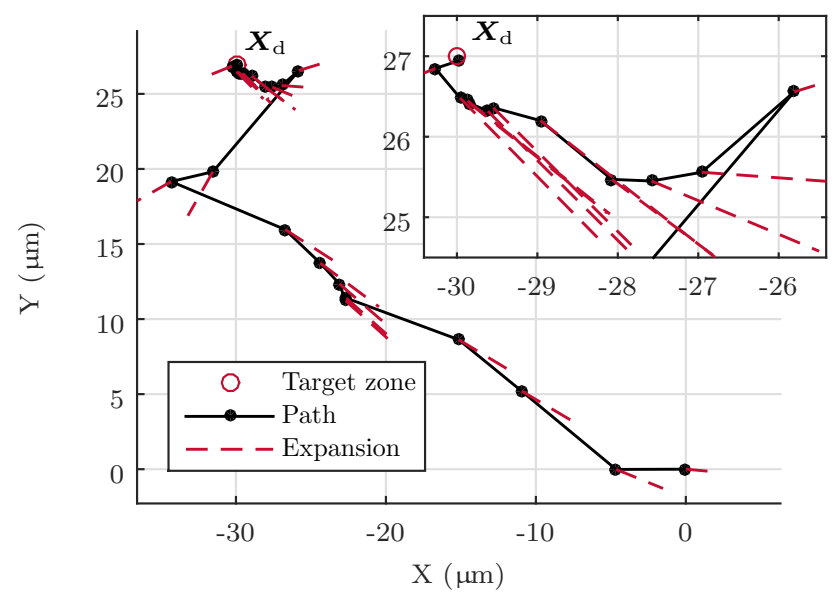

Fig. 3.8: Typical path of the fiber tip in one of the 9 experiments. Each point is the deformation after cooling. The target $X_{\mathrm{d}}=(-30,27)$ is reached within 22 steps. The dashed lines indicate the direction of thermal expansion at that point.

\subsubsection{Bending magnitude}

Nine identical tube samples have been aligned to their target locations, with a total of 159 laser pulses. On average, 17.6 iterations per tube were needed to reach the target location. All measurements were combined to identify the sensitivity and spread of the deformations to the laser power. Figure 3.9 shows the final deformation angle $(\alpha)$ for each laser pulse. While $\alpha$ globally increases with increasing laser power as expected, the spread of $\alpha$ also increases with increasing power.

To identify the cause of the spread at high power, the bending angle due to thermal expansion $(\beta)$ at the end of the laser pulse is shown in Fig. 3.10. The thermal expansion is directly correlated to the temperature, and hence to the absorbed laser power. While $\alpha$ and $\beta$ show a similar spread, there is no clear direct relation between $\alpha$ and $\beta$. Therefore the spread in $\alpha$ can not entirely be attributed to the laser-material interaction.

Table 3.1: Process parameters used in experiments.

\begin{tabular}{lll}
\hline Parameter & Value & Unit \\
\hline Tube outer diameter & 635 & $\mu \mathrm{m}$ \\
Tube inner diameter & 330 & $\mu \mathrm{m}$ \\
Laser spot diameter $\left(1 / e^{2}\right)$ & 400 & $\mu \mathrm{m}$. \\
Laser pulse duration & 200 & $\mathrm{~ms}$ \\
Cooling time & 60 & $\mathrm{~s}$ \\
\hline
\end{tabular}




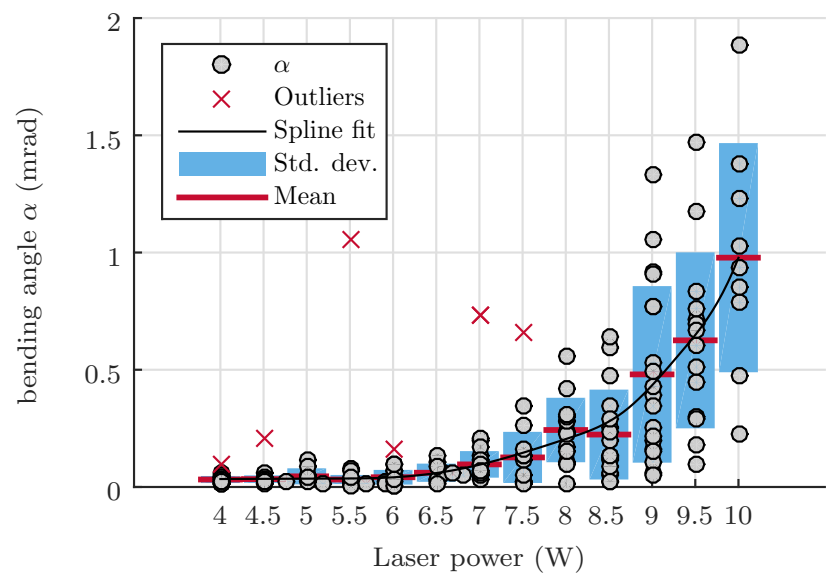

Fig. 3.9: Power used in experiments vs the maximum expansion angle $\alpha$. The outliers are indicated by crosses and excluded from the fit.

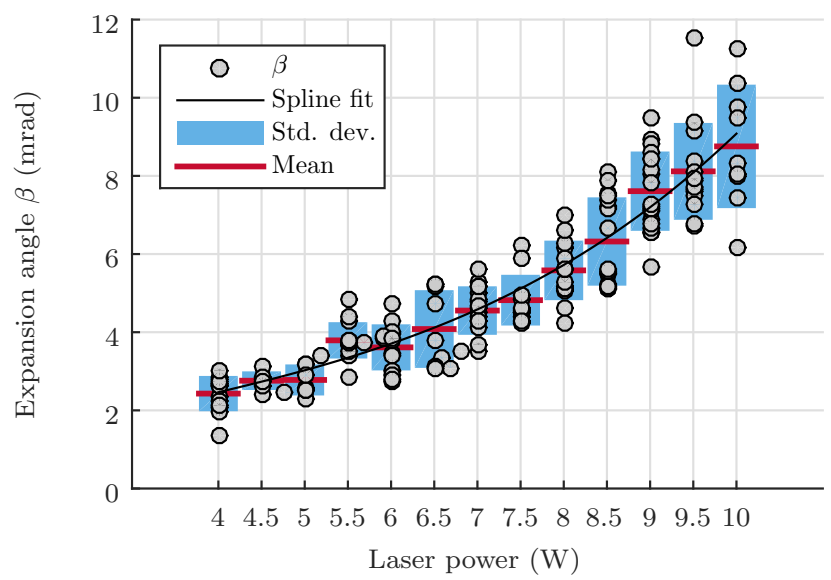

Fig. 3.10: Power used in experiments vs the maximum expansion angle $\beta$

That is because the deformation angle $\alpha$ is strongly dependent on internal stresses already present in the tube. These initial stresses can be present from the drawing process of the tube, or from previous laser pulses near the current location. The latter is the main contributor to the unpredictable behavior of the bending angle in these experiments. For example, a pulse next to a previously irradiated area results in a much larger bending angle for that pulse. This is the result of the high compressive stresses that are already present, resulting in a larger compressive plastic deformation. The opposite is true for a pulse radially opposite to a previously irradiated area. Here, 


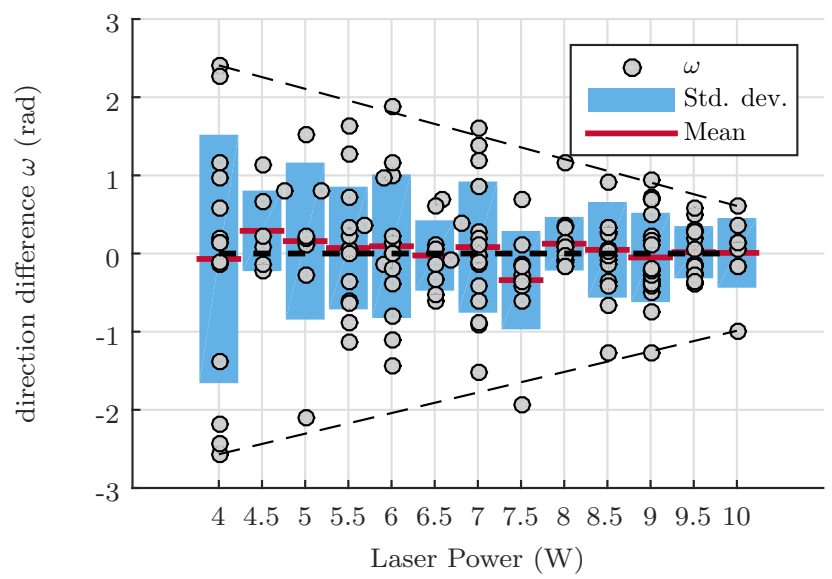

Fig. 3.11: Difference between direction of expansion and direction final motion. The dashed lines indicate the trend of the extreme values encountered in the measurements. Using higher power ensures a more deterministic bending direction.

the initial stress is tensile, resulting in a smaller compressive plastic strain and hence, a smaller bending angle.

The maximum bending angle in these experiments was found to equal $1.9 \mathrm{mrad}$ at $P=10 \mathrm{~W}$, which is a translation of about $13 \mu \mathrm{m}$ at the fiber tip when $d=7 \mathrm{~mm}$. Repeating this at the same location resulted in a smaller deformation, but when a new heating location adjacent to the previous was chosen, a large bending angle could be obtained again. No restriction on the total maximum displacement stroke has been found, and is limited to the inner diameter of the tube. For the used tubes this is $100 \mu \mathrm{m}$ in all directions. Therefore, with an alignment accuracy of $0.1 \mu \mathrm{m}$, the ratio of accuracy to stroke is $1: 1000$.

\subsubsection{Bending direction}

Aside from predicting the magnitude of the bending angle, the bending direction is equally important. When the tube is homogeneous and free of internal stresses, a bending direction directly opposing the thermal expansion direction is expected, i.e. the bending direction difference $\omega$ equals $0^{\circ}$ (see Fig. 3.6). However this is not the case, as for the mentioned reasons, stresses are present. Figure 3.11 shows this difference for all measurements with different laser power settings. The dashed lines indicate the trend of the extreme values encountered in the measurements. For a low laser power, the bending direction is more unpredictable than for high power, with a large spread up to $\pm 150^{\circ}$. This should be avoided, as $\delta_{\mathrm{d}}$ will increase when $-90^{\circ}>\omega>90^{\circ}$. When 
using higher laser power, the bending direction is more deterministic, and is opposing the expansion direction with a higher certainty.

\subsection{Towards prediction of optimal process parameters}

The large spread in bending angle and direction introduces the need for a statistical approach in planning the optimal settings for the next bending step. This planning is a tradeoff between using a high laser power to have a deterministic radial direction, but a large uncertainty in bending angle, or using a lower laser power, with a large uncertainty of direction, but with a deterministic (small) bending angle. When only the translation of the fiber tip is critical, $d$ can be chosen small, to allow for a high laser power while limiting the displacement $\delta_{\mathrm{r}}$. This increases the certainty in direction and magnitude of the motion, at the cost of a limited maximum displacement.

\subsection{Conclusions}

With the experimental setup presented, the deformation of laser bending micro tubes has been measured in real-time. Although accurate positioning was hampered by magnitude and direction deviations, experiments on micro tube actuators have shown that it is possible to use such an actuator to align an optical fiber with an accuracy of $0.1 \mu \mathrm{m}$. This result is promising for applications where small optical components need high precision alignment. The alignment can be done after assembly, avoiding the risk of misalignment during the assembly process. Moreover, the initial alignment accuracy can be relaxed to more than $10 \mu \mathrm{m}$, which reduces the assembly complexity. No special structures in the tubes are needed, which makes each actuator very lowcost. Despite the large spread in displacement and direction, a careful selection of the process parameters from prior knowledge allows for a quick convergence to the targeted deformation. These results show that it is possible to fully automate the process, by using an algorithm that selects the optimal process settings with the knowledge gained in previous steps. Such an algorithm, which minimizes the number of iterations, is currently being developed. 


\title{
Chapter 4 \\ Robust precision alignment algorithm for micro tube laser forming
}

\begin{abstract}
It is shown that laser tube bending can be used as a high precision actuator to permanently align small (optical) components. Although the process causes significant scattering in bending angle and direction, the desired deformation can be achieved by multiple steps of decreasing size once the target location is in proximity. In this paper an iterative learning method is proposed which, for each bending step, determines the best values of the main driving parameters; the axial laser spot position on the tube and the laser power. These parameters depend on the direction and distance to the target location and the results of previous pulses. This algorithm is self-learning by using information of all previous steps and therefore works for different tube geometries. Moreover the learning is robust for differences in for example the laser absorption between the tubes. A fully automated experimental micro tube bending setup has been developed using the proposed method in an algorithm to align an optical fiber to a virtual target with $0.1 \mu \mathrm{m}$ accuracy, using tubes with a diameter between $450 \mu \mathrm{m}$ and $700 \mu \mathrm{m}$.
\end{abstract}

This chapter is reprinted from: Folkersma, K. G. P. Brouwer, D. M. Römer, G. R. B. E. "Robust precision alignment algorithm for micro tube laser forming". In: - (2015). Submitted for publication. 

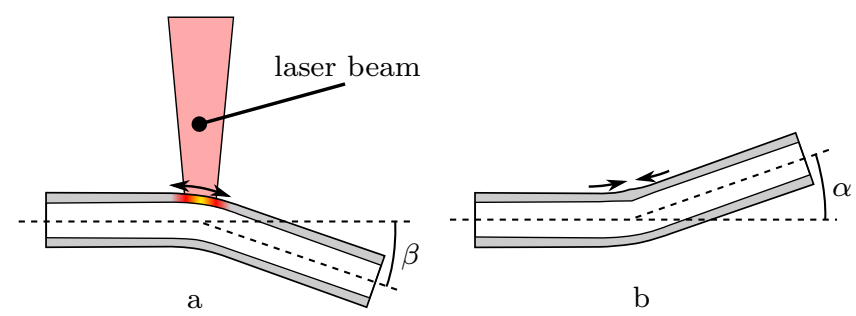

Fig. 4.1: Tube laser bending. a: Laser-induced heat results in thermal expansion, and a bending of angle $\beta$ away from the laser beam. b: after cooling, the tube bends towards the laser beam, resulting in a final angle of $\alpha$.

\subsection{Introduction}

The ongoing development in photonic integrated circuits requires advances in manufacturing and packaging of these waveguide chips [62]. Recent developments in waveguide design allow for shorter wavelengths into the UV range, combined with high powers up to $300 \mathrm{~mW}$ [4]. Fibers and waveguides supporting short wavelengths have small mode field diameters, which demands an increased alignment accuracy of the fiber to the photonic chip. This means that a lateral alignment accuracy in the order of $0.1 \mu \mathrm{m}$ is required to obtain an acceptable optical insertion loss [4]. Traditional passive alignment methods, such as etched V-grooves, are not suitable here since the geometrical tolerances of commercial available fibers do not meet the requirements [2]. Therefore, there is a need for an alignment method to (re)align the fiber actively by an integrated actuator. This one-time alignment can be done after any manufacturing processes which might disturb the alignment, e.g. due to assembly and bonding.

Such (re)alignment can be achieved by laser-forming of metallic structures. Laser micro-forming has been used widely in applications where sub-micron position adjustments are needed $[18,31,32,40,63,64]$. Laser forming is a contact-less process and allows for a stepwise deformation of the material under consideration. A dedicated structure that is part of the product can be used as an alignment actuator. Most studies on precision alignment using laser forming are based on planar actuators [30, $32,41,50]$. However, when multiple fibers in an array with a pitch $<1 \mathrm{~mm}$ need to be aligned, those actuators have a too large footprint in the actuation direction. Due to this limited space, laser tube bending actuators offers great potential for a compact high precision actuation [57]. 


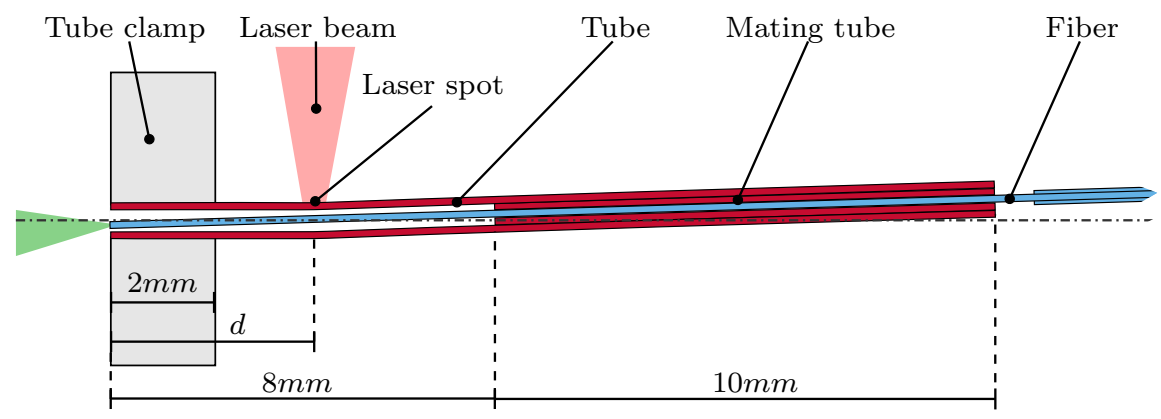

Fig. 4.2: Fiber and tube assembly.

\subsubsection{Laser micro tube bending}

The tube bending mechanism is activated by heating of one side of the tube, either by a stationary laser spot or by scanning the laser spot over the surface of the tube in the axial or radial direction, see Fig. 4.1a. The resulting thermal strain in the material introduces a compressive stress in the tube that exceeds the yield stress. Given the tube wall does not buckle, this results in a compressive plastic strain. Then, when the tube cools down, the heated volume of the tube wall will effectively contract. This is usually referred to as the Upsetting Mechanism [14]. The result is a bending of the tube towards the laser beam, see Fig. 4.1b. This approach can be repeated multiple times to increase the bending angle.

In literature, few authors have studied laser bending of tubes with a diameter smaller than $1 \mathrm{~mm}$. Jamil et al. [19] and Chandan et al. [65] recently studied the bending of nickel and stainless steel micro tubes respectively, both with an outer diameter of about $1 \mathrm{~mm}$ and a wall thickness between $50 \mu \mathrm{m}$ and $150 \mu \mathrm{m}$. Qi and Namba studied the laser bending of $8 \mathrm{~mm}$ diameter 304 stainless steel rods[64], by scanning the laser spot in the axial direction of the tube. The authors achieved a repeatable minimum bending angle of the rod of $1.75 \times 10^{-3} \mathrm{mrad}$. Moreover, it was observed that multiple scans increase the bending angle linearly, except for the first scan, which shows a significantly larger bending.

Previously reported results on laser forming of micro tubes show large uncertainties in bending angle, even if the input parameters (laser power and position) are accurately known [57]. Despite this scattering in bending angle, it was possible to position an optical fiber within a lateral accuracy of $0.1 \mu \mathrm{m}$ by carefully selecting the process parameters for each deformation step. However, the optimal settings for the next step can only be found from empirical data.

Such a statistical approach has been applied on plate laser bending by Henninge et al. [40], where a limitation on the achievable bending accuracy has been identified in relation with the experimental variance of the bending angle. However the plate bending deformation is considered in one direction only. This is not the case for 
tube bending, where the bending can be in any direction provided that the laser spot can be positioned around the tube. This eliminates the risk of permanently overshooting the target bending angle. Then the final accuracy is determined by the smallest achievable bending step. Furthermore it is not required to plan the number of irradiations beforehand. Instead, new optimal settings can be calculated for every step, in an iterative learning method.

\subsubsection{Goal}

The goal of this research is to develop a robust algorithm that determines the optimal process parameters to align small components to a predefined position with a minimum number of steps, by laser forming of a micro-tube. The alignment of an optical fiber with respect to an optical chip is taken as an example. The alignment algorithm should be robust for the spread in response to the input parameters and minimize the number of steps to reach the target position of the fiber tip within $0.1 \mu \mathrm{m}$.

\subsection{Experimental setup}

To test the performance of the tube bending alignment algorithm, an experimental setup has been developed that allows for fully unattended laser bending of a micro tube to align an optical fiber tip to a pre-set destination position. The optical fibers to be aligned, are single-mode optical fibers with a diameter of $125 \mu \mathrm{m}$. Figure 4.2 shows the assembly of the tube with the fiber fixed to one end. The free end of the fiber (left in this figure) is to be aligned to a target in two directions $(X, Y)$. This is achieved by bending the tube at a position $d$ from the fiber tip. Assuming the bending angle $\alpha$ is small, the translation of the fiber tip equals $\delta_{\mathrm{d}}=d \cdot \alpha$. The fiber is mounted concentrically in a $18 \mathrm{~mm}$ long tube that will be deformed, and centered by a $10 \mathrm{~mm}$ long mating tube, see Fig. 4.2. Both are fixed with adhesive. The tube is clamped over $2 \mathrm{~mm}$ length to fix it to the setup. Three different sizes of tubes are tested (see table 4.1). The used tube material is 304 stainless steel with a hard temper treatment after drawing.

A fiber laser (max. $100 \mathrm{~W}, 1080 \mathrm{~nm}$ ) showing a Gaussian intensity distribution and a $1 / e^{2}$ spot diameter of $400 \mu \mathrm{m}$ is used to heat and deform the tubes. The laser spot is either positioned directly on the tube, or via one of two fixed mirrors near the tube, see Fig. 4.3. A camera is mounted on the focusing head to align the laser to the tube. Using the tip/tilt mirror, three radial positions spaced $120^{\circ}$ from each other, and the complete tube length are accessible by the laser spot. Additionally, since the spot size is smaller than the tube diameter, a small deviation of $\pm 35^{\circ}$ from these radial positions can be tolerated by moving the laser spot off-center, see Fig 4.4. 


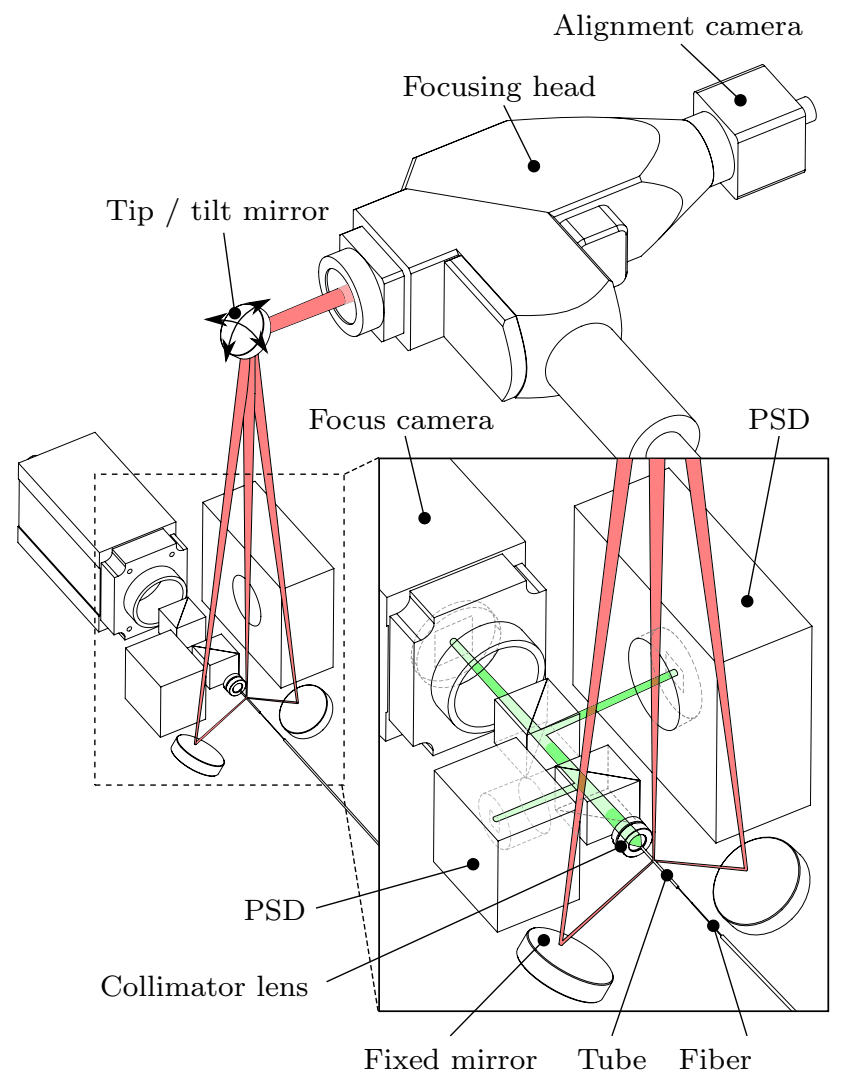

Fig. 4.3: Schematic overview of the experimental setup.

The experimental setup depicted in Fig. 4.3 is used to measure the displacement of the fiber tip in real-time. The displacement is measured by two duo-lateral Position Sensing Detectors (PSD). A collimator lens focuses the light emitted from the fiber on the two PSDs via beam-splitters, see Fig. 4.3. The tube clamp (see Fig. 4.2) can be translated by three translation stages, and it's position and orientation is measured by 5 capacitive displacement sensors, with a resolution of $50 \mathrm{~nm}$. The relation of the signal from the PSDs and the fiber position is calibrated by moving the tube, and measuring the translation by the capacitive sensors. By checking with the capacitive sensors, the maximum absolute error of measuring the fiber tip position was found to be $0.2 \mu \mathrm{m}$ with a repeatability better than $0.1 \mu \mathrm{m}$. After calibration, the capacitive sensors are used to subtract any external influences (for example vibrations or thermal variations) from the measurement.

All measurement signals are processed by a Matlab Simulink Real-time environment, sampling at $5 \mathrm{kHz}$. For each deformation step, the signals are processed to 
extract the relative tube deformation magnitude and direction. The beam position, laser power, triggering and tube positioning stages are all fully computer-controlled. The setup and measurement system is explained in more detail in [57].

\subsection{Experimental results}

Earlier work [57] showed that the relation between laser power and the tube bending angle is subject to significant scattering. To test the effect of the tube dimensions, three tube types, listed in table 4.1, are tested in the experimental setup. Due to the relatively high values of the wall thickness of tube type 2 , a longer pulse time of $200 \mathrm{~ms}$ is chosen for this tube. This is to prevent a steep temperature gradient over the wall thickness, introducing additional bending stresses, which could invalidate the comparison of the result to those of the other tubes. Due to the fully automated setup, the deformations of a large number of bending steps could be measured to identify the scattering for multiple tube samples.

Table 4.1: Tube dimensions and laser parameters used in the experiments

\begin{tabular}{llllllll}
\hline type & $\begin{array}{l}\text { Outer } \\
\text { diam. } \\
(\mu \mathrm{m})\end{array}$ & $\begin{array}{l}\text { Inner } \\
\text { diam. } \\
(\mu \mathrm{m})\end{array}$ & $\begin{array}{l}\text { Wall } \\
\text { thickness } \\
(\mu \mathrm{m})\end{array}$ & $\begin{array}{l}\text { Laser } \\
\text { power } \\
(\mathrm{W})\end{array}$ & $\begin{array}{l}\text { Pulse } \\
\text { duration } \\
(\mathrm{ms})\end{array}$ & $\begin{array}{l}\text { number of } \\
\text { samples }\end{array}$ & $\begin{array}{l}\text { total number of } \\
\text { measurements }\end{array}$ \\
\hline 1 & 457 & 343 & 57 & $3.5-6.5$ & 100 & 7 & 148 \\
2 & 635 & 330 & 152 & $5-10$ & 200 & 23 & 442 \\
3 & 711 & 533 & 89 & $5-10$ & 100 & 10 & 266 \\
\hline
\end{tabular}

The relation between the laser power and the final bending angle $\alpha$ is shown in Fig. 4.5 and the deviation $\omega$ from the expected bending direction is shown in Fig. 4.6. This expected direction of bending is opposite to the direction of expansion $\phi_{\exp }$, and therefore opposite to the laser spot, see Fig 4.4. The direction deviation has a mean equal to zero [57], but since the sign of the direction error is not of interest, the absolute value is used, yielding $\omega=\left|\phi_{\mathrm{r}}-\phi_{\exp }-\pi\right|$.

As can be concluded from these figures, the amount of scattering in $\alpha$ increases with increasing laser power for all tube types. This means that large steps in $\alpha$, induced by relatively large laser power, show a high uncertainty in final bending angle. However, at high laser power, $\phi_{\mathrm{r}}$ is more deterministic, i.e. less scattering is present in the direction. This means that there is a tradeoff between large angles with high uncertainty in magnitude, but a predictable direction, or a guaranteed small angle with an unpredictable direction of bending. Furthermore, tube type 2 shows a large uncertainty in bending direction compared to type 1 and 3. This is best explained by the larger wall thickness of the type 2 tube, in combination with a longer pulse duration. The long pulse duration is required to obtain a uniform heat distribution 


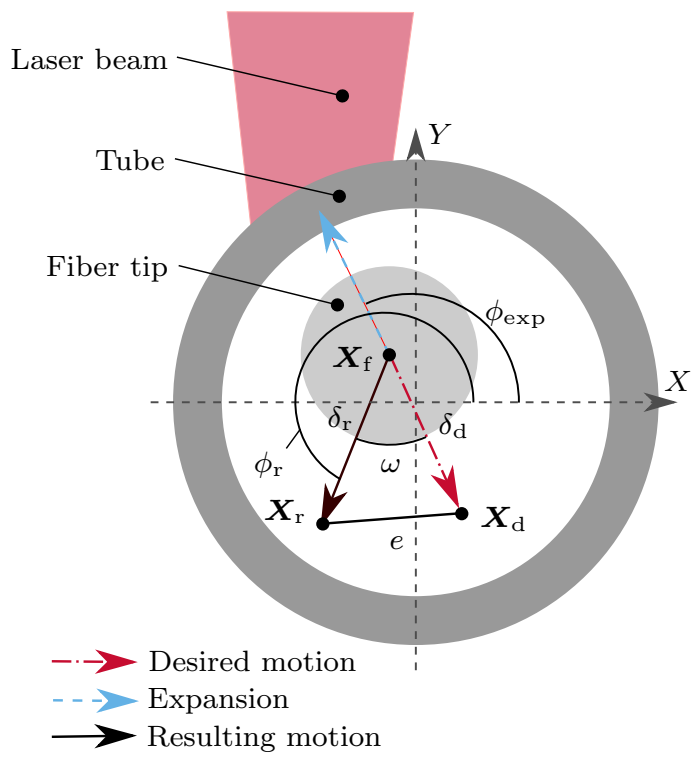

Fig. 4.4: Translation coordinates at the fiber tip.

over the wall thickness, but also results in a larger heated volume in the axial and tangential direction of the tube. This increases the chance of (re-)heating an area with internal stresses, for example due to previous bending steps, potentially relaxing these stresses.

\subsection{Alignment algorithm}

The final deformation can only be determined after cooling of the tube, which can take up to $25 \mathrm{~s}$. Therefore, to reduce the cycle time per tube, the number of iteration steps to reach the target position $\boldsymbol{X}_{\mathrm{d}}$ of the fiber should be minimized.

\subsubsection{Parameter selection}

Despite the scattering in displacement, it is possible to make guaranteed small steps when the distance $\delta_{\mathrm{d}}$ to the target position is small, using a low laser power in combination with a small distance of the laser spot from the tip $d$ [57], see Fig. 4.2. However, due to the tradeoff between high certainty in bending angle $\alpha$ and high certainty in bending direction $\omega$ (see section 4.3 ), tuning $P$ and $d$ directly proportional to the de- 


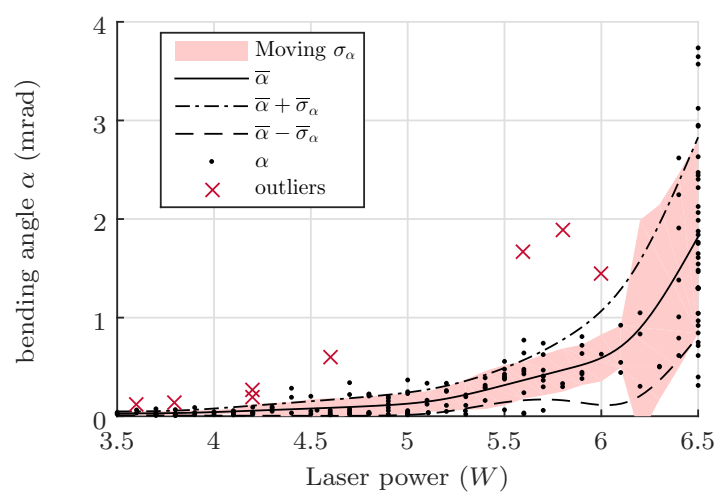

(a) Tube type \#1

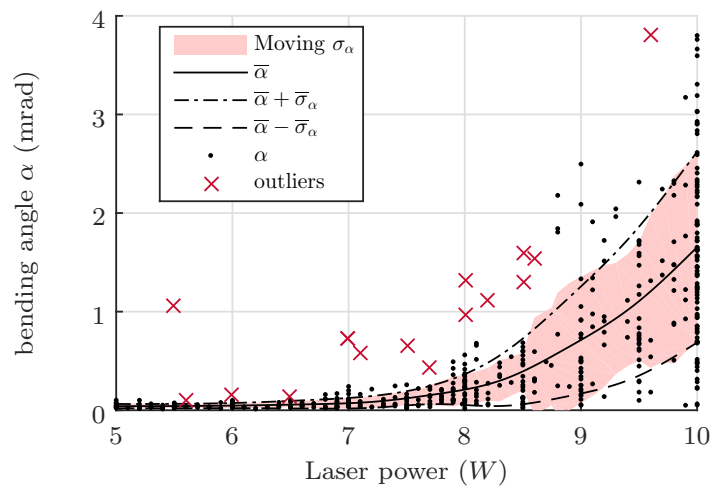

(b) Tube type \#2

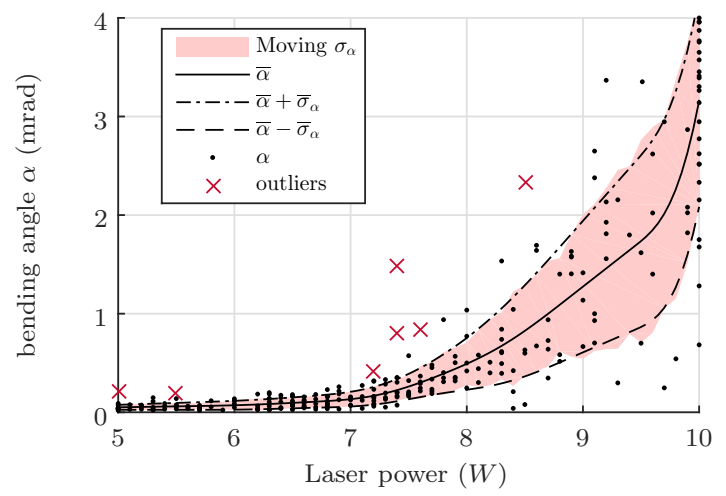

(c) Tube type \#3

Fig. 4.5: Measured bending angle $(\alpha)$ for the three tube geometries as a function of the laser power $(P)$. Each point represents a single bending step. Outliers are removed by Grubbs' test [66] with with significance level 0.075. The shaded areas indicate the standard deviation around the mean value of $\alpha$. 


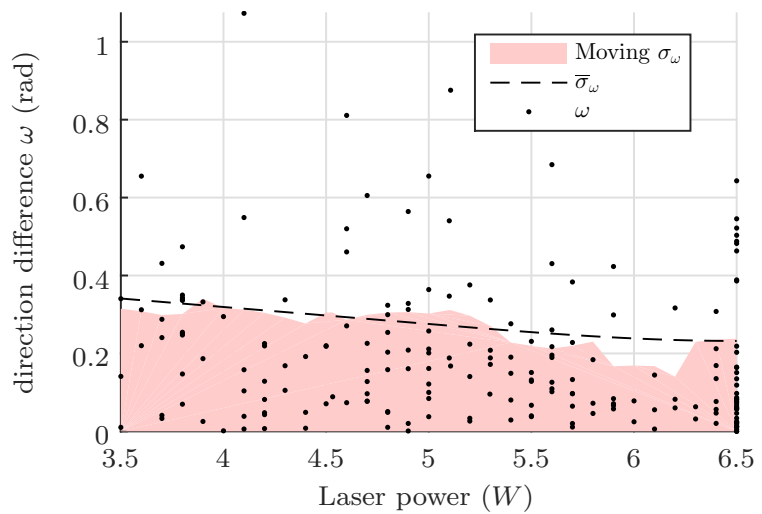

(a) Tube type \#1

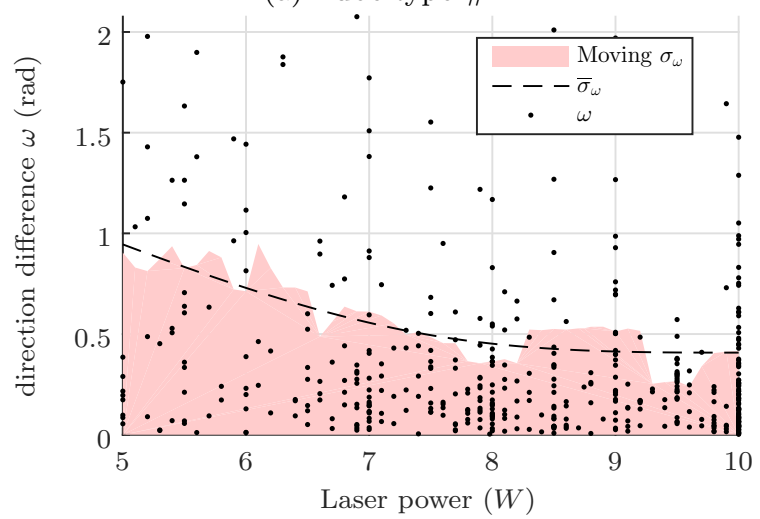

(b) Tube type \#2

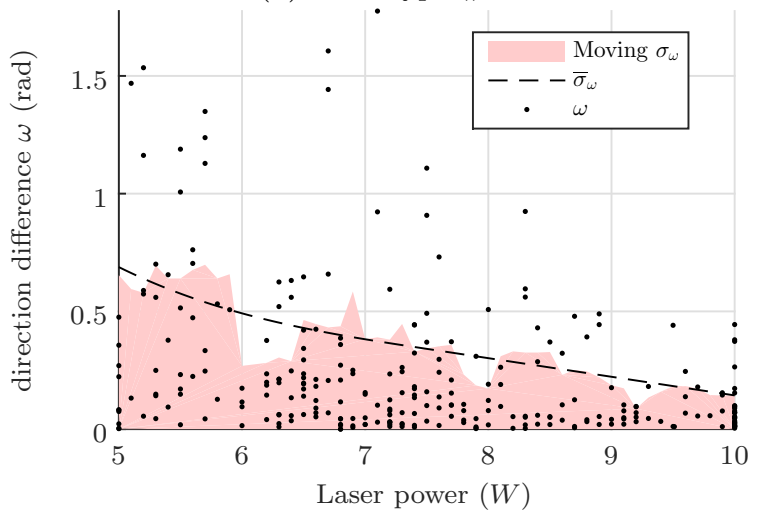

(c) Tube type \#3

Fig. 4.6: Measured absolute difference between direction of expansion $\left(\phi_{\exp }\right)$ and direction of final motion $\left(\phi_{\mathrm{r}}\right)$ for the three tube geometries. $\omega=\left|\phi_{\mathrm{r}}-\phi_{\exp }-\pi\right|$, see Fig 4.4. Note the different scales on the y-axis. 
sired step size is not the optimal approach. Instead, the number of steps is minimized when the expected value of the distance between the target position and the actual position after the bending step is minimized, given that the desired step size $\delta_{\mathrm{d}}$ does not exceed the maximum step size.

The scattering of $\alpha$ and $\omega$ is assumed to be uncorrelated and to have a normal probability distribution. The standard deviations of $\alpha$ and $\omega$, denoted as $\sigma_{\alpha}$ and $\sigma_{\omega}$ respectively, are obtained by a moving standard deviation (with a window of $0.5 \mathrm{~W}$ ) over all available (historical) data. The historical data of $\alpha, \sigma_{\alpha}$ and $\sigma_{\omega}$ are fitted as a function of $P$ by a cubic spline (with 10, 10 and 5 knots respectively) to obtain the expectancy of the bending angle $\mathbf{E}[\alpha]=\bar{\alpha}$, its standard deviation $\bar{\sigma}_{\alpha}$ and the standard deviation of the direction error $\bar{\sigma}_{\omega}$ respectively, see Fig. 4.5 and Fig. 4.6. To improve the robustness of these fits even when there are few data points available, the fit is constrained to be globally increasing and concave for $\bar{\alpha}$ and $\bar{\sigma}_{\alpha}$ and globally decreasing for $\bar{\sigma}_{\omega}$.

Both parameters $P$ and $d$ are tuned by the algorithm, with the distance to the target $\delta_{\mathrm{d}}$ as input. For any $\delta_{\mathrm{d}}>0$, any combination of $d$ and $P$ that satisfies

$$
\begin{aligned}
\delta_{\mathrm{d}} & =d \cdot \bar{\alpha}(P) \text { with}, \\
3 \mathrm{~mm} & \leq d \leq 7 \mathrm{~mm} \text { and } \\
P_{\min } & \leq P \leq P_{\max },
\end{aligned}
$$

the expected value of the resulting distance is equal to the desired distance. That is,

$$
\mathbf{E}\left[\delta_{\mathrm{r}}\right]=\delta_{\mathrm{d}}
$$

$P_{\max }$ and $P_{\min }$ are the maximum and minimum power for the current tube geometry (see table 4.1), and the limits in $d$ are due to the tube clamp and mating tube, see Fig. 4.2.

With equation (4.1), $P$ remains as degree of freedom to be optimized, by minimizing the expectancy of the error after bending. Without loss of generality, all iteration steps can be simplified to a relative step, by moving and rotating the coordinate system such that the fiber tip starts at $\boldsymbol{X}_{\mathrm{f}}=[0,0]$, and the target is at $\boldsymbol{X}_{\mathrm{d}}=\left[\delta_{\mathrm{d}}, 0\right]$, see Fig 4.7. The new position after bending is defined by

$$
\boldsymbol{X}_{\mathrm{r}}=\left[\begin{array}{c}
\delta_{\mathrm{r}} \cos \omega \\
\delta_{\mathrm{r}} \sin \omega
\end{array}\right]
$$

where the $\omega$ and $\delta_{\mathrm{r}}$ are normally distributed as $\omega \sim \mathcal{N}\left(0, \sigma_{\omega}\right)$ and $\delta_{\mathrm{r}} \sim \mathcal{N}\left(\delta_{\mathrm{d}}, \sigma_{\delta}\right)$, with $\sigma_{\delta}=d \cdot \sigma_{\alpha}$.

The resulting error is the distance between the new position and the target position. That is, 


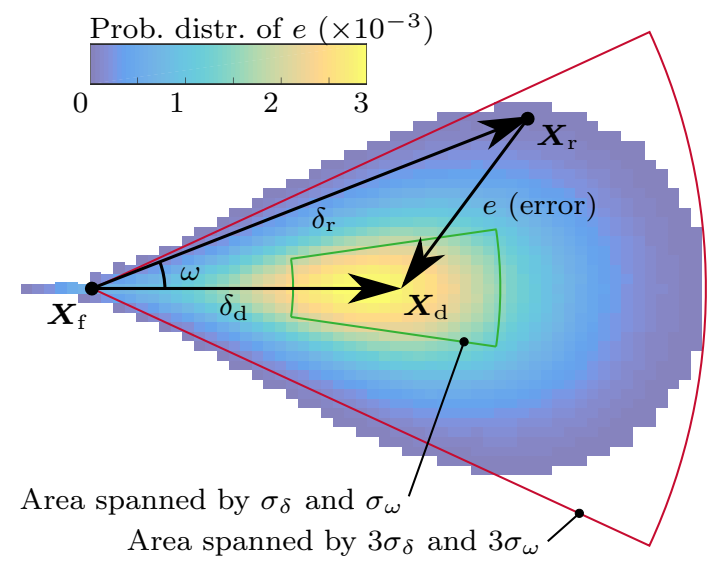

Fig. 4.7: Visualization of the error $e$ after bending, moving the fiber tip from $\boldsymbol{X}_{\mathrm{f}}$ to $\boldsymbol{X}_{\mathrm{r}}$, where the desired target was $\boldsymbol{X}_{\mathrm{d}}$. The green and red areas are spanned by one and three times the standard deviation of $\omega$ and $\delta$ respectively. The colored area is an example of the probability distribution of $e$ for tube type 3 , with $\delta_{\mathrm{d}}=10 \mu \mathrm{m}$, $P=10 \mathrm{~W}$ and $d=3.15 \mu \mathrm{m}$.

$$
\begin{aligned}
e & =\left\|\boldsymbol{X}_{\mathrm{r}}-\boldsymbol{X}_{\mathrm{d}}\right\| \\
& =\sqrt{\left(\delta_{\mathrm{r}} \cos \omega-\delta_{\mathrm{d}}\right)^{2}+\left(\delta_{\mathrm{r}} \sin \omega\right)^{2}} \\
e^{2} & =\delta_{\mathrm{d}}^{2}+\delta_{\mathrm{r}}^{2}-2 \delta_{\mathrm{d}} \delta_{\mathrm{r}} \cos \omega
\end{aligned}
$$

The expected value of the squared error is defined by

$$
\begin{aligned}
\mathbf{E}\left[e^{2}\right] & =\delta_{\mathrm{d}}^{2}+\mathbf{E}\left[\delta_{\mathrm{r}}^{2}\right]-2 \delta_{\mathrm{d}} \mathbf{E}\left[\delta_{\mathrm{r}}\right] \mathbf{E}[\cos \omega] \\
& =\delta_{\mathrm{d}}^{2}+\left(\delta_{\mathrm{d}}^{2}+\sigma_{\delta}^{2}\right)-2 \delta_{\mathrm{d}} \delta_{\mathrm{d}} \exp \left(\frac{-\sigma_{\omega}^{2}}{2}\right) \\
& =\sigma_{\delta}^{2}+2 \delta_{\mathrm{d}}^{2}\left(1-\exp \left(\frac{-\sigma_{\omega}^{2}}{2}\right)\right)
\end{aligned}
$$

Note that $\sigma_{\delta}$ and $\sigma_{\omega}$, are estimated by $d \cdot \bar{\sigma}_{\alpha}(P)$ and $\bar{\sigma}_{\omega}(P)$ respectively, which are functions of the laser power $P$. Equation 4.4 ensures $e \geq 0$, therefore minimizing $\mathbf{E}\left[e^{2}\right]$ within the allowed range of $P$, gives the same result as minimizing $\mathbf{E}[e]$. That is,

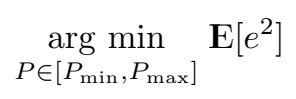

The optimum laser power $P_{\mathrm{opt}}$ resulting in this minimum is found numerically, and substituting this in equation (4.1) yields $d_{\text {opt }}$. A special case is when the desired step size can not be achieved in one step. That is when $\delta_{\mathrm{d}}>\delta_{\max }$, where 


$$
\delta_{\max }=d_{\max } \cdot \bar{\alpha}\left(P_{\max }\right),
$$

For this case, the power is set to $P_{\max }$ and the distance to the fiber tip is set to $d_{\max }$.

\subsubsection{Iterative learning}

Each deformation step contains new measurement information about the bending process. Therefore, between each step, the last measurement is added to the historical data, and new fits $\left(\bar{\alpha}, \bar{\sigma}_{\alpha}\right.$ and $\left.\bar{\sigma}_{\omega}\right)$ are calculated (see section 4.4.1). Subsequently, the optimal values for $d$ and $P$ are updated with the new fits. The complete flow for one alignment is shown in Fig. 4.9. The automatic learning makes the algorithm independent of geometry and material of the tube. When using a new tube type, the user needs to identify the maximum laser power (to prevent melting), and do 10-20 'manual' bending steps at different laser power settings to get a stable fit for $\bar{\alpha}, \bar{\sigma}_{\alpha}$ and $\bar{\sigma}_{\omega}$.

Like other laser forming mechanisms [41], measurements on different tubes have shown that the scattering in $\alpha$ and $\omega$ for a single tube is less than for many different tubes of the same type. Therefore, when fitting the updated data, a higher weight is put on the measurement points that are from the current tube sample. This makes the algorithm more robust to per-sample differences like variations in the laser absorption coefficient.

\subsection{Results}

\subsubsection{Optimal parameters}

The results of the optimal parameters for the three tube types versus the desired step size $\delta_{\mathrm{d}}$ are presented in Fig. 4.8 on a logarithmic scale. The data from Fig. 4.5 and Fig. 4.6 were used as input for the algorithm. For large distances, $P_{\text {opt }}$ and $d_{\text {opt }}$ are set to the maximum values and with decreasing $\delta_{\mathrm{d}}$, the distance $d$ is decreased, while the power is kept high, due to the higher certainty in direction. When $d$ is at it's minimum value, the power must be decreased to prevent a too large step. For even smaller distances, $P_{\text {opt }}$ increases with a step and the same shape can be observed again. This step occurs, when multiple local minima are present in $\mathbf{E}\left[e^{2}\right]$ within the allowable range of $P$ and $d$. When for decreasing $\delta_{\mathrm{d}}$ the global minimum is not in this allowable range anymore, another minimum will now be the optimal solution, resulting in a sudden step in $P_{\mathrm{opt}}$ and $d_{\mathrm{opt}}$. 


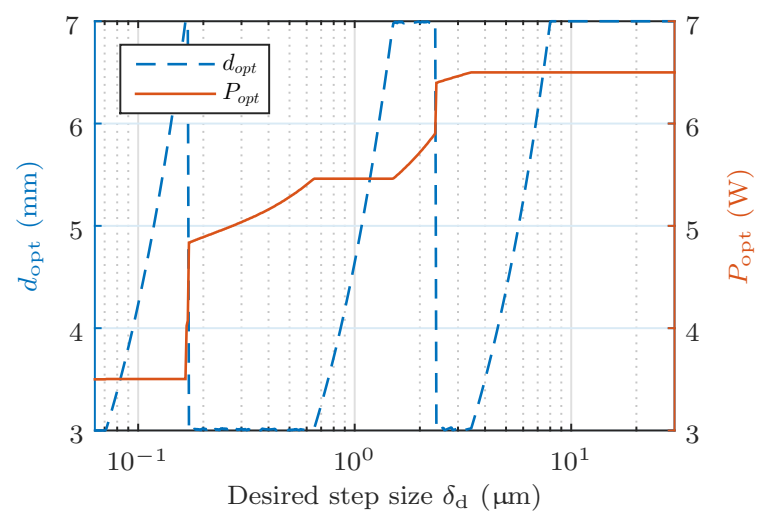

(a) Tube type \#1

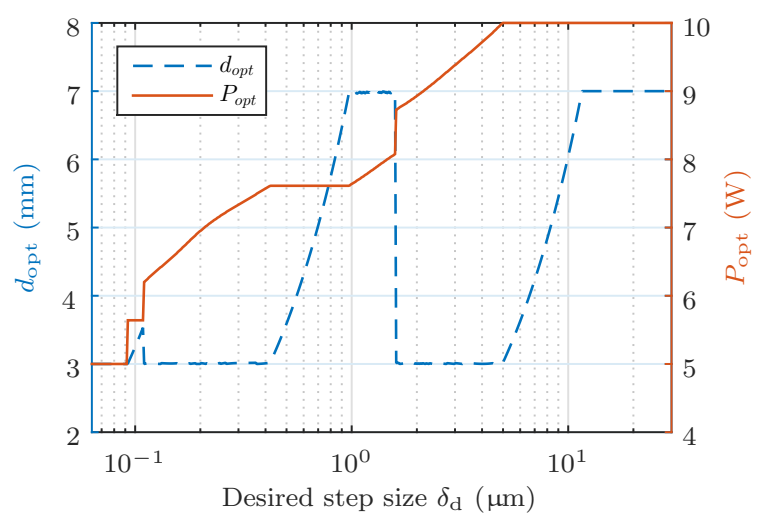

(b) Tube type \#2

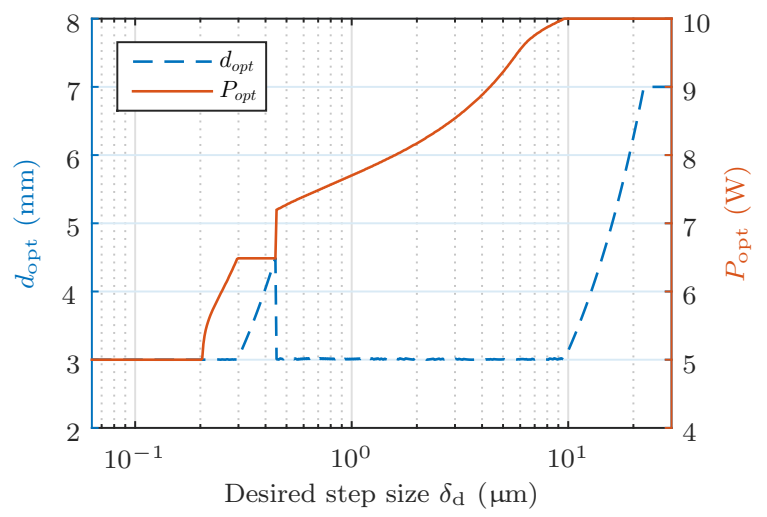

(c) Tube type \#3

Fig. 4.8: Example of the optimal settings from historical data shown in figures 4.5 and 4.6 for the distance to the fiber tip $d$ and laser power $P$. 


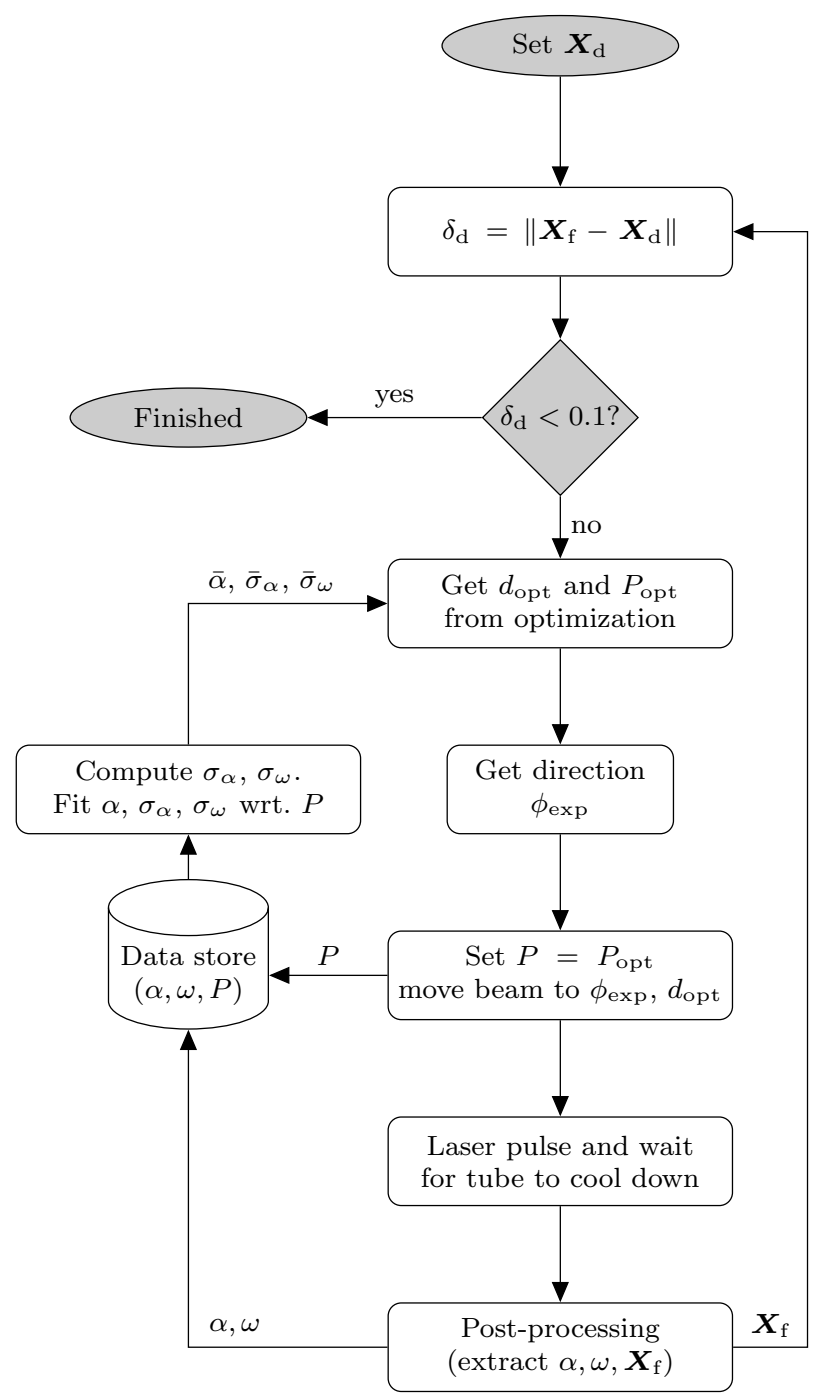

Fig. 4.9: Flowchart of the alignment algorithm.

\subsubsection{Simulation of algorithm}

During development of the algorithm, quick testing of it's performance was needed. Therefore, a simple simulation was developed, that includes the scattering in final deformation and direction shown in Fig. 4.5 and 4.6. It is assumed that the scattering has a normal distribution, with a standard deviation that is calculated from the 
measurements. The simulation takes the laser power $P$ and the positions $d$ and $\phi_{\exp }$ as input, and gives the relative translation of the fiber tip.

Figure 4.10 shows the cumulative probability of reaching the target within $0.1 \mu \mathrm{m}$ for a number of steps. 10000 alignment trials are simulated for each tube type, each with a random destination at a distance of $30 \mu \mathrm{m}$. The simulations show that tube types 1 and 2 perform about the same. That is, to reach the target with a certainty of $95 \%, 19.5$ and 18.5 steps are needed respectively. Tube type 3 performs better and needs 14.5 steps to reach $95 \%$ certainty. This is due to the relatively large maximum bending angle, combined with a low scattering in direction when using a high laser power (see Fig. 4.6c).

The number of steps when the desired accuracy is less can also be simulated. For example, using tube type 3, a final accuracy of $0.2 \mu \mathrm{m}$ or $0.5 \mu \mathrm{m}$ is achieved in 10 and 8 steps respectively. This means a significant reduction in alignment time when the required accuracy can be relaxed.

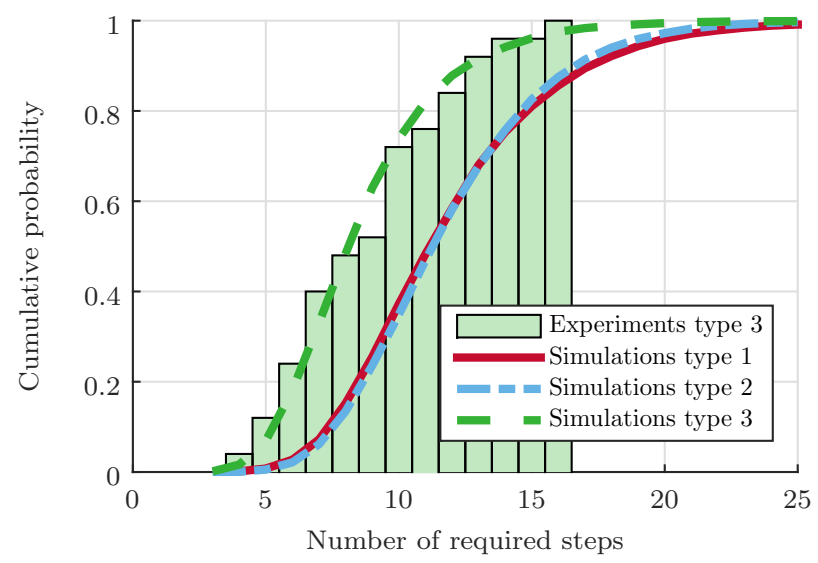

Fig. 4.10: Simulated cumulative probability of reaching the destination with an accuracy of $0.1 \mu \mathrm{m}$. The histogram shows the same for 35 alignment experiments on tube type 3 . The total distance is $30 \mu \mathrm{m}$ for both the simulations and the measurements.

\subsubsection{Alignment experiments}

The algorithm has been implemented with the experimental setup to do fully unattended alignment to a pre-set target position. Fig. 4.11 shows examples of a typical path of the fiber tip for two experiments on tube type 3. The dots show the stationary position of the fiber tip after each step and the dashed lines indicate the direction of thermal expansion. The complete path of the fiber tip is not shown for clarity. In 
Fig. 4.11b, the scattering is visible when the bending steps are small, causing frequent overshoot of the target. This is not the case for 4.11a, where only 4 bending steps were required to reach the target. These alignment experiments were performed for all tube types. For 25 experiments using tube type 3, the cumulative probability histogram for the number of required steps is shown in Fig. 4.10. The simulation matches well with these experiments on all tube types.

\subsection{Conclusion}

With the use of the algorithm presented in this work, it is shown that components can be aligned with a precision of $0.1 \mu \mathrm{m}$ using laser forming of a micro tube, even though the laser forming process causes significant scattering in the response of the bending angle and direction. The alignment of an optical fiber to a virtual target has been used as a test case. The fiber is concentric in the tube, and bending of the tube results in a translation of the fiber tip. The algorithm minimizes the expected value of the error between the target position and the actual position after a bending step, by using measured data from previous steps. Two parameters are tuned by the algorithm, the laser power and the axial distance of the laser spot to the fiber tip.

Simulations of the algorithm, using the measured empirical data, show good agreement with alignment trials done in experiments. Furthermore the algorithm is robust for changes in bending response for different tubes, due to the on-line learning of the response per tube sample. Finally, it can be concluded from the simulations that tubes which have a relatively large diameter with small wall thickness perform best with the algorithm. 


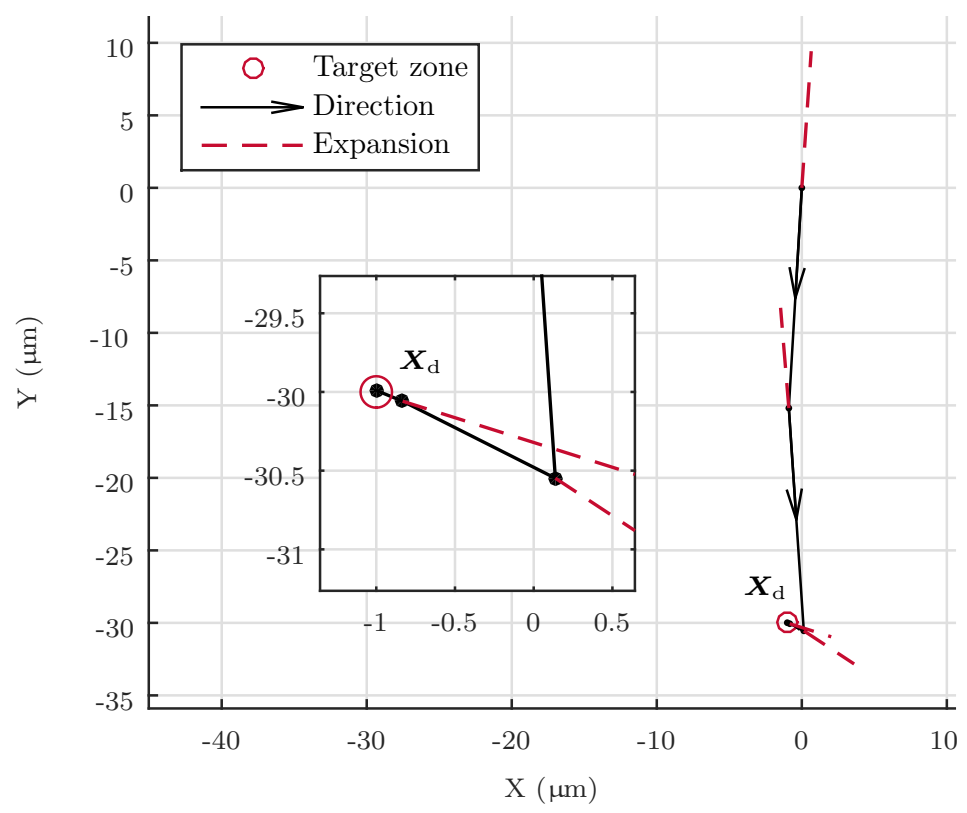

(a) Aligning to $\boldsymbol{X}_{\mathrm{d}}=(-1,-30)$ in 4 steps with tube type 3 .

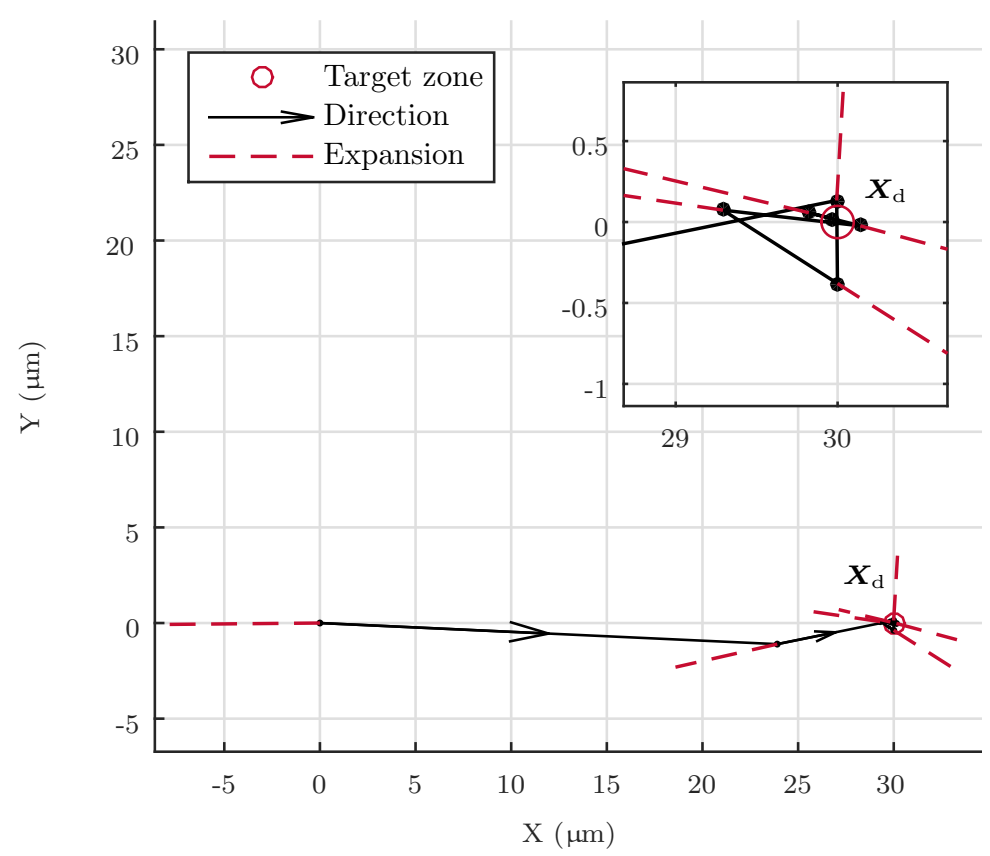

(b) Aligning to $\boldsymbol{X}_{\mathrm{d}}=(30,0)$ in 7 steps with tube type 3.

Fig. 4.11: Measured path of the fiber tip during alignment. The points are stationary positions after each step. The dashed lines indicate the direction of thermal expansion. 


\title{
Chapter 5 \\ High precision optical fiber alignment using laser tube forming
}

\begin{abstract}
In this paper we present a method to align optical fibers within $0.2 \mu \mathrm{m}$ of the optimal position, using tube laser bending and in-situ measuring of the coupling efficiency. For near-UV wavelengths, passive alignment of the fibers with respect to the waveguides on photonic integrated circuit chips does not suffice. In prior research it was shown that permanent position adjustments to an optical fiber by tube laser bending meets the accuracy requirements for this application. This iterative alignment can be done after any assembly steps. A method was developed previously that selects the optimal laser power and laser spot position on the tube, to minimize the number of iterations required to reach the target position. In this paper that method is extended to the case where the absolute position of the fiber tip can not be measured. By exploiting the thermal expansion motion at a relatively low laser power, the fiber tip can be moved without permanent deformation (only elastic strain) of the tube. An algorithm has been developed to search for the optimal fiber position, by actively measuring and maximizing the coupling efficiency. This search is performed before each bending step. Experiments have shown that it is possible to align the fiber with an accuracy of $0.2 \mu \mathrm{m}$ using this approach.
\end{abstract}

This chapter is reprinted with permission from Springer from Folkersma, K. G. P. Römer, G. R. B. E. Brouwer, D. M. Herder, J. L. "High precision optical fiber alignment using tube laser bending". In: The International Journal of Advanced Manufacturing Technology (2015). Accepted for publication.

DOI: $10.1007 / \mathrm{s} 00170-015-8143-6$. 


\subsection{Introduction}

Recent development in photonic integrated circuits (PIC's) require advances in the optical alignment and assembly of the components. For single-mode fiber coupled optical chips, the fiber alignment and packaging is the most expensive phase in the manufacturing of these devices [3]. Moreover, for small wavelengths in the near-UV range, the mode field diameter is small, resulting in a required lateral alignment accuracy in the order of $0.1 \mu \mathrm{m}$, to obtain an acceptable insertion loss [62]. Passive alignment methods, such as etched V-grooves in glass or silicon, can not be employed here, due to the geometrical tolerances (most notably the core-cladding concentricity) of commercial available fibers exceeding the alignment requirements [2]. This also implies that fiber array assemblies can not be aligned simultaneously, since the coreto-core pitch can not be guaranteed to be within the required tolerances.

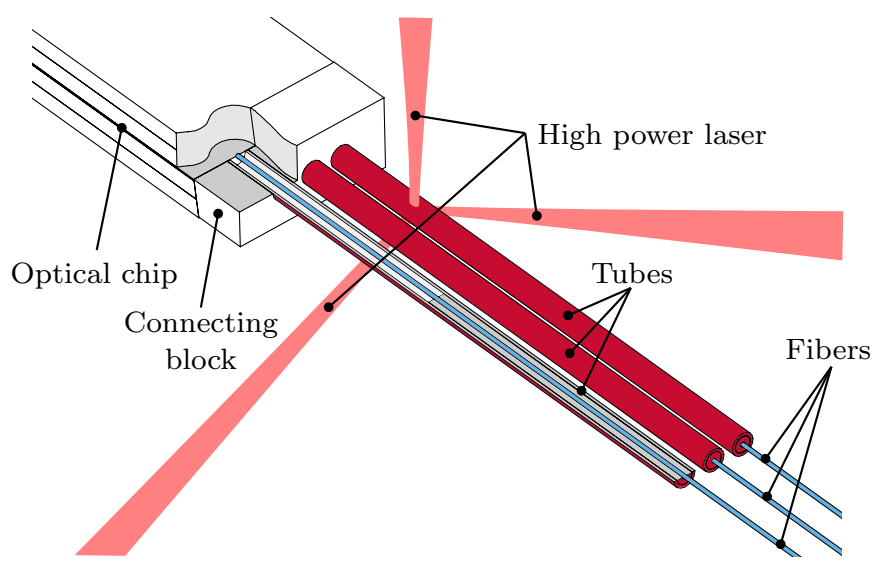

Fig. 5.1: Sketch of how multiple fibers can be aligned to a PIC using tube bending.

Therefore we propose a one-time active alignment per fiber, where the optical coupling efficiency is minimized by sending light through the device and measuring the transmitted power. A hill-climbing algorithm or other optimization method can be used to optimize the transmission while moving and aligning the fiber by, for example, a high-precision motorized stage [6,7]. When the optimal position is found, the fiber is fixed to the chip, usually by UV-curing adhesive [2]. However, adhesives are prone to shrinkage during or after the curing process, which causes misalignment after the final bonding step [8]. Therefore, there is a need for alignment methods to (re)align the fiber actively by an actuator integrated in the device. This one-time alignment is done after any manufacturing processes that might disturb the alignment, such as shrinkage of the used adhesives.

Previous work has shown that laser bending of metal tubes is a feasible method to achieve this one-time precision alignment [57], despite the significant scattering of the 
bending magnitude and direction of this process. The scattering in bending magnitude was found to increase for increasing laser power (and therefore with increasing bending magnitude). On contrary, the scattering in bending direction was found to decrease with increasing laser power.

Figure 5.1 shows a sketch of how the tubes and fibers are positioned to the chip. The fibers are fixed in the tubes and the tubes are fixed to the connection block. The connection block can be aligned and joined to the chip, which would typically result in fiber to chip accuracies in the order of $2 \mu \mathrm{m}$ to $5 \mu \mathrm{m}$. This assembly allows the use of laser bending to align the individual fibers precisely with respect to the waveguides in the chip.

This paper aims at developing a tube laser bending algorithm to align an optical fiber to a PIC, making use of only the light through the fiber for position sensing. Due to the fiber being fully enclosed by the tube, there is no knowledge of the absolute fiber tip position. However, by moving the fiber the coupling efficiency can be maximized by actively measuring the transmitted power. The complete iteration scheme for aligning one fiber to its target can be broken down as:

1. Scan. Estimate the relative target position by moving the fiber using a scanning algorithm.

2. Parameter selection. Determine optimal laser power and beam position on the tube to reach the estimated target position.

3. Bending. Execute the laser bending step and measure the coupling efficiency.

4. Stop condition. Evaluate the stop condition based on the coupling efficiency. If it is not met, go to step 1 .

The following sections explain these steps in more detail. First the fiber alignment tube actuator that was previously developed is detailed in section 5.2. The proposed scan algorithm as well as the thermal expansion motion is presented in section 5.3. In section 5.4 the selection of the laser power and laser spot position to reach the scanned target is explained. The scan and bending step are repeated until the stop condition given in section 5.5 is met. The algorithms are tested with an experimental setup, see section 5.6. The results of experiments with the scan algorithm and alignment experiments are given in section 5.7.1 and 5.7.2 respectively. Finally, the results are discussed in section 5.8 and the conclusions are summarized in section 5.9.

\subsection{Fiber alignment by laser tube bending}

The assembly of the tube and the optical fiber is shown in Fig. 5.2. The single-mode optical fiber is fixed concentrically in the $18 \mathrm{~mm}$ long metal tube using a $10 \mathrm{~mm}$ long mating tube. The laser spot is located at an axial distance $d$ from the fiber tip, at an angle $\phi_{\text {exp }}$. The 304 stainless steel tubes received a hard temper treatment after drawing. The tube has a outer diameter of $711 \mu \mathrm{m}$ and a wall thickness of $89 \mu \mathrm{m}$. These dimensions were found to perform the best with the alignment algorithm [61]. 


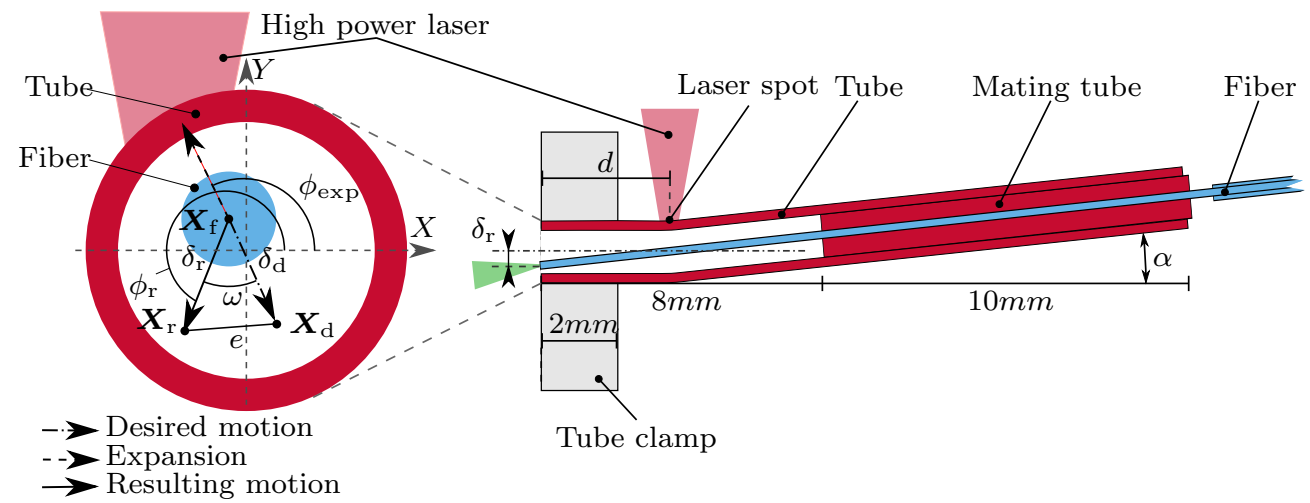

Fig. 5.2: Fiber and tube assembly used in the experiments. The coordinates of the fiber tip are depicted on the left.

The bending angles are small, therefore the lateral displacement of the fiber tip can be expressed as $\delta_{\mathrm{r}}=d \cdot \alpha$, where $\alpha$ is the bending angle after the tube has cooled down (see Fig. 5.2).

\subsection{Scanning for the target position}

The optimal position of the fiber is where the transmitted power from the fiber into the PIC is maximized. The relative coupling efficiency can be measured by measuring the laser power transmitted through the chip, while a fixed-power laser source is connected to the fiber.

When using the Gaussian beam approximation [5] and assuming the angular alignment is perfect and the axial separation is zero, the theoretical coupling efficiency of the interconnect reads:

$$
\eta=\left(\frac{2 w_{\mathrm{f}} w_{\mathrm{c}}}{w_{\mathrm{f}}^{2}+w_{\mathrm{c}}^{2}}\right)^{2} \exp \left(-\frac{2 \delta^{2}}{w_{\mathrm{f}}^{2}+w_{\mathrm{c}}^{2}}\right),
$$

Where $\delta$ is the lateral offset between the fiber and target, and $w_{\mathrm{f}}$ and $w_{\mathrm{c}}$ are the modefield radii of the fiber and chip respectively. Figure 5.3 shows the coupling efficiency for $w_{\mathrm{f}}=1.55 \mu \mathrm{m}$ and $w_{\mathrm{c}}=2.25 \mu \mathrm{m}$, which is used in the remainder of this paper. The fact that the optimal coupling efficiency is not 1 , is due to the mode mismatching of the fiber and the chip. As can be concluded from the figure, for $\delta=0.2 \mu \mathrm{m}$, the loss is $1 \%$ of the optimal coupling efficiency. When $\delta$ is larger than $4 \mu \mathrm{m}$, the coupling efficiency is close to zero, and cannot be reliably measured. 


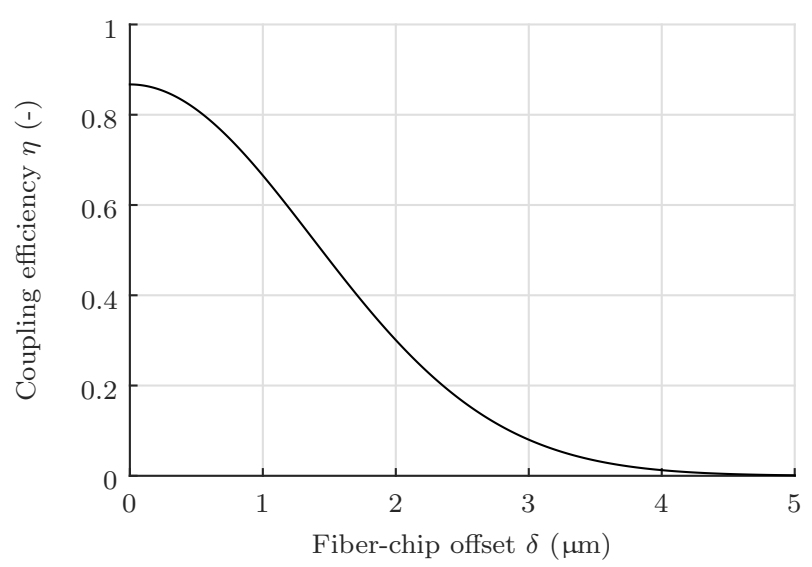

Fig. 5.3: Theoretical coupling efficiency of a fiber to chip coupling for $w_{\mathrm{f}}=1.55 \mu \mathrm{m}$ and $w_{\mathrm{c}}=2.25 \mu \mathrm{m}$, assuming perfect tilt and axial alignment.

\subsubsection{Thermal expansion motion}

The coupling efficiency through the interconnect is the only measured quantity for the two-dimensional alignment. Therefore, a searching method for the optimal alignment position is required. This searching can be done between each bending step, by exploiting the thermal expansion motion when heating the tube by laser irradiation.

That is, at low laser power ( $1 \mathrm{~W}$ to $3 \mathrm{~W}$ ) and short pulse duration $(50 \mathrm{~ms})$, the yield stress in the tube is not exceeded, and only thermal and elastic strain occurs. That means that the final bending angle after cooling down is not changed. The direction of thermal expansion is assumed to be equal to the laser spot angle around the tube $\left(\phi_{\exp }\right)$, and is therefore known. The magnitude of the thermal expansion bending angle $\beta$ however, is not known.

Using the experimental setup (described in section 5.6), it has been found that the bending due to thermal expansion reproduces very well. A prerequisite for this repeatability is that no initial stresses are present in the tube near the laser spot and no oxidation of the tube surface due to the laser heat is formed. Therefore, the bending angle due to thermal expansion is characterized at $d=7.5 \mathrm{~mm}$, which is outside the region where the actual bending is to occur $(3 \mathrm{~mm} \leq d \leq 7 \mathrm{~mm})$. Fig. 5.4 shows the measurement of $\beta$ for 36 laser pulses on different locations on four identical tubes, all at a laser power of $3 \mathrm{~W}$. The repeatability of this expansion angle $\beta$ is $0.15 \mathrm{mrad}$, which corresponds with a repeatability of $1.1 \mu \mathrm{m}$ at the fiber tip. The maximum bending angle at the end of the pulse is $\beta_{\max }=3.2 \mathrm{mrad}$, corresponding to a tip displacement of $24 \mu \mathrm{m}$. This limits area in which the target can be found to be a circle with a radius of $24 \mu \mathrm{m}$ around the current position $\boldsymbol{X}_{\mathrm{f}}$ (see Fig 5.2). The same measurements have been repeated for a laser power of $2 \mathrm{~W}$ and $1.5 \mathrm{~W}$. The repeatability of the expansion 
angle were found to equal $0.12 \mathrm{mrad}$ and $0.10 \mathrm{mrad}$ respectively, corresponding with a fiber tip position repeatability of $0.9 \mu \mathrm{m}$ and $0.75 \mu \mathrm{m}$.

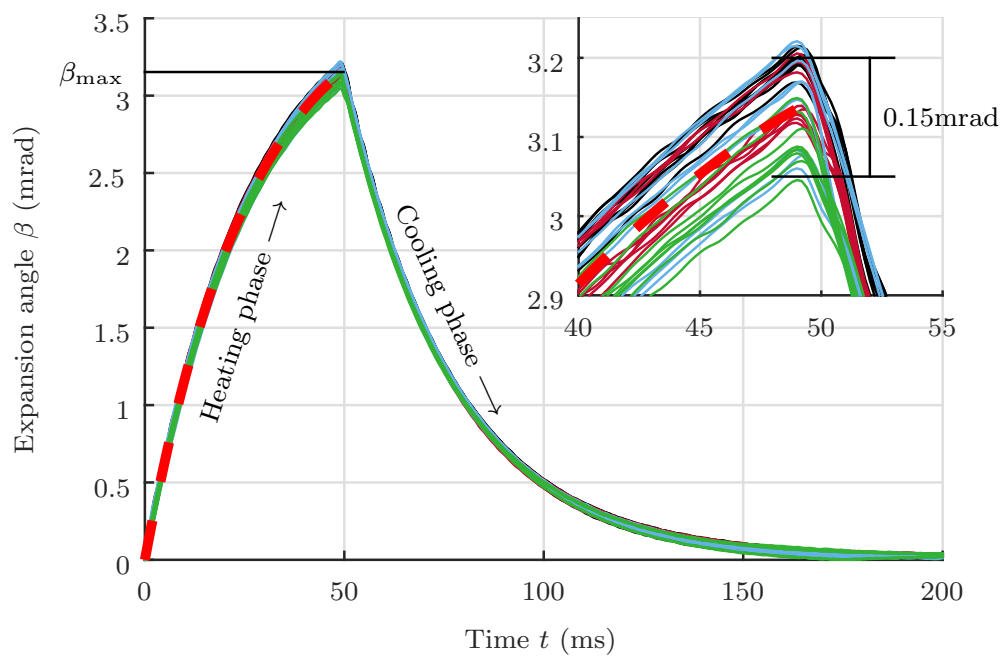

Fig. 5.4: Measured bending angle for 36 laser pulses at different positions on four identical tubes (each tube is indicated by a separate color). For the pulse duration of $50 \mathrm{~ms}$ and laser power of $3 \mathrm{~W}$, the yield stress is not exceeded, and therefore the final deformation angle is zero. The dashed red line indicates the 4th order polynomial fit through the heating phase, used for estimating the angle for thermal expansion.

To estimate $\beta$ when aligning the fiber to a chip (where the fiber tip position is unknown), the heating phase of these measurements is fitted with a 4 th order polynomial $\bar{\beta}$, shown by the red dashed line in Fig. 5.4. This curve relates the elapsed time $t$ of the laser pulse to the expansion angle. With the known scan direction $\phi_{\text {scan }}=\phi_{\exp }$, the position of the fiber tip $\boldsymbol{X}_{\mathrm{f}}$ during heating can be estimated by:

$$
\hat{\boldsymbol{X}}_{\mathrm{f}}(t)=d \cdot \bar{\beta}(t)\left[\begin{array}{c}
\cos \phi_{\text {scan }} \\
\sin \phi_{\text {scan }}
\end{array}\right]
$$

\subsubsection{Scanning algorithm}

To find the maximum coupling efficiency, the fiber is moved by thermal expansion in the direction $\phi_{\text {scan }}^{(i)}$, where $i$ is the $i^{\text {th }}$ scanning iteration. The initial direction $\phi_{\text {scan }}^{(1)}$ is set to the direction of the initial guess of the relative target position $\hat{\boldsymbol{X}}_{\mathrm{d}}^{(0)}$. This 
initial guess is the estimated destination position from the previous scanning action, or is set by the user when it is the first scan.

The relative coupling efficiency $\eta$ is measured in real time during the scan. However, its maximum value $\eta_{\text {opt }}$ for a perfect alignment is unknown due to uncertainties of the transmission through the chip and fibers.

If no signal is found (i.e. $\max \eta(t)=0$ ), or if the number of scan iterations is less than $4, \phi_{\text {scan }}$ is set in the center of the largest 'unscanned' area, and the measurement is repeated. With this method, the 4 initial scan iterations always result in a ' + ' shape of the scan path. Figure 5.5 shows the flowchart of the scanning algorithm.

When a signal is found, the maximum coupling efficiency $\eta_{\max }^{(i)}$, occurs at $t=t_{\max }$. The best estimate of $\boldsymbol{X}_{\mathrm{d}}$ is now $\hat{\boldsymbol{X}}_{\mathrm{d}}^{(i)}=\hat{\boldsymbol{X}}_{\mathrm{f}}\left(t_{\max }\right)$. The next scan direction is now chosen according to a simple hill-climbing algorithm by

$$
\begin{aligned}
& \phi_{\text {step }}^{(i+1)}=-0.5 \phi_{\text {step }}^{(i)} \\
& \phi_{\text {scan }}^{(i+1)}=\phi_{\text {scan }}^{\left(i_{\text {best }}\right)}+\phi_{\text {step }}^{(i+1)},
\end{aligned}
$$

where $i_{\text {best }}$ is the scan iteration where the overall maximum coupling efficiency occurred. This means that the next scan direction alternates around the direction where the best coupling efficiency was measured, with the step size halving each iteration.

If a signal $(\eta)$ is found for 4 or more scan iterations, a 2-dimensional Gaussian surface is fitted through the measurement data $\left(\eta\right.$ and $\left.\hat{\boldsymbol{X}}_{\mathrm{f}}\right)$ of all previous iterations. If the squared 2-norm of the residuals of this fit is above 10, it is discarded. This is necessary to prevent bad fits due to numerical problems or noise in the measured data. If the fit is discarded, the hill-climbing is continued. Otherwise, the maximum of this fit is now the best estimate of $\boldsymbol{X}_{\mathrm{d}}$, and $\phi_{\mathrm{scan}}^{(i+1)}$ is set to the direction of this maximum.

The iteration is stopped when the change in coupling efficiency from the previous iteration and the difference with the overall maximum is within a tolerance $\eta_{\text {tol }}$. That is, when both

$$
\begin{aligned}
& \left|\eta_{\max }^{(i)}-\eta_{\text {max }}^{(i-1)}\right|<\eta_{\text {tol }} \text { and } \\
& \left|\eta_{\max }^{(i)}-\eta_{\text {max }}^{\left(i_{\text {best }}\right)}\right|<\eta_{\text {tol }}
\end{aligned}
$$

are satisfied. With decreasing $\eta_{\text {tol }}$, the target position estimation is more accurate, at the cost of more iterations. Therefore, the tolerance depends on the coupling efficiency $\eta_{0}$ before the scan as $\eta_{\text {tol }}=0.1 \cdot\left(1-\eta_{0}\right)$. That is, the tolerance is $10 \%$ of the difference of the initial coupling efficiency to the theoretical maximum. This results in a more accurate estimation of $\boldsymbol{X}_{\mathrm{d}}$ when the target is already close.

Furthermore, the laser power is lowered when the target is near, to increase the accuracy of the fit $\bar{\beta}$ (see section 5.3.2). The power is reduced to $2 \mathrm{~W}$ or $1.5 \mathrm{~W}$ when the estimated distance to the target is below $2 \mu \mathrm{m}$ or $1 \mu \mathrm{m}$ respectively. 


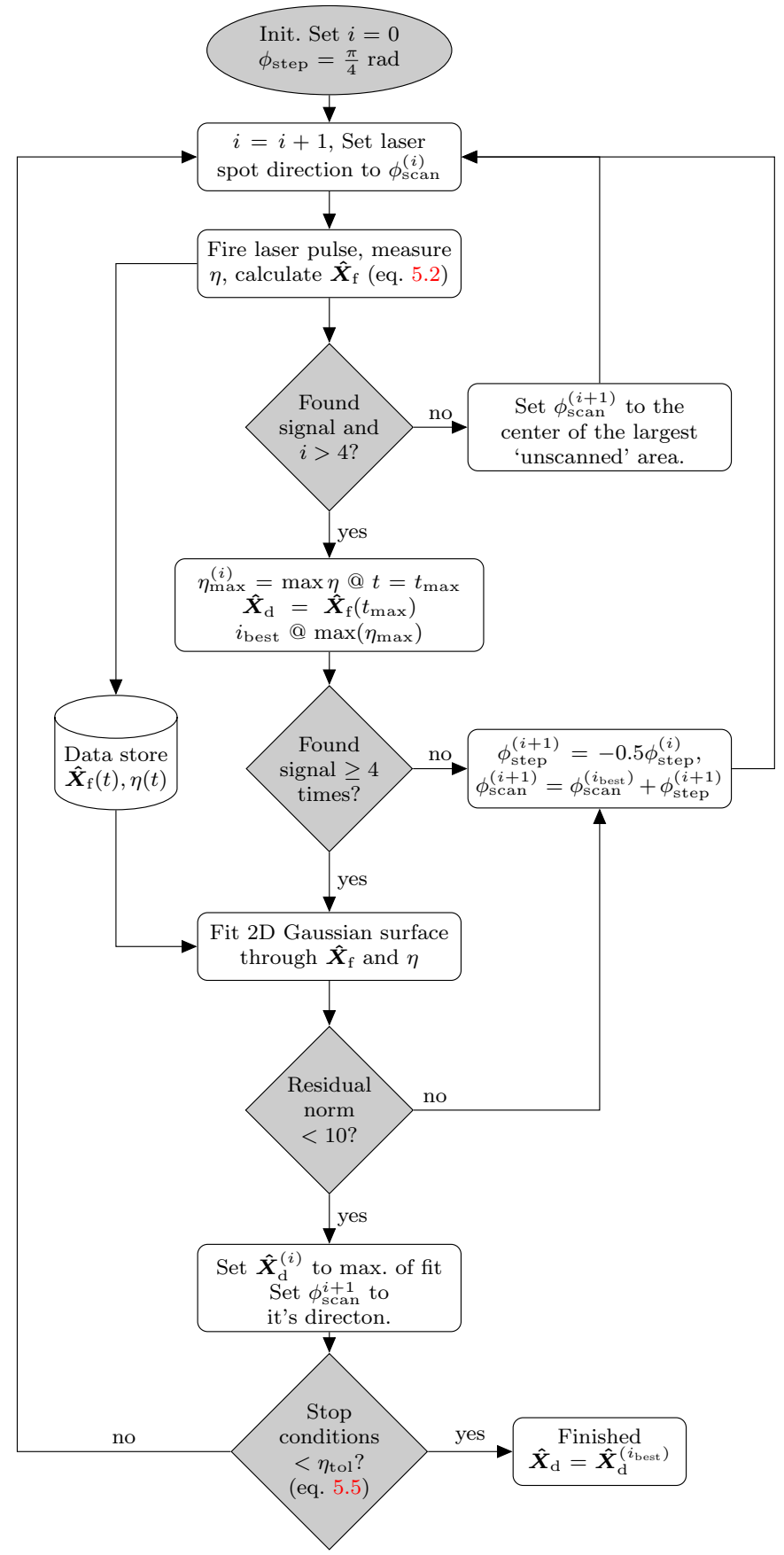

Fig. 5.5: Flowchart of the scanning algorithm. 


\subsection{Laser parameter selection}

The estimated destination location $\hat{\boldsymbol{X}}_{\mathrm{d}}$ is found by scanning before each bending step (see section 5.3.2). This position is relative to the current fiber position $\boldsymbol{X}_{\mathrm{f}}$. Therefore the estimated distance of the fiber tip to the target is $\hat{\delta}_{d}=\left\|\hat{\boldsymbol{X}}_{\mathrm{d}}\right\|$.

An method has been developed [61], that determines the optimal laser power $P_{\text {opt }}$ and laser spot position $d_{\mathrm{opt}}$ to minimize the required number of bending steps. This method takes the scattering into account, by 'learning' from position measurements of previous bending steps. A tradeoff has been identified between high certainty in either the bending angle $\alpha$ when choosing a low laser power, or in bending direction $\phi_{\mathrm{r}}$ when choosing a high laser power. An optimum in $d$ and $P$ can be found or each desired step size $\delta_{\mathrm{d}}$, by minimizing the expectation of the error $e$ (see Fig. 5.2) after the bending step, by assuming a normal probability distribution for $\alpha$ and $\omega$, with a mean and variance depending on the laser power $P$.

However, as stated earlier in this paper, it is assumed that the fiber position can not be measured directly. Therefore, the learning algorithm from [61] can not be used. It is therefore required to gather historical response data of the bending angle and direction to the laser power beforehand. Figure 5.6 shows the optimal parameters used in this paper, based on the measurements presented in [61].

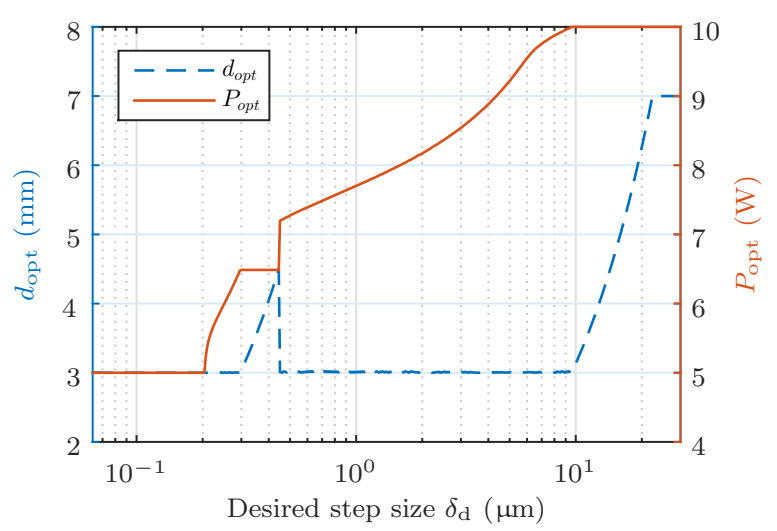

Fig. 5.6: The optimal parameters depending on the desired fiber tip displacement $\delta_{\mathrm{d}}$, based on the optimization and data from [61]. The laser power is limited to $10 \mathrm{~W}$ to prevent melting of the tube. 


\subsection{Stop condition of alignment iteration}

The scanning and bending iterations continue until the coupling efficiency $\eta$ is within $1 \%\left(0.15 \mu \mathrm{m}\right.$, see eq. (5.1)) of the optimal coupling efficiency $\eta_{\mathrm{opt}}$. However, $\eta_{\mathrm{opt}}$ is unknown beforehand. Therefore, $\eta_{\text {opt }}$ is estimated by the maximum coupling efficiency that has been measured during the past scanning and bending steps. This estimated maximum $\hat{\eta}_{\text {opt }}$ converges to $\eta_{\text {opt }}$ with an increasing number of bending and scanning steps. The stop condition is defined by

$$
1-\frac{\eta}{\hat{\eta}_{\mathrm{opt}}}<0.01
$$

However, the stop condition can be met before $\hat{\eta}_{\text {opt }}$ has converged close to $\eta_{\text {opt }}$. This is avoided by requiring the condition in eq. (5.6) is met twice. The scan step in between those two bending steps (see section 5.3.2) ensures that the estimate $\hat{\eta}_{\mathrm{opt}}$ is improved, due to the scanning in all directions.

\subsection{Experimental setup}

To test the performance of the scanning and alignment algorithms, an experimental setup has been developed that allows for fully unattended laser bending of the tube to align an optical fiber to a pre-set destination position.

A fiber laser (max. $100 \mathrm{~W}, 1080 \mathrm{~nm}$ ) showing a Gaussian intensity distribution and a $1 / e^{2}$ spot diameter of $400 \mu \mathrm{m}$, is used to heat and deform the tubes. The laser spot is either positioned directly on the tube, or via one of two fixed mirrors near the tube, see Fig. 5.7. A camera is mounted on the focusing head to align the laser beam to the tube. Using the tip/tilt mirror, three radial positions spaced $120^{\circ}$ from each other, and the complete tube length are accessible by the laser spot. Additionally, since the spot size is smaller than the tube diameter, a small deviation of $\pm 35^{\circ}$ from these radial positions can be tolerated. This means that for $\phi_{\exp }$ three evenly spaced 'blind spots' of $50^{\circ}$ are present that can not be reached by the laser beam.

While the position of the fiber can not be measured during the fiber to chip alignment, the lateral displacement of the fiber tip is of interest to evaluate the performance of the algorithm. Therefore, this experimental setup is used to measure the fiber tip position by the light emitted from the fiber, instead of the coupling efficiency. This means that a PIC chip is not used in this setup. However, the coupling efficiency with respect to such a chip is simulated in real-time by using eq. (5.1) and the measured distance to the destination $\delta_{\mathrm{d}}$. This simulated coupling efficiency is therefore used to test the alignment algorithm.

Figure 5.7 shows the optical elements to measure the displacement of the fiber tip. A collimator lens focuses the light emitted from the fiber on two duo-lateral Position 


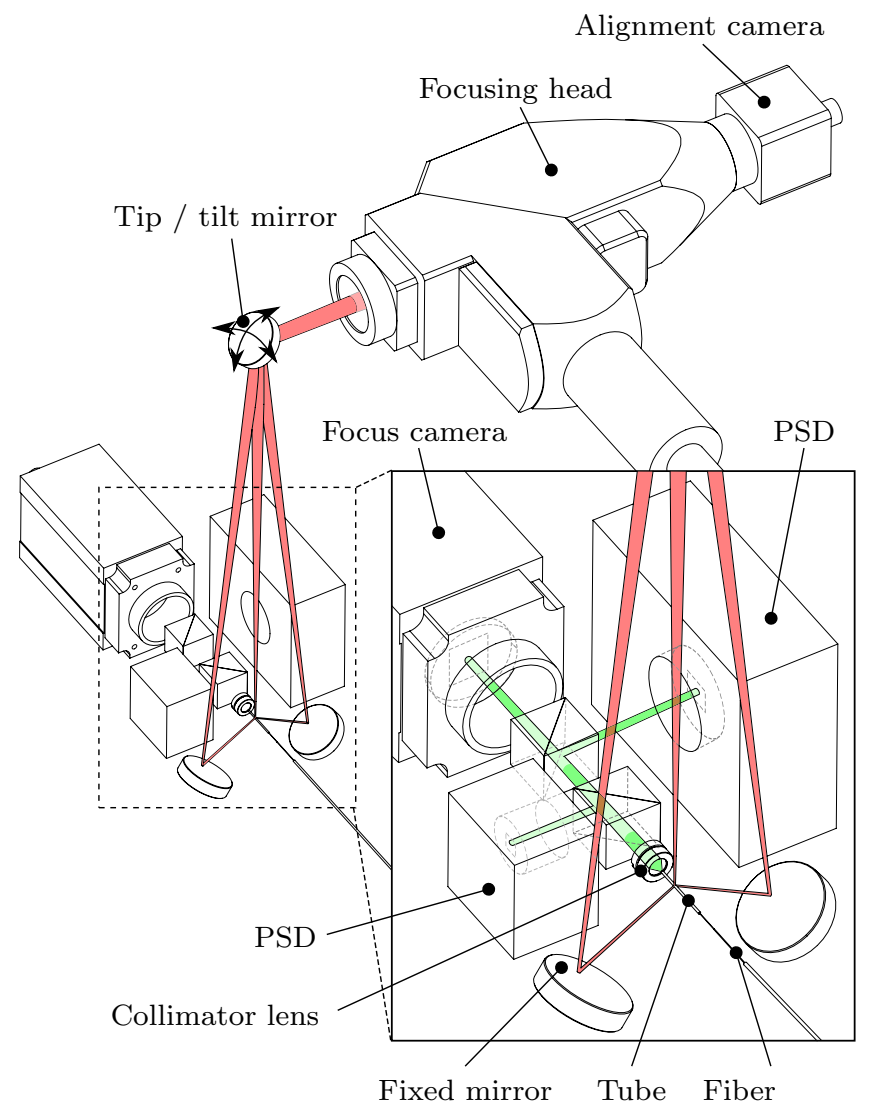

Fig. 5.7: Schematic overview of the experimental setup.

Sensing Detectors (PSDs) via beam-splitters. The tube is clamped over $2 \mathrm{~mm}$ length to fix it to the setup (see Fig. 5.2) and can be translated by three translation stages. To calibrate the PSD signals with respect to the lateral displacement, the position of the clamp is measured by capacitive displacement sensors. The relation of the signal from the PSDs and the fiber position is calibrated by moving the clamp with the tube, and measuring the translation by the capacitive sensors. After calibration, the capacitive sensors are used to subtract any external influences (for example vibrations or thermal variations) from the measurement. The resulting signal gives the lateral position of the fiber tip with a maximum absolute measurement error of $0.2 \mu \mathrm{m}$ and a repeatability better than $0.1 \mu \mathrm{m}$.

All measurement signals are processed by a Matlab Simulink Real-time environment, sampling at $5 \mathrm{kHz}$. For each deformation step, the signals are processed to extract the relative tube deformation magnitude and direction. The beam position, 
laser power, triggering and tube positioning stages are all fully computer-controlled. The setup and measurement system is explained in more detail in [57].

\subsection{Results}

Both the scanning and alignment algorithms were tested with the experimental setup. Five alignment experiments are performed, where the initial distance to the target was set to $10 \mu \mathrm{m}$, each with a random direction, see table 5.1.

Table 5.1: The results of 5 alignment experiments. All experiments start at the location $\boldsymbol{X}_{\mathrm{f}}=(0,0)$

\begin{tabular}{llll}
\hline$\#$ & Target $\boldsymbol{X}_{\mathrm{d}}(\mu \mathrm{m})$ & Nr. of steps & Final error $e(\mu \mathrm{m})$ \\
\hline 1 & $(-8,6)$ & 16 & 0.19 \\
2 & $(1,10)$ & 8 & 0.04 \\
3 & $(-6,-8)$ & 12 & 0.19 \\
4 & $(5,9)$ & 5 & 0.09 \\
5 & $(-95)$ & 12 & 0.09 \\
\hline
\end{tabular}

\subsubsection{Target searching experiments}

The scan algorithm has been evaluated with the experiments listed in table 5.1. The estimated target position error is defined as $e_{\mathrm{scan}}=\left|\hat{\boldsymbol{X}}_{\mathrm{d}}-\boldsymbol{X}_{\mathrm{d}}\right|$. Figure 5.8 shows the histogram of the error relative to the distance to the target $\left(e_{\text {scan }} / \delta_{\mathrm{d}}\right)$ for 94 scan experiments. The histogram shows that $90 \%$ of the scans have an error that is smaller than the distance to the target, resulting in a bending step that is likely to converge to the target. The remaining $10 \%$ of the scans have an error larger than the distance to the target, which mostly happens when the $\delta_{\mathrm{d}}<0.5 \mu \mathrm{m}$. This is a limitation on the accuracy of the fit $\bar{\beta}$ at the start of the pulse (see section 5.3.1). This accuracy is mostly limited by the sampling time of the acquisition hardware combined with the fast motion of the fiber during the thermal expansion. An even lower laser power would result in a slower expansion, but $1.5 \mathrm{~W}$ is the minimum power for the used laser system. 


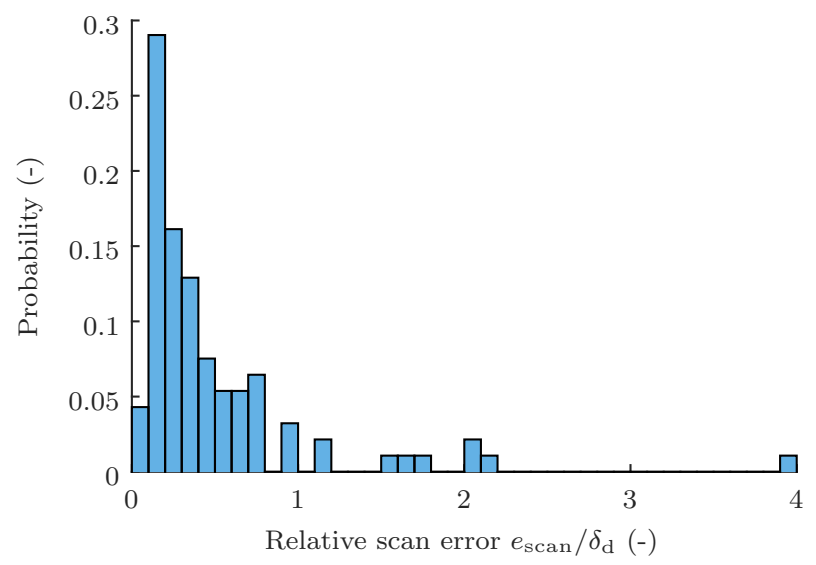

Fig. 5.8: Histogram of the relative error of the scanning algorithm to the (real) distance to the target $\delta_{\mathrm{d}}$ for 94 scan experiments. $e_{\text {scan }}=\left|\hat{\boldsymbol{X}}_{\mathrm{d}}-\boldsymbol{X}_{\mathrm{d}}\right|$.

\subsubsection{Alignment experiments}

The alignment algorithm has been tested using the estimated target positions $\hat{\boldsymbol{X}}_{\mathrm{d}}$ (see section 5.7.1). For experiments listed in table 5.1, the number of steps required to reach the stop condition is between 5 and 16. All experiments ended within $0.2 \mu \mathrm{m}$ from the target position. A typical path is shown in Fig. 5.9. Note the large deviation from the planned path for the second step in this figure. This is due to the 'blind spots' on the tube that cannot be accessed by the laser (see section 5.6), instead the closest accessible direction is chosen.

\subsection{Discussion}

In this paper we have shown the principle of precision optical fiber alignment by laser tube forming on steel tubes. It is expected that even better accuracy and stability can be obtained using tubes from low thermal expansion metals such as Invar. Unlike steel, the linear thermal expansion coefficient (CTE) of Invar at room temperature $\left(1.6 \times 10^{-6} \mathrm{~K}^{-1}\right)$ is comparable to that of the chip $\left(1 \times 10^{-6} \mathrm{~K}^{-1}\right.$ to $\left.2.5 \times 10^{-6} \mathrm{~K}^{-1}\right)$. Above $200{ }^{\circ} \mathrm{C}$ the CTE of Invar rises sharply, making it suitable for laser forming, while the position is stable at the operating temperature of the device.

Furthermore, the length of the tube has been chosen such that $d$ can be chosen between $3 \mathrm{~mm}$ and $7 \mathrm{~mm}$, allowing for a wide range of step sizes $\delta_{\mathrm{d}}$. However, it is expected that the initial 'rough' alignment of the tube assembly is within $5 \mu \mathrm{m}$. Figure 5.6 shows that in this case $d_{\text {opt }}$ does not exceed $4.5 \mathrm{~mm}$. Therefore, the tube (and the free fiber length) can be shortened significantly, to increase the stiffness of fiber 


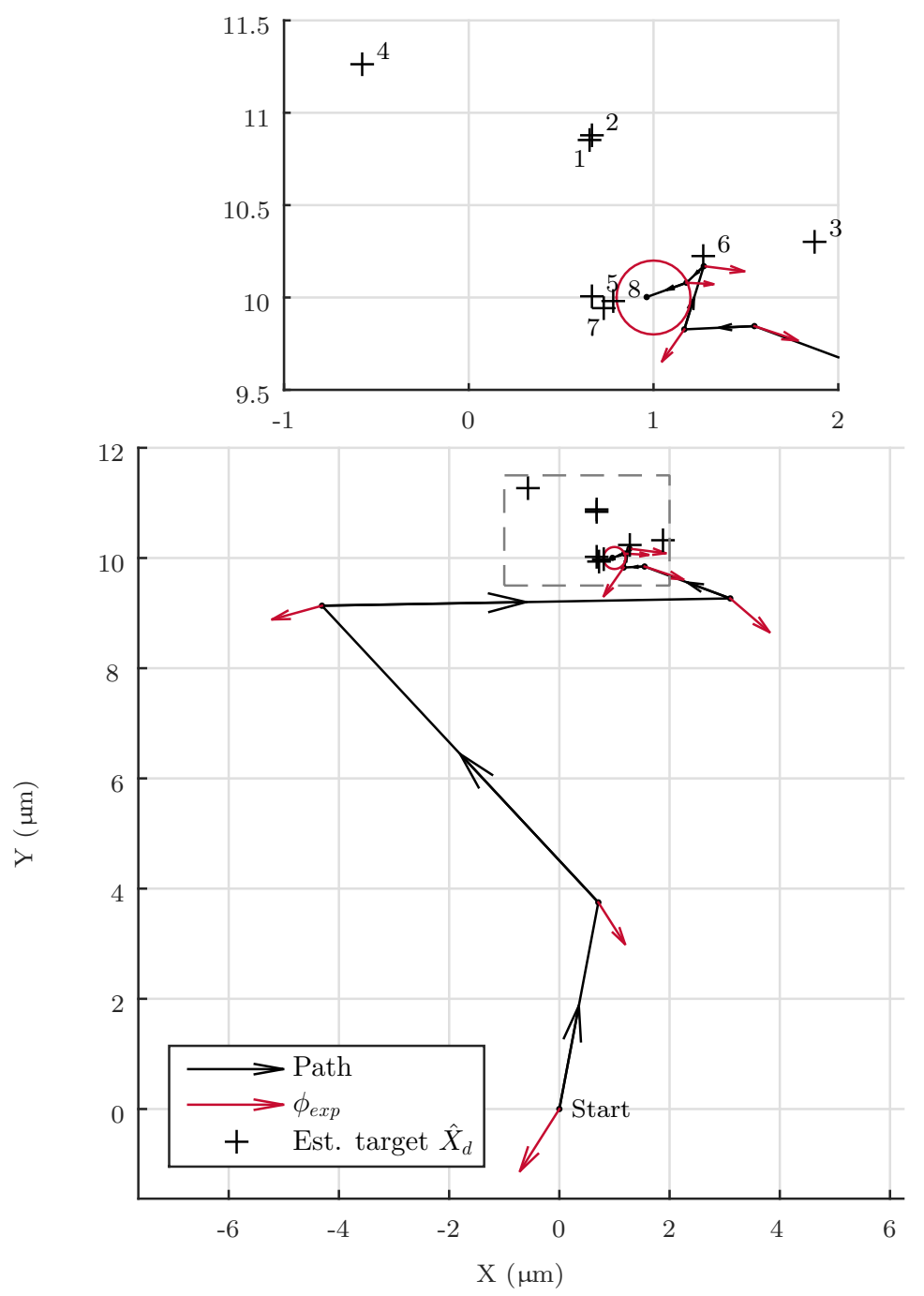

Fig. 5.9: Path of alignment experiment 2 (see table 5.1). The red circle indicates the actual target zone. The black line indicates the location of the fiber tip between each deformation step, connected by straight lines. The red arrows indicate the measured direction of the thermal expansion at each bending step. The scanned estimated destination $\hat{\boldsymbol{X}}_{\mathrm{d}}$ is indicated by a numbered '+', corresponding to the scan prior to each bending step. 
tip position and reduce its mass. This improves the stability of the fiber tip when the device is subject to external vibrations.

\subsection{Conclusion}

Fiber positioning using micro tube laser bending was demonstrated to be accurate enough for the alignment with respect to an photonic integrated circuit chip. Because the fiber position can not be measured inside the tube, the optical coupling efficiency is measured instead. The maximum of this coupling efficiency is found by moving the fiber tip, by exploiting the thermal expansion motion of the tube. A scanning algorithm is developed to find the estimated position of this maximum, even when no light is transmitted in the initial position. The estimated position is used as target for the laser forming step, resulting in a permanent deformation. This is repeated until a stop condition based on the coupling efficiency is met.

Experiments using this searching and alignment algorithm show that a final accuracy of $0.2 \mu \mathrm{m}$ is achieved within 5 to 16 steps. The accuracy is limited by the repeatability of the thermal expansion motion and the measurement timing precision, while scanning for the target position. 


\section{Chapter 6 \\ Conclusions and recommendations}

\subsection{Conclusions}

A novel integrated actuator for high precision assembly of an optical fiber with respect to a photonic integrated circuit chip has been proposed. After a fiber is coarsely joined up to 10 microns of a target, a laser forming actuator fine positions the fiber to a sub micron level. This actuator consists of a simple millimeter sized prismatic tube in which the fiber is fixed concentrically. When the position of the fiber can be measured directly, the fiber was aligned to the target within $0.1 \mu \mathrm{m}$. By using the coupling efficiency as a measure of misalignment, this accuracy was within $0.2 \mu \mathrm{m}$, without the need of position sensors.

The presented results show that laser forming in general can be used for high accuracy alignment, even when the repeatability of the process is low. This is achieved by a 'learning' algorithm that takes the scattering of the process in account from previous measurements, and set the optimal process laser power and beam position. A further prerequisite for achieving a high accuracy alignment is the ability of the laser forming actuator to generate a bi-directional motion, while laser forming deformations are restricted to one direction only. For the tube actuator presented, this is achieved by freely positioning the laser spot around the tube, which allows for correction of overshoot of the target position.

In the remainder of this section, the main conclusions of this thesis are summarized and related to the research objectives as defined in section 1.5.

Objective: Explore and quantify the repeatability, sensitivity and range of motion to variations in the process and its parameters, of laser forming deformations.

For both the in-plane three-bridge actuator and the tube actuator, the sensitivities of the deformations with respect to the laser power and geometry of the actuator have been identified. The sensitivity for the three-bridge actuators was found to range between $0.1 \mu \mathrm{m}$ and $1.3 \mu \mathrm{m}$ per laser pulse. This sensitivity was found to increase with increasing bridge width, and decrease with increasing bridge thickness. For the 
tube actuator the sensitivity has been identified for three different tube geometries. A maximum bending angle of $4 \mathrm{mrad}$ per pulse was found, while the minimum measured bending angle of $0.05 \mathrm{mrad}$ was limited to the repeatability of the measurement system. For both actuators no hard limit was found for the range of motion, however the inner diameter of the tube actuator limits the range of motion of the fiber.

$2 \mathrm{D}$ and 3D FEM models and a reduced lumped model have been have been developed for the three-bridge actuator, to be able identify this sensitivity without experiments. The results from the reduced model matches well with the 2D FEM model, at a fraction of the computational load compared to the FEM models. However, all models showed large deviation from the experimental results for repeated laser irradiation steps. This was mainly attributed to limitations in the hardening function used in the 3D FEM model, combined with the alternating compressive and tensile stresses in the bridges. Despite the low absolute accuracy of the models, the models are a valuable tool for gaining insight in the relative sensitivity to several input parameters. Furthermore, this reduced model was used to study the statistical behavior of alignment algorithms by simulating a large number of alignment trails with a low computational effort.

For both actuator types, a significant scattering of the deformation magnitude for repeated measurements with the same conditions have been found. Measurements of the temperature on laser-irradiated Invar sheet revealed that a low surface roughness (obtained by careful polishing) has a positive effect on the repeatability of the absorption coefficient. However, similar measurements on the bridges of a polished three bridge actuator showed a significant scattering up to $12.5 \%$ of the maximum laserinduced temperature. This was attributed to geometrical inaccuracies of the samples, combined with a low polishing quality at the edges of the bridges.

The temperature of the stainless steel tubes has not been measured directly. However, the repeatability of the thermal expansion is within $0.15 \mathrm{mrad}(5 \%)$ when a relatively low laser power $(<3 \mathrm{~W})$ is used to prevent plastic deformation. Therefore, the scattering of the bending angle of up to $50 \%$ was mainly attributed to the internal stresses in the material due to previous bending steps. Furthermore, the scattering in magnitude of the bending angle was found to increase with increasing laser power, while the scattering bending direction was found to decrease with increasing laser power.

Objective: Based on these insights, develop robust algorithms for aligning components with sub-micrometre accuracy using laser forming.

With the knowledge of the sensitivity and uncertainty of the laser forming deformations, the alignment to a target has been fully automated. For the three bridge actuator, alignment of the translation degree of freedom has been tested with a numerical simulation of the developed algorithm. This algorithm 'learns' from the fist 15 iterations, and adapts the laser power for the subsequent steps. It has been shown that $78 \%$ of the alignment trials are within the required accuracy of $0.1 \mu \mathrm{m}$. The remaining $22 \%$ overshoots the target, and can not be corrected for, due to the one-directional deformation, which is characteristic for the upsetting mechanism. 
Because laser forming is a slow process (each step can take up to $25 \mathrm{~s}$ to complete), the alignment algorithm for the tube actuator minimizes the number of required steps to reach the target within a specified accuracy. While laser forming of tubes is also based on the upsetting mechanism, it is not restricted to bending in one direction. Due to the continuous prismatic geometry of the tube, the bending can be chosen in any radial direction by moving the laser spot to a specific location on the tube surface. The laser power and laser spot location are optimized by minimizing the expected value of the error for the current bending iteration. This expected value is obtained from from statistical data of the scattering in bending magnitude and direction of all previous bending steps. This continuous learning of the algorithm makes it robust for process uncertainties, like for example variations in the laser absorption coefficient. Furthermore, this learning makes the algorithm adapt to new tube geometries and materials with only a few calibration experiments. Experiments have shown that the best performing actuator geometry (tube diameter of $710 \mu \mathrm{m}$ and a wall thickness of $90 \mu \mathrm{m}$ ) needs 14.5 steps to reach the target position within $0.1 \mu \mathrm{m}$ with $95 \%$ certainty.

Objective: Develop a suitable laser forming actuator with an accompanying experimental setup, that can be applied for aligning an optical fiber with respect to an optical chip with sufficient accuracy.

A tube bending actuator has been developed that consists of a stainless steel tube concentric around the fiber. The fiber is fixed to one end of the tube, while the other end of the tube is bonded to the PIC chip. Bending the tube at a distance from the chip results mainly in a translation of the fiber tip. Three tube geometries have been tested, with an outer diameter between $450 \mu \mathrm{m}$ and $710 \mu \mathrm{m}$ and a wall thickness between $50 \mu \mathrm{m}$ and $150 \mu \mathrm{m}$. An experimental setup has been developed that optically measures the fiber tip position with a repeatability better than $0.1 \mu \mathrm{m}$. Furthermore, this setup allows for fully computer controlled laser spot positioning on the tube. Experiments have shown that this actuator is capable of aligning the fiber tip to a target with a lateral accuracy of $0.1 \mu \mathrm{m}$. The simple continuous geometry of the actuators makes them cost effective.

Objective: Apply these algorithms and the actuator to the fiber alignment case and determine its performance by experiments.

When the tube actuator is fixed to a PIC chip, the absolute fiber tip position can not be measured because the fiber is fully enclosed by the actuator. Instead, the coupling efficiency is measured and maximized during the alignment. To find this maximum, a scanning algorithm is developed that uses the thermal expansion at low laser power, to induce motion without permanent plastic deformation. For $90 \%$ of the scanning experiments, the estimated target position converged to the actual target position. The other $10 \%$ of the scans have an error that is larger than the actual distance to the target. This was attributed to limitations in the data acquisition rate of the experimental setup, combined with the fast thermal expansion. This scan algorithm has been combined with the algorithm for finding the optimal laser parameters for a desired step size. Experiments have shown that the alignment accuracy is better than $0.2 \mu \mathrm{m}$ within 5 to 16 iterations using this method. 


\subsection{Recommendations}

A number of recommendations for future research are suggested in this section, as well as some opportunities for improving the performance of the fiber alignment actuator.

- Axial separation. The tube actuator presented in this thesis is only used for lateral alignment of the fiber. However, the axial separation of the fiber to the chip is ideally zero, to increase the coupling efficiency. Therefore, the tube actuator should be combined with other laser forming actuators, like the three-bridge actuator presented in chapter 2, to add a third translation for decreasing the axial separation, after the lateral alignment is corrected.

- Process speed improvements. Laser forming actuation is a fairly slow process because the achieved deformation is only accurately known when the actuator has fully cooled down to room temperature. For the proposed tube actuators, this can take up to $25 \mathrm{~s}$ per heating cycle. However, accurate knowledge of this deformation is not required for large steps at high laser power, where the uncertainty in deformation magnitude is already high (see section 4.3). Therefore, the alignment time could be reduced substantially by starting the next iteration well before the previous step reached a steady state.

Furthermore, active cooling using an inert gas may be employed. However, vibrations of the actuator due to turbulent gas flow may decrease the accuracy of the position measurements. In that case, the position measurement should be performed only after the cooling.

When an array of fibers is to be aligned, one laser source can be shared by switching the laser beam to different actuators, or even multiple devices, while the others are in the cooling phase. When this switching takes one second, one laser source can be used for simultaneous assembly of 20 fibers, significantly reducing the investment costs for large production volumes.

- Thermal stability. The actuators for fiber alignment in this thesis are tested with stainless steel tubes. However, the linear coefficient of thermal expansion of steel $\left(17.3 \times 10^{-6} \mathrm{~K}^{-1}\right)$ is high compared to that of the optical chip $\left(1 \times 10^{-6} \mathrm{~K}^{-1}\right.$ to $2.5 \times 10^{-6} \mathrm{~K}^{-1}$ ), consisting of silicon or quartz glass. This might lead to misalignment at fluctuations in operating temperature of the device. Therefore, low thermal expansion alloys such as Invar $\left(1.6 \times 10^{-6} \mathrm{~K}^{-1}\right)$ should be used to better match the thermal expansion of the chip. As shown in chapter 2, such materials work well with laser forming, due to the steep rise in coefficient of thermal expansion for elevated temperatures.

An additional advantage of these materials is the short cooling time before a steady state deformation is achieved. This is because the cooling time down to the point where these materials show a low coefficient of thermal expansion is very short, compared to the remaining cooling time to room temperature. 
- Long term stability. Measurements of the long term deformation of laser forming actuators are needed to determine their stability in the lifetime of the device. Due to the high residual stresses, close to the yield stress of the material, creep might occur when the operating temperature of the device is high. While laser forming has been successfully used in manufacturing processes, no literature was found on the long term stability.

- Deformation sensing. In chapter 5 the position of the fiber tip can not be measured because it is fully enclosed by the tube and chip. However, direct contact-less relative measurements of the deformation of the tube can be made by optical methods such as interferometry or triangulation. These deformation measurements can be used instead of the thermal expansion fit proposed in section 5.3.1. This eliminates the calibration step of this thermal expansion as well as the dependency of the target estimation accuracy on the repeatability of the expansion deformation.

- Fiber tip position stiffness. The free length of the fiber within the tube actuator was chosen to be $8 \mathrm{~mm}$, see Fig. 4.2. This allows the laser spot position to be chosen between $3 \mathrm{~mm}$ and $7 \mathrm{~mm}$ from the chip. However, a long free length reduces the stiffness of the fiber tip position, and might lead to alignment problems when external vibrations are exerted on the device. Therefore the free length is ideally as short as possible. Experiments on tubes have shown that only a few of the larger steps use the maximum laser spot distance from the chip. The free fiber length could therefore be decreased to increase the stiffness, at the cost of maximum step size. Additionally, both the actuator tube and the mating tube can be shortened to reduce the mass of the actuator and therefore the sensitivity to vibrations.

- Actuator fixation. The assembly and fixation of the tube array (see Fig. 5.1) to the optical chip has not be considered in this thesis. Although this initial alignment can be coarse, an important requirement of such a fixation is positional stability, even for fluctuating operating temperatures. Adhesive bonding can offer a stable fixation, but the re-alignment should not be started before any creep of the adhesives has settled. Other bonding methods that do not suffer from long term creep, like laser welding or soldering could be used, but require metallizing of (a part of) the chip [2]. 


\section{References}

[1] Paschotta, R. Encyclopedia of Laser Physics and Technology. Vol. 1. article on 'single-mode fibers', accessed on 2015-08-26. Wiley-VCH, Oct. 2008. ISBN: 9783-527-40828-3.

URL: https://www.rp-photonics.com/single_mode_fibers.html.

[2] Boudreau, R. A. B. S. M. Passive Micro-Optical Alignment Methods. Vol. 1. Boca Raton: CRC Press, 2005. IsBN: 0-8247-0706-0.

[3] Zhou, H. "A novel assembling technique for fiber collimator arrays using UVcurable adhesives". In: Advanced Packaging, IEEE Transactions on 25.4 (Nov. 2002), pp. 481-487. ISSN: 1521-3323.

DOI: $10.1109 /$ TADVP. 2002.807602 .

[4] Wörhoff, K. Heideman, R. G. Leinse, A. Hoekman, M. "TriPleX: a versatile dielectric photonic platform". In: Advanced Optical Technologies 4.2 (2015), pp. 189-207.

DOI: $10.1515 /$ aot $-2015-0016$.

[5] Marcuse, D. "Loss Analysis of Single-Mode Fiber Splices". In: Bell System Technical Journal 56.5 (1977), pp. 703-718. ISSN: 1538-7305.

DOI: $10.1002 / j .1538-7305.1977 . t b 00534 . x$.

[6] Gabler, C. Li, K. Hackwood, S. Beni, G. "An Optical Alignment Robot System". In: Integration and Packaging of Optoelectronic Devices. Vol. 0703. Proc. SPIE. 1987, pp. 8-28.

DOI: $10.1117 / 12.965184$.

[7] Zhang, R. Shi, F. "A novel algorithm for fiber-optic alignment automation". In: Advanced Packaging, IEEE Transactions on 27.1 (Feb. 2004), pp. 173-178. ISSN: $1521-3323$.

DOI: $10.1109 /$ TADVP. 2004.825434.

[8] Lin, Y. Liu, W. Shi, F. "Adhesive joint design for minimizing fiber alignment shift during UV curing". In: Advanced Packaging, IEEE Transactions on 29.3 (Aug. 2006), pp. 520-524. ISSN: 1521-3323. DOI: $10.1109 /$ TADVP. 2005.850505.

[9] Senior, J. M. Jamro, M. Y. Optical fiber communications: principles and practice. Pearson Education, 2009. ISBN: 978-0130326812.

[10] Dearden, G, Edwardson, S. P. "Some recent developments in two-and threedimensional laser forming for 'macro' and 'micro' applications". In: Journal of Optics A: Pure and Applied Optics 5.4 (2003), S8.

[11] Magee, J. "Laser bending of high strength alloys". In: Journal of Laser Applications 10.4 (1998), pp. 149-155.

DOI: http://dx.doi.org/10.2351/1.521844.

[12] Dearden, G, Edwardson, S. "Laser assisted forming for ship building". In: SAIL, Williamsburg, VA (2003), pp. 2-4.

[13] Hao, N. Li, L. "Finite element analysis of laser tube bending process". In: Applied Surface Science 208-209.0 (2003), pp. 437 -441. ISSN: 0169-4332. DOI: $10.1016 / \mathrm{S} 0169-4332$ (02) 01429-0. 
[14] Li, W. Yao, Y. L. "Laser Bending of Tubes: Mechanism, Analysis, and Prediction". In: Journal of Manufacturing Science and Engineering 123.4 (2001), pp. $674-681$.

DOI: $10.1115 / 1.1392992$.

[15] Geiger, M. Vollertsen, F. Deinzer, G. Flexible straightening of car body shells by laser forming. Tech. rep. SAE Technical Paper, 1993.

DOI: $10.4271 / 930279$.

[16] Chen, G. Xu, X. "Experimental and 3D Finite Element Studies of CW Laser Forming of Thin Stainless Steel Sheets". In: Journal of Manufacturing Science and Engineering 123.1 (Apr. 2000), pp. 66-73. ISSN: 1087-1357. DOI: $10.1115 / 1.1347036$.

[17] Stevens, V. Celentano, D. Ramos-Grez, J. Walczak, M. "Experimental and Numerical Analysis of Low Output Power Laser Bending of Thin Steel Sheets". In: Journal of Manufacturing Science and Engineering 134.3 (May 2012), pp. 031010-031010. ISSN: 1087-1357.

DOI: $10.1115 / 1.4005807$.

[18] Hoving, W. "Accurate manipulation using laser technology". In: Lasers in Material Processing 3097 (1997). Ed. by L. H. J. F. Beckmann, pp. 284-295. DOI: $10.1117 / 12.281087$.

[19] Jamil, M. C. Fauzi, E. I. Juinn, C. Sheikh, M. "Laser bending of pre-stressed thin-walled nickel micro-tubes". In: Optics \& Laser Technology 73.0 (2015), pp. 105-117. ISSN: 0030-3992.

DOI: $10.1016 / j . o p t l a s t e c .2015 .04 .012$.

[20] Kuang, J.-H. Hung, T.-P. "Laser Hammering Technique in Butterfly Laser Diode Module". In: Electronics Packaging Technology Conference 9th. 2007, pp. $874-881$. DOI: $10.1109 / \mathrm{EPTC} .2007 .4469710$.

[21] Hamann, C. Rosen, H.-G. "Relaisfederjustierung mittels gepulster Nd:YAGLaser". German. In: Laser/Optoelektronik in der Technik / Laser/Optoelectronics in Engineering. Ed. by W. Waidelich. Springer Berlin Heidelberg, 1990, pp. 661665. ISBN: 978-3-540-51433-6.

DOI: $10.1007 / 978-3-642-48372-1 \_139$.

[22] Shen, H. Vollertsen, F. "Modelling of laser forming - A review". In: Computational Materials Science 46.4 (2009), pp. 834 -840. ISSN: 0927-0256.

DOI: $10.1016 / j . c o m m a t s c i .2009 .04 .022$.

[23] Geiger, M. Vollertsen, F. "The Mechanisms of Laser Forming". In: CIRP Annals - Manufacturing Technology 42.1 (1993), pp. 301-304. ISSN: 0007-8506. DOI: $10.1016 / \mathrm{S} 0007-8506$ (07) 62448-2.

[24] Dirscherl, M. Esser, G. Schmidt, M. "Ultrashort Pulse Laser Bending". In: Journal of Laser Micro/Nanoengineering 1.1 (2006), p. 6.

[25] Ocaña, J. "Laser shock microforming of thin metal sheets". In: Applied Surface Science 255.10 (2009). Laser and Plasma in Micro- and Nano-Scale Materials Processing and DiagnosticsProceedings from the European Material Research 
Society Spring Meeting 2008 Symposium B, pp. 5633-5636. ISSN: 0169-4332. DOI: $10.1016 /$ j.apsusc.2008.10.084.

[26] Wu, Y. Aicheng, Z. Jing, C. Shengyi, L. "Simulation and Experimental Study of Laser Hammering for Laser Diode Packaging". In: Components and Packaging Technologies, IEEE Transactions on 30.1 (2007), pp. 163-169.

DOI: $10.1109 /$ TCAPT . 2007.892097.

[27] Kang, S.-G. "Fabrication of semiconductor optical switch module using laser welding technique". In: Advanced Packaging, IEEE Transactions on 23.4 (Nov. 2000), pp. $672-680$. ISSN: 1521-3323.

DOI: $10.1109 / 6040.883757$.

[28] Hoving, W. "Method of Mutually displacing at least two parts of an actuator, and actuator for use in such a method". Pat. 5,572,895. 1996.

[29] Shen, H. Wang, X. Qiang, W. "Online postwelding shift compensation in butterfly laser module packages based on welding spot distance". In: Optical Engineering 48.12 (2009), pp. 124301-124301-7.

DOI: $10.1117 / 1.3275457$.

[30] Olowinsky, A. Bosse, L. "Laser beam micro forming as a new adjustment technology using dedicated actuator structures". In: Smart Sensors, Actuators, and MEMS. Vol. 5116. 2003, pp. 285-294.

DOI: $10.1117 / 12.498626$.

[31] Stark, M. Esser, G. Lamott, A. Geiger, M. "Laser-based microalignment for fabrication of highly precise 2D fiber collimator arrays". In: Photon Processing in Microelectronics and Photonics III. Vol. 5339. San Jose, Ca, USA: SPIE, 2004, pp. 144-155.

DOI: $10.1117 / 12.529072$.

[32] Zantvoort, J. "Lensed Fiber-Array Assembly With Individual Fiber Fine Positioning in the Submicrometer Range". In: Selected Topics in Quantum Electronics, IEEE Journal of 12.5 (2006), pp. 931 -939. ISSN: 1077-260X.

DOI: $10.1109 /$ JSTQE.2006.882633.

[33] Leinse, A. "TriPleX waveguide platform: low-loss technology over a wide wavelength range". In: Integrated Photonics: Materials, Devices, and Applications II. Vol. 8767. 2013, 87670E-87670E-13. DOI: $10.1117 / 12.2020574$.

[34] Telford, W. G. "Analysis of UV-excited fluorochromes by flow cytometry using near-ultraviolet laser diodes". In: Cytometry Part A 61.1 (2004), pp. 9-17. DOI: 10.1002 / cyto.a.20032.

[35] Koster, H. DNA sequencing by mass spectrometry. US Patent 5,691,141. Nov. 1997.

[36] Kress-Rogers, E. Brimelow, C. J. Instrumentation and sensors for the food industry. Woodhead Publishing, 2001. ISBN: 1855735601.

[37] Griffiths, J. Edwardson, S. Dearden, G. Watkins, K. "Finite Element modelling of laser forming at macro and micro scales". In: Physics Procedia 5, Part B (2010), pp. $371-380$. ISSN: 1875-3892. DOI: $10.1016 / j \cdot$ phpro.2010.08.064. 
[38] Jung, H.-C. "A Study on Laser Forming Processes with Finite Element Analysis". PhD thesis. University of Canterbury, Christchurch, New Zealand, 2006.

[39] Cheng, J. Yao, Y. L. "Microstructure Integrated Modeling of Multiscan Laser Forming". In: Journal of Manufacturing Science and Engineering 124.2 (Apr. 2002), pp. 379-388. ISSN: 1087-1357.

DOI: $10.1115 / 1.1459088$.

[40] Hennige, T, Holzer, S, Vollertsen, F, Geiger, M, "On the working accuracy of laser bending". In: Journal of Materials Processing Technology 71.3 (1997), pp. $422-432$. ISSN: 0924-0136.

DOI: $10.1016 /$ S0924-0136(97)00108-8.

[41] Folkersma, K. G. P. Römer, G. R. B. E. Brouwer, D. M. Huis in 't Veld, A. J. "In-plane laser forming for high precision alignment". In: Optical engineering 53.12 (2014), pp. 126105-126105.

DOI: $10.1117 / 1$. OE.53.12.126105.

[42] Esser, G. Schmidt, M. Dirscherl, M. "Laser adjustable actuators for highaccuracy positioning of micro components". In: Fourth International Symposium on Laser Precision Microfabrication. Ed. by I. Miyamoto, A. Ostendorf, K. Sugioka and H. Helvajian. Vol. 5063. SPIE, 2003, pp. 177-182.

DOI: $10.1117 / 12.540461$.

[43] Zimmermann, M. Schmidt, M. Dirscherl, M. Rank, M. "Laser micro adjustment - from new basic process knowledge to the application". In: Journal of Laser Applications 19 (2007), p. 124.

DOI: $10.2351 / 1.2567766$.

[44] Vollertsen, F, Komel, I, Kals, R, "The laser bending of steel foils for microparts by the buckling mechanism-a model". In: Modelling and Simulation in Materials Science and Engineering 3.1 (1995), p. 107.

DOI: $10.1088 / 0965-0393 / 3 / 1 / 009$.

[45] Zhang, X. R. Xu, X. Tam, A. C. "Microscale bending using pulsed and cw laser". In: Laser Applications in Microelectronic and Optoelectronic Manufacturing VI. Ed. by M. C. Gower, H. Helvajian, K. Sugioka and J. J. Dubowski. Vol. 4274. San Jose, CA, USA: SPIE, 2001, pp. 58-65.

DOI: $10.1117 / 12.432552$.

[46] Kyrsanidi, A. Kermanidis, T. Pantelakis, S. "Numerical and experimental investigation of the laser forming process". In: Journal of Materials Processing Technology 87.1-3 (1999), pp. 281 -290. ISSN: 0924-0136.

DOI: $10.1016 /$ S0924-0136 (98) 00367-7.

[47] Pretorius, T. Laser Forming. Ed. by J. Dowden. Vol. 119. Springer Series in Materials Science. Springer Netherlands, 2009, pp. 281-314. ISBN: 978-1-40209340-1.

DOI: $10.1007 / 978-1-4020-9340-1 \_9$.

[48] Safdar, S. Li, L. Sheikh, M. Liu, Z. "Finite element simulation of laser tube bending: Effect of scanning schemes on bending angle, distortions and stress distribution". In: Optics $\&$ Laser Technology 39.6 (2007), pp. 1101 -1110. ISSN: 
0030-3992.

DOI: $10.1016 / j . o p t l a s t e c .2006 .09 .014$.

[49] Safdar, S. Li, L. Sheikh, M. A. Liu, Z. "The Effect of Nonconventional Laser Beam Geometries on Stress Distribution and Distortions in Laser Bending of Tubes". In: Journal of Manufacturing Science and Engineering 129.3 (2007), pp. 592-600.

DOI: $10.1115 / 1.2716715$.

[50] Shen, H. "Mechanism of laser micro-adjustment". In: Journal of Physics D: Applied Physics 41.24 (2008), p. 245106.

DOI: $10.1088 / 0022-3727 / 41 / 24 / 245106$.

[51] Folkersma, K. G. P. Römer, G. R. B. E. Brouwer, D. M. Huis in 't Veld, A. J. "High precision laser forming for microactuation". In: Proc. SPIE, Laser Applications in Microelectronic and Optoelectronic Manufacturing (LAMOM) XIX. Vol. 8967. 2014, 89671B-89671B-12.

DOI: $10.1117 / 12.2037675$.

[52] Thomson, G. Pridham, M. "Improvements to laser forming through process control refinements". In: Optics \& Laser Technology 30.2 (1998), pp. $141-146$. ISSN: 0030-3992.

DOI: $10.1016 /$ S0030-3992(98)00037-1.

[53] Shen, H. Yao, Z. "Numerical and experimental investigation of cooling time in laser micro-adjustment of two-bridge actuators". In: Applied Thermal Engineering 31.8-9 (2011), pp. 1447 -1456. ISSN: 1359-4311.

DOI: $10.1016 / j$.applthermaleng.2011.01.013.

[54] Kyrsanidi, A. Kermanidis, T. Pantelakis, S. "An analytical model for the prediction of distortions caused by the laser forming process". In: Journal of Materials Processing Technology 104.1-2 (2000), pp. 94 -102. ISSN: 0924-0136.

DOI: $10.1016 /$ S0924-0136(00)00520-3.

[55] Xu, X. "Laser-based microscale bending for microelectronics fabrication". In: Laser Applications in Microelectronic and Optoelectronic Manufacturing V. Ed. by H. Helvajian, K. Sugioka, M. C. Gower and J. J. Dubowski. Vol. 3933. San Jose, CA, USA: SPIE, 2000, pp. 299-308.

DOI: $10.1117 / 12.387567$.

[56] Shen, H. Peng, L. Hu, J. Yao, Z. "Study on the mechanical behavior of laser micro-adjustment of two-bridge actuators". In: Journal of Micromechanics and Microengineering 20.11 (2010), p. 115010.

DOI: $10.1088 / 0960-1317 / 20 / 11 / 115010$.

[57] Folkersma, K. G. P. Brouwer, D. M. Römer, G. R. B. E. "Micro tube laser forming for precision component alignment". In: - (2015). Submitted for publication.

[58] Guan, Y. Yuan, G. Sun, S. Zhao, G. "Process simulation and optimization of laser tube bending". English. In: The International Journal of Advanced Manufacturing Technology 65.1-4 (2013), pp. 333-342. ISSN: 0268-3768.

DOI: $10.1007 / \mathrm{s} 00170-012-4172-6$. 
[59] Hao, N. Li, L. "An analytical model for laser tube bending". In: Applied Surface Science 208209 (2003). Physics and Chemistry of Advanced Laser Materials Processing, pp. $432-436$. ISSN: 0169-4332. DOI: $10.1016 / \mathrm{S} 0169-4332$ (02) 01428-9.

[60] Hsieh, H.-S. Lin, J. "Study of the buckling mechanism in laser tube forming". In: Optics $\&$ Laser Technology 37.5 (2005), pp. 402 -409. ISSN: 0030-3992. DOI: $10.1016 / j . o p t l a s t e c .2004 .06 .004$.

[61] Folkersma, K. G. P. Brouwer, D. M. Römer, G. R. B. E. "Robust precision alignment algorithm for micro tube laser forming". In: - (2015). Submitted for publication.

[62] Böttger, G. Schröder, H. Jordan, R. "Active or passive fiber-chip-alignment: approaches to efficient solutions". In: Optoelectronic Interconnects XIII. Vol. 8630. 2013, pp. 863006-863006-17.

DOI: $10.1117 / 12.2014176$.

[63] Zantvoort, J. Khoe, G.-D. Waardt, H. "Fiber array-to-photonic-chip fixation and fine tuning using laser support adjustment". In: Selected Topics in Quantum Electronics, IEEE Journal of 8.6 (2002), pp. 1331 -1340. ISSN: 1077-260X. DOI: $10.1109 / \mathrm{JSTQE} .2002 .806688$.

[64] Qi, L. Namba, Y. "Precision laser adjustment using $\{\mathrm{CW}\}$ diode laser". In: Precision Engineering 35.1 (2011), pp. 126-132. ISSN: 0141-6359. DOI: $10.1016 / j \cdot$ precisioneng.2010.08.002.

[65] Chandan, K. Saha, P, Mishra, P. K. "Laser Bending of Micro Tubes". In: Innovating The Future Through Manufacturing. Alpha Science Int. Ltd., 2005, p. 227. DOI: $10.1080 / 00401706.1969 .10490657$.

[66] Grubbs, F. E. "Procedures for detecting outlying observations in samples". In: Technometrics 11.1 (1969), pp. 1-21. DOI: $10.1080 / 00401706.1969 .10490657$.

[67] Folkersma, K. G. P. Römer, G. R. B. E. Brouwer, D. M. Herder, J. L. "High precision optical fiber alignment using tube laser bending". In: The International Journal of Advanced Manufacturing Technology (2015). Accepted for publication.

DOI: $10.1007 / \mathrm{s} 00170-015-8143-6$. 



\section{Dankwoord}

Daar is dan eindelijk het eindresultaat in de vorm van dit boekje. Maar zonder de hulp, inzichten en steun van veel mensen was dit er niet gekomen. Hierbij wil ik iedereen bedanken die direct of indirect betrokken is geweest bij de totstandkoming van dit proefschrift.

Ten eerste wil ik mijn directe begeleiders Gert-Willem Römer en Dannis Brouwer bedanken voor hun nuchtere begeleiding en waardevolle input. Ook weet ik dankzij jullie wat nu het verband is tussen een grote garage en zagen. Dannis, bedankt voor je enthousiasme, nuttige discussies en tips, of het nou over de opstelling, sensoren, auto's of trekkers ging. Gert-Willem, bedankt voor de inzichten die je me gegeven hebt over de laser-materiaal interacties en de hulp bij het oplossen bij de vele praktische problemen. Ook zal ik onze belevenissen in de minder goede wijken van San Francisco na de Photonics West conferentie niet snel vergeten.

Daarnaast wil ik Bert Huis in't Veld bedanken als promotor in de eerste drie jaar. Just Herder, bedankt dat je me voor de tweede keer wilde 'opvangen', eerst als afstudeer-prof na het vertrek van Herman Soemers, en nu als promotor.

De overige leden van de commissie, Geoffrey Dearden, Leon Abelmann, Marcel Tichem en Willem Hoving wil ik ook graag bedanken voor het deelnemen aan de promotiecommissie en voor het lezen en beoordelen van mijn proefschrift.

Ronald Dekker en Douwe Geuzebroek, bedankt voor alle nuttige informatie over het echte probleem bij fiber-alignment bij XiO, en dat ik de eerste maanden dit met eigen ogen en handen mocht ondervinden.

Verder wil ik de staf van de vakgroep bedanken voor hun hulp en advies bij grote en kleine dingen waarmee ik jullie lastig viel. Allereerst Martina, bedankt voor al je praktische hulp, van de organisatie van conferentiebezoeken tot het invullen van de promotieformulieren. Leo, zonder jouw was de opstellingen die ik de afgelopen vier jaar heb gebouwd niet tot stand gekomen, bedankt voor het maken van die talloze onderdeeltjes die soms binnen een paar uur al op m'n bureau lagen. Gerald, jouw hulp bij het in bedrijf nemen van de nieuwe laser en alle elektronica die daar bij kijken kwam, was onmisbaar voor de opstelling. Ronald, Johannes, Pathiraj, Jaap en Wouter, bedankt voor de gezellige koffiemomentjes in het lab met de rest van de 
vakgroep, met leerzame of minder leerzame discussies. Ik geloof dat we het gros van de wereldproblemen inmiddels wel hebben opgelost, met een kop koffie in de hand.

Ook wil ik mijn PhD collega's door de jaren heen bedanken, en in het bijzonder mijn kamergenoten, Dirk, Jitendra, Bert, Jan, Sander en Marijn, bedankt voor de gezelligheid en discussies, maar ook de directe praktische hulp in Matlab of $\mathrm{ATE}_{\mathrm{E} X}$ wanneer ik weer eens mompelend naar het scherm staarde omdat ik ergens niet uit kwam.

Dennis en Tim, bedankt dat jullie mijn Paranimfen willen zijn, en samen met Rudy en Karen er voor hebben gezorgd dat ik nog een beetje beweging en gezonde voeding kreeg in de laatste paar zware maanden. Verder wil ik alle vrienden bij Dispuut WHAP en Scouting Fraeylema bedanken voor de afleiding naast al het werk, en het begrip dat ik niet altijd aanwezig kon zijn de afgelopen tijd.

Mijn familie, Pieter, Gineke, Marjanne, Auke (en natuurlijk Pelle en Boris), hoewel jullie waarschijnlijk geen chocola konden maken van de technische inhoud, hebben jullie me altijd gesteund om dit te kunnen volbrengen. Het begrip dat ik minder vaak naar het mooie Groningen kon komen de laatste tijd betekent veel voor me.

Mira, tenslotte wil ik jou bedanken voor de motivatie en steun tijdens mijn werk en organisatie in mijn chaotische momentjes. Maar vooral wil ik je bedanken voor je liefde die je in m'n leven hebt gebracht. 